Aus der Abteilung Kardiologie und Pneumologie

(Prof. Dr. med. G. Hasenfuß)

im Zentrum Innere Medizin

der Medizinischen Fakultät der Universität Göttingen

\title{
Einfluss der Antiarrhythmika Flecainid und Amiodaron auf die kontraktile Funktion und die Kraft-Frequenz-Beziehung des Herzens
}

Untersuchungen am isolierten insuffizienten menschlichen Myokard und gesunden Kaninchenmyokard

\author{
INAUGURAL - DISSERTATION \\ zur Erlangung des Doktorgrades \\ der Medizinischen Fakultät \\ der Georg-August-Universität zu Göttingen \\ vorgelegt von \\ Christian Pagel \\ aus Goslar
}

Göttingen 2009 
Dekan:

I. Berichterstatter:

II. Berichterstatter / in:

III. Berichterstatter / in:
Prof. Dr. med. C. Frömmel

Prof. Dr. med. B. Pieske

Priv.-Doz. Dr. med. Th. Kriebel

Tag der mündlichen Prüfung: $\quad 09.08 .2010$ 


\section{Inhaltsverzeichnis}

Abkürzungsverzeichnis 1

1. Einleitung 5

1.1. Ätiologie und Epidemiologie der Herzinsuffizienz 6

1.2. Elektromechanische Kopplung und ihre Störungen bei der Herzinsuffizienz 6

1.2.1. Die sarkolemmale Membran und integrale Proteine 8

1.2.2. Der sarkolemmale Natrium-Kalzium-Austauscher (NCX) 9

1.2.3. Das sarkoplasmatische Retikulum (SR) 10

1.2.4. Der Kalziumfreisetzungskanal des SR (Ryanodin-Rezeptor) 11

1.2.5. Die Kalzium-ATPase des SR (SERCA) 11

1.2.6. Das Regulatorprotein Phospholamban (PLB) 13

1.3. Die Kraft-Frequenz-Beziehung 13

1.4. Arrhythmien und antiarrhythmische Therapie bei der Herzinsuffizienz 15

1.4.1. Das Klasse-Ic-Antiarrhythmikum Flecainid 16

1.4.2. Das Klasse-III-Antiarrhythmikum Amiodaron 17

1.5. Ziele und Fragestellungen der vorliegenden Arbeit 18

2. Material und Methoden 19

2.1. Untersuchtes Gewebe 19

2.1.1. Insuffizientes humanes Myokard 19

2.1.2. Klinische Patientendaten 19

2.1.3. Transport und Präparation 21

2.1.4. Nicht-insuffizientes Kaninchenmyokard 23

2.2. Lösungen und Substanzen 24

2.2.1. Tyrodelösung 24

2.2.2. Kardioplegie 25

2.2.3. Verwendete Substanzen 25 
$\begin{array}{ll}\text { 2.3. Messapparaturen } & 28\end{array}$

2.3.1. Aequorinanlage - Versuchsaufbau und verwendete Geräte 28

2.3.2. Aequorinanlage - Versuchsvorbereitung 31

2.3.3. Anlage zur Messung der isometrischen Kontraktionskraft (4er-Anlage) -

Versuchsaufbau und verwendete Geräte 33

2.3.4. 4er-Anlage - Versuchsvorbereitung 34

2.4. Versuchsprotokolle 35

2.4.1. Flecainid-Konzentrations-Wirkungs-Kurve (KWK) 35

2.4.2. Wirkung von Flecainid auf die Kontraktionskraft mit simultaner Registrierung intrazellulärer Kalzium-Transienten 35

2.4.3. Amiodaron-Konzentrations-Wirkung-Kurve (KWK) 36

2.4.4. Einfluss von Flecainid auf die Kraft-Frequenz-Beziehung des terminal insuffizienten humanen Myokards

2.4.5. Einfluss von Amiodaron auf die Kraft-Frequenz-Beziehung des terminal insuffizienten humanen Myokards

2.4.6. Einfluss von Flecainid und Amiodaron auf die Kraft-Frequenz-Beziehung des nicht-insuffizienten Kaninchen-Myokards

2.5. Auswertung der Versuche

2.5.1. Untersuchte Parameter 38

2.5.2. Bestimmung der Querschnittsfläche 38

2.5.3. Normierung der Daten 39

2.5.4. Statistische Auswertung 39

3. Ergebnisse 40

3.1. Basale funktionelle Effekte von Flecainid:

Untersuchungen am menschlichen, terminal insuffizienten Myokard 40

3.1.1. Konzentrations-Wirkungs-Kurve (KWK) 40

3.1.2. Registrierung intrazellulärer Kalzium-Transienten 43 


\subsection{Basale funktionelle Effekte von Amiodaron:}

\subsection{Kraft-Frequenz-Beziehung unter Flecainid und Amiodaron}

am terminal insuffizienten humanen Myokard 46

3.3.1. Kraftamplitude unter Flecainid und Amiodaron 46

3.3.2. Diastolische Spannung unter Flecainid und Amiodaron 50

3.3.3. Zeitparameter der isometrischen Kontraktion unter Flecainid und Amiodaron 51

3.3.4. $\mathrm{dF} / \mathrm{dt}_{\max }$ unter Flecainid und Amiodaron $\quad 51$

3.3.5. Querschnittsflächen der Muskelstreifenpräparate 54

\subsection{Kraft-Frequenz-Beziehung unter Flecainid und Amiodaron} am nicht-insuffizienten Kaninchen-Myokard 55

3.4.1. Kraftamplitude unter Flecainid und Amiodaron 55

3.4.2. Diastolische Spannung unter Flecainid und Amiodaron 56

3.4.3. Zeitparameter der isometrischen Kontraktion unter Flecainid und Amiodaron $\quad 57$

3.4.4. $\mathrm{dF} / \mathrm{dt}_{\max }$ unter Flecainid und Amiodaron $\quad 57$

4. Diskussion $\quad 61$

4.1. Verwendung von multizellulären Muskelstreifenpräparaten 61

4.2. Registrierung intrazellulärer Kalzium-Transienten 61

4.3. Wirkungen von Flecainid und Amiodaron am terminal insuffizienten humanen Myokard 63

4.3.1. Inotrope Effekte von Flecainid am humanen Myokard 63

4.3.2. Wirkmechanismus von Flecainid 64

4.3.3. Einfluss von Flecainid auf die Kraft-Frequenz-Beziehung 65

4.3.4. Diastolische Funktion unter Flecainid 66

4.3.5. Inotrope Effekte von Amiodaron am humanen Myokard 67

4.3.6. Wirkmechanismus von Amiodaron und dem Lösungsvermittler Polysorbat $80 \quad 68$

4.3.7. Einfluss von Amiodaron auf die Kraft-Frequenz-Beziehung 70 
4.4. Klinische Relevanz der Ergebnisse

4.4.1. Flecainid in der antiarrhythmischen Therapie bei Herzinsuffizienz 71

4.4.2. Amiodaron in der antiarrhythmischen Therapie bei Herzinsuffizienz 72

$\begin{array}{ll}\text { 5. Zusammenfassung } & 74\end{array}$

$\begin{array}{ll}\text { 6. Tabellen } & 75\end{array}$

6.1. Flecainid und Amiodaron, KWK und Kalziumtransienten 75

6.1.1. Konzentrations-Wirkungs-Kurve für Flecainid 75

6.1.2. Intrazelluläre Kalziumtransienten für Flecainid 76

6.1.3. Konzentrations-Wirkungs-Kurve für Amiodaron 77

6.1.4. Konzentrations-Wirkungs-Kurve für das Lösungsmittel $\quad 78$

6.2. Kraft-Frequenz-Beziehung, Antiarrhythmika (humanes Myokard) 79

$\begin{array}{lll}\text { 6.2.1. } & \text { Flecainid } & 79\end{array}$

$\begin{array}{lll}\text { 6.2.2. Amiodaron } & 81\end{array}$

6.3. Kraft-Frequenz-Beziehung, Antiarrhythmika (Kaninchen-Myokard) 84

$\begin{array}{lll}\text { 6.3.1. } & \text { Flecainid } & 84\end{array}$

6.3.2. Amiodaron 86

$\begin{array}{ll}\text { 7. Literaturverzeichnis } & 89\end{array}$ 


\section{Abkürzungsverzeichnis}
AAR $=$ Antiarrhythmika
$\mathrm{AC} \quad=$ Adenylatzyklase
ACE $=$ Adenosine Converting Enzyme
$\mathrm{ADH}=$ Antidiuretisches Hormon (Synonym: Vasopressin)
ADP $=$ Adenosin-diphosphat
AGW $\quad=$ Ausgangswert
Aldact $=$ Aldosteron-Antagonisten (Diuretika)
$\mathrm{AM}=$ Amiodaron
$\mathrm{AP} \quad=$ Aktionspotential
APD $=$ Aktionspotential-Dauer
ARB $=$ Angiotensin-II-Rezeptorblocker
ASS $=$ Thrombozytenaggregationshemmer
ATP $=$ Adenosin-triphosphat
$\mathrm{BDM}=$ 2,3-Butandion-Monoxim
Beta $=$ Beta-adreno-Rezeptor-Blocker
${ }^{\circ} \mathrm{C}=$ Grad Celsius (Temperaturskala)
CAMK II = Kalzium-Calmodulin-Kinase II
cAMP $=$ zyklisches Adenosin-monophosphat
cGMP $=$ zyklisches Guanosin-monophosphat
CI $=$ cardiac index (engl.), Herzindex in $1 / \mathrm{min}$
$\mathrm{Cl}^{-}=$Chlorid (Chlor in ionisierter Form)
$\mathrm{cm}=$ Zentimeter
$\mathrm{CO}_{2}=$ Kohlendioxid
$\mathrm{Ca}^{2+} \quad=$ Kalzium in ionisierter Form
$\left[\mathrm{Ca}^{2+}\right]_{\mathrm{i}}=$ intrazelluläre Kalzium Konzentration
Da $=$ Dalton (Molekülgewicht)
DÄAM = Desäthyl-Amiodaron
DAG $=$ Diacylglycerol
DCM = dilatative Kardiomyopathie
$+\mathrm{dF} / \mathrm{dt}=$ maximale Kraftanstiegsgeschwindigkeit in $\mathrm{mN} / \mathrm{mm}^{2}$
$-\mathrm{dF} / \mathrm{dt}=$ maximale Relaxationsgeschwindigkeit in $\mathrm{mN} / \mathrm{mm}^{2}$
Dig = Digitalis-Herzglykoside 


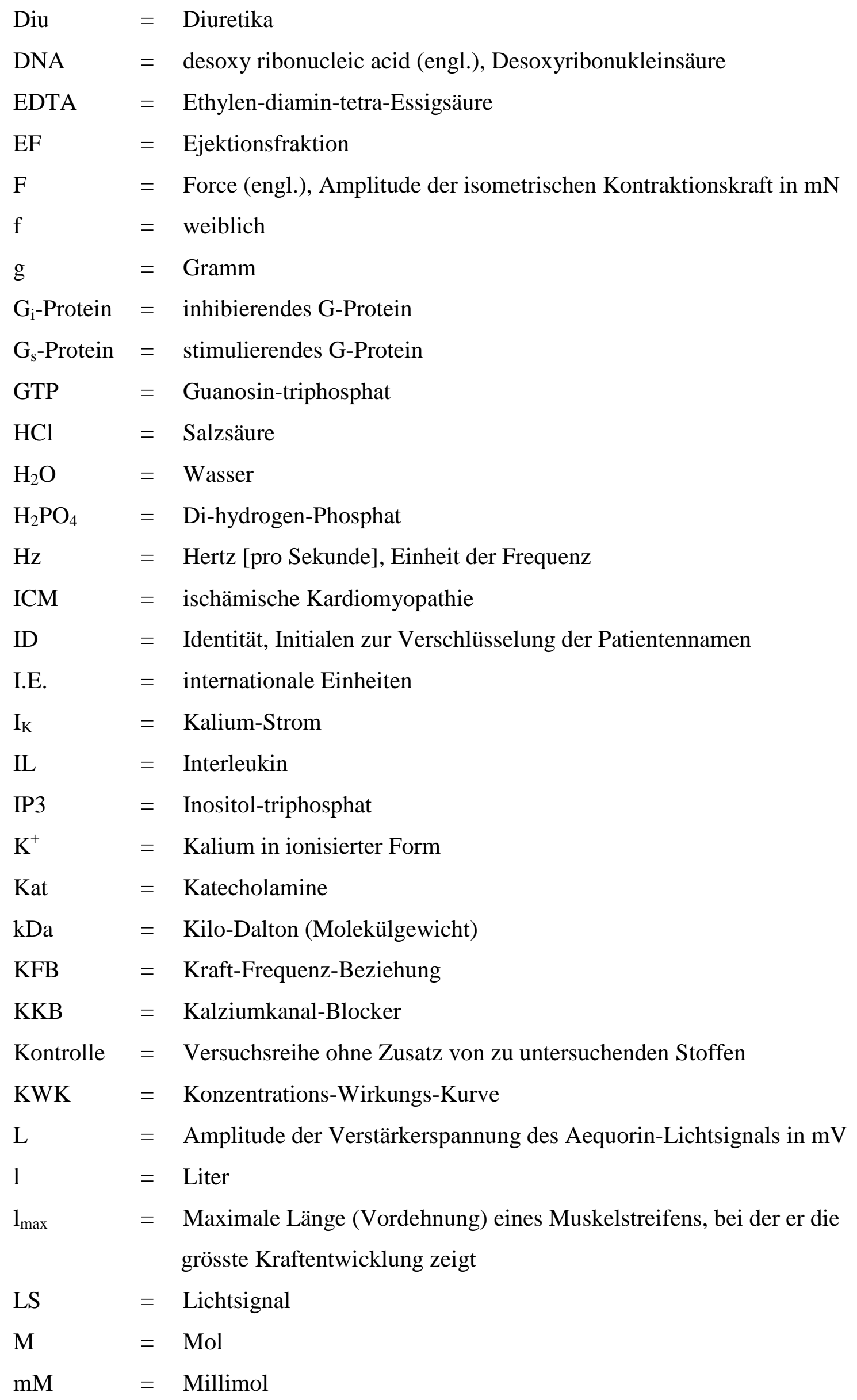









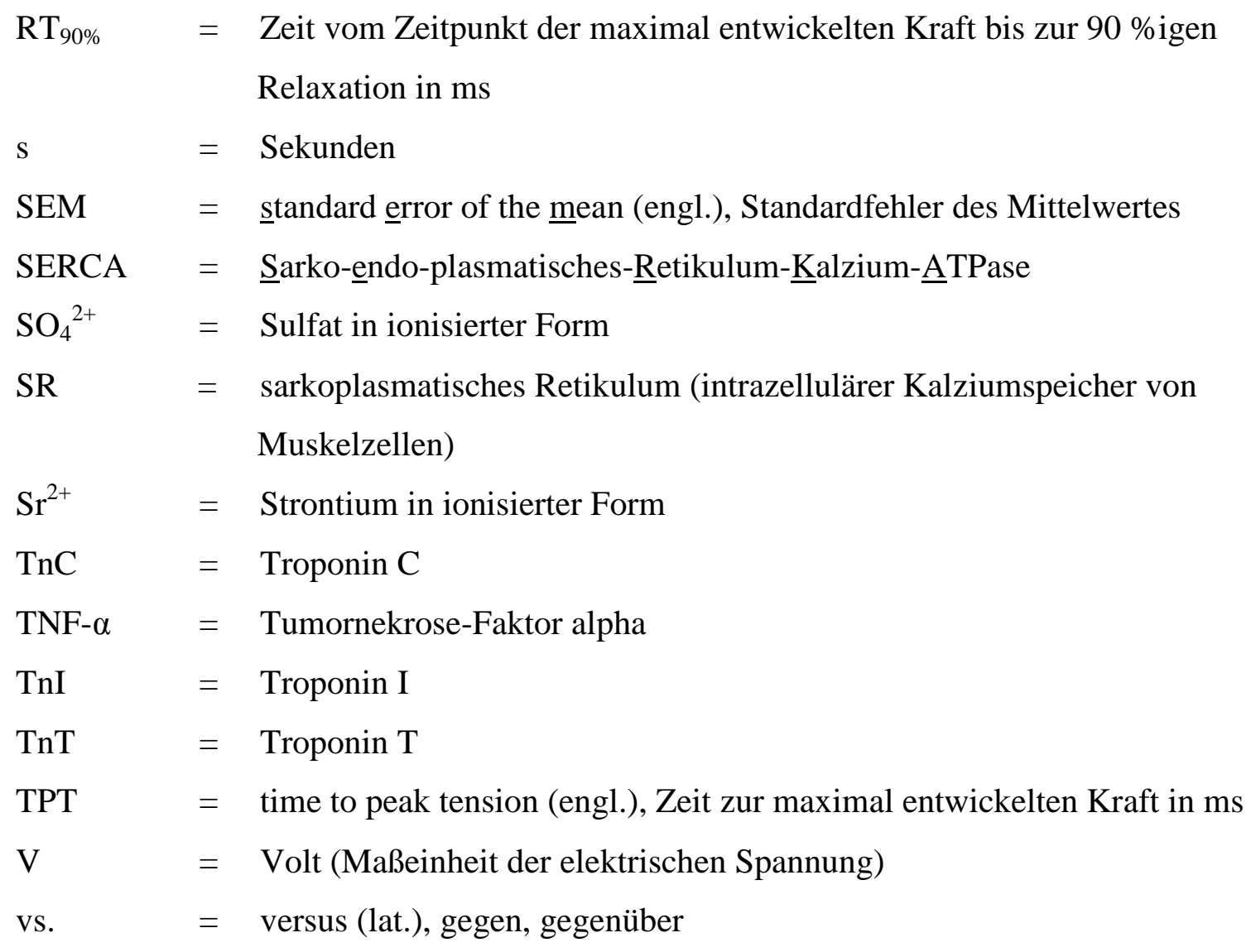




\section{Einleitung}

Die Prävalenz der chronischen Herzinsuffizienz nimmt deutlich zu und hat in den westlichen Industrieländern eine große klinische und gesundheitsökonomische Bedeutung. Bei fast der Hälfte der Patienten die an einer Herzinsuffizienz versterben, ist die Todesursache ein plötzlicher Herztod, dessen Ursache in der Regel tachykarde ventrikuläre Rhythmusstörungen sind (Cleland et al. 2002). Dieser Umstand unterstreicht den Stellenwert einer antiarrhythmischen Therapie bei der Herzinsuffizienz. Antiarrhythmika haben immer auch Einfluss auf die Myokardfunktion, dieser kommt insbesondere bei Herzinsuffizienz kurz- wie auch längerfristig eine wichtige prognostische Bedeutung zu. Das bei Herzinsuffizienz am häufigsten gebrauchte Antiarrhythmikum ist Amiodaron. Als kontraindiziert für die Anwendung bei systolischer Herzinsuffizienz gilt hingegen Flecainid, unter anderem aufgrund seines nachgewiesenen negativ inotropen Effektes. Der Einfluss der beiden Substanzen auf die diastolische Funktion des Herzens ist unbekannt. Die in vitro detailliert messbaren Auswirkungen dieser Pharmaka auf die Kontraktilität und Relaxation des terminal insuffizienten Myokards sind somit für die Beurteilung der Einsetzbarkeit dieser Medikamente bei systolischer oder diastolischer Herzinsuffizienz sehr wertvoll.

Die vorliegende Arbeit untersucht daher die Wirkungen von Amiodaron und Flecainid auf die Kontraktilität und den Kalziumstoffwechsel und die Funktionsparameter der diastolischen Funktion bei terminaler Herzinsuffizienz im isolierten humanen Myokard im Vergleich zu gesundem Tiermyokard des Kaninchens.

Auf den folgenden Seiten soll zunächst eine Einführung zur Herzinsuffizienz und dem dabei gestörten Kalziumstoffwechsel der Herzmuskelzelle gegeben werden und im Verlauf auf die Rolle von Amiodaron und Flecainid näher eingegangen werden. 


\section{1. Ätiologie und Epidemiologie der Herzinsuffizienz}

Das insuffiziente Herz ist nicht mehr in der Lage, die Organe ausreichend mit Blut und damit mit Sauerstoff zu versorgen. Das führt dazu, dass der Gewebestoffwechsel zunächst unter Belastung und später auch in Ruhe nicht mehr gewährleistet werden kann (Belastungs- oder Ruheinsuffizienz). Klinisch führt das unter anderem zu Symptomen wie Müdigkeit, Leistungsmindernug, Dyspnoe bei Belastung oder sogar in Ruhe, Ödembildung in den abhängigen Körperpartien, Lungenödem, Tachykardien, Hepatomegalie, Aszites und oberer Einflussstauung (Hoppe und Erdmann 2001).

$\mathrm{Zu}$ den häufigsten Ursachen in Deutschland für die Entstehung einer Herzinsuffizienz zählt die koronare Herzerkrankung (ischämische Kardiomyopathie ICM), welche zu einem ischämischen Myokardschaden führt. Bei $50 \%$ der Patienten ist dies die Ursache (Cowie et al. 1997). Weiterhin kann eine Herzinsuffizienz durch chronische Druck- oder Volumenbelastung der Ventrikel entstehen (arterielle Hypertonie, Klappenvitium oder Shunt) oder aufgrund einer dilatativen Kardiomyopathie DCM. Diese kann idiopathisch, toxisch (Alkohol, Zytostatika), autoimmun oder auch postinfektiös (virale oder bakterielle Myokarditis) verursacht sein (Regan 1990, Magnusson et al. 1994, Jansen et al. 2003). In Deutschland liegt die Prävalenz in den alten Bundesländern bei etwa 1,9 Millionen Menschen (3\% der Bevölkerung). Die Zahl der dadurch bedingten Hospitalisationen hat sich so in den letzten 15 Jahren verdreifacht. Bei Patienten über 65 Jahren ist die kongestive Herzinsuffizienz heute die häufigste Klinikdiagnose (Eriksson 1995). Die Prognose ist trotz optimaler therapeutischer Bemühungen schlecht. Alle klinischen Stadien einbezogen sind fünf Jahre nach Auftreten der ersten Symptome nur noch $50 \%$ der Patienten am Leben, bei Entwicklung einer Herzinsuffizienz nach Myokardinfarkt ist die Letalität noch höher (Eriksson 1995, Claasen et al. 1998). Diese Daten verdeutlichen die aktuell große und zukünftig wachsende gesundheitsökonomische Bedeutung dieser Erkrankung.

\subsection{Elektromechanische Kopplung und ihre Störungen bei der Herzinsuffizienz}

Bevor auf die einzelnen Störungen des Kalziumstoffwechsels eingegangen wird, soll hier noch einmal der physiologische Vorgang der elektro-mechanischen Kopplung dargestellt werden. Auf alle beteiligten Strukturen wird im weiteren Text eingegangen werden. Die 
Depolarisation des Myozyten durch ein Aktionspotential führt zur Erhöhung der Offenwahrscheinlichkeit der spannungsabhängigen L-Typ-Kalziumkanäle, wodurch zunächst eine geringe Menge an Kalzium in das Zytosol gelangt. Diese relativ geringe Kalzium-Menge bewirkt die Freisetzung einer größeren Menge Kalzium aus dem sarkoplasmatischen Retikulum (SR) durch Bindung an den Ryanodin-Rezeptor - kalziuminduzierte Kalziumfreisetzung (Izu et al. 2001, Bers 2002). Das so aus dem intrazellulären Kalziumspeicher (dem SR) freigesetzte Kalzium bindet an Troponin C und führt über eine Konformationsänderung des Troponin-Tropomyosin-Komplexes zur Querbrückenbildung zwischen Aktin und Myosin und damit zur Kontraktion (Bers 2001). Sinkt $\left[\mathrm{Ca}^{2+}\right]_{\mathrm{i}}$ während der Diastole, hauptsächlich durch Rücktransport durch die SERCA in das SR, so nimmt die Anzahl der Querbrückeninteraktionen pro Zeiteinheit ab, bis es zur vollständigen Relaxation der Herzmuskelzelle kommt. Darüber hinaus wird zytosolisches Kalzium zu einem Teil auch durch den sarkolemmalen Natrium-Kalzium Austauscher (NCX) aus der Zelle heraustransportiert und ein kleiner Teil auch von der sarkolemmalen Kalzium-ATPase nach extrazellulär eliminiert. Abbildung 1 zeigt schematisch die Vorgänge bei der elektromechanischen Kopplung der Herzmuskelzelle.

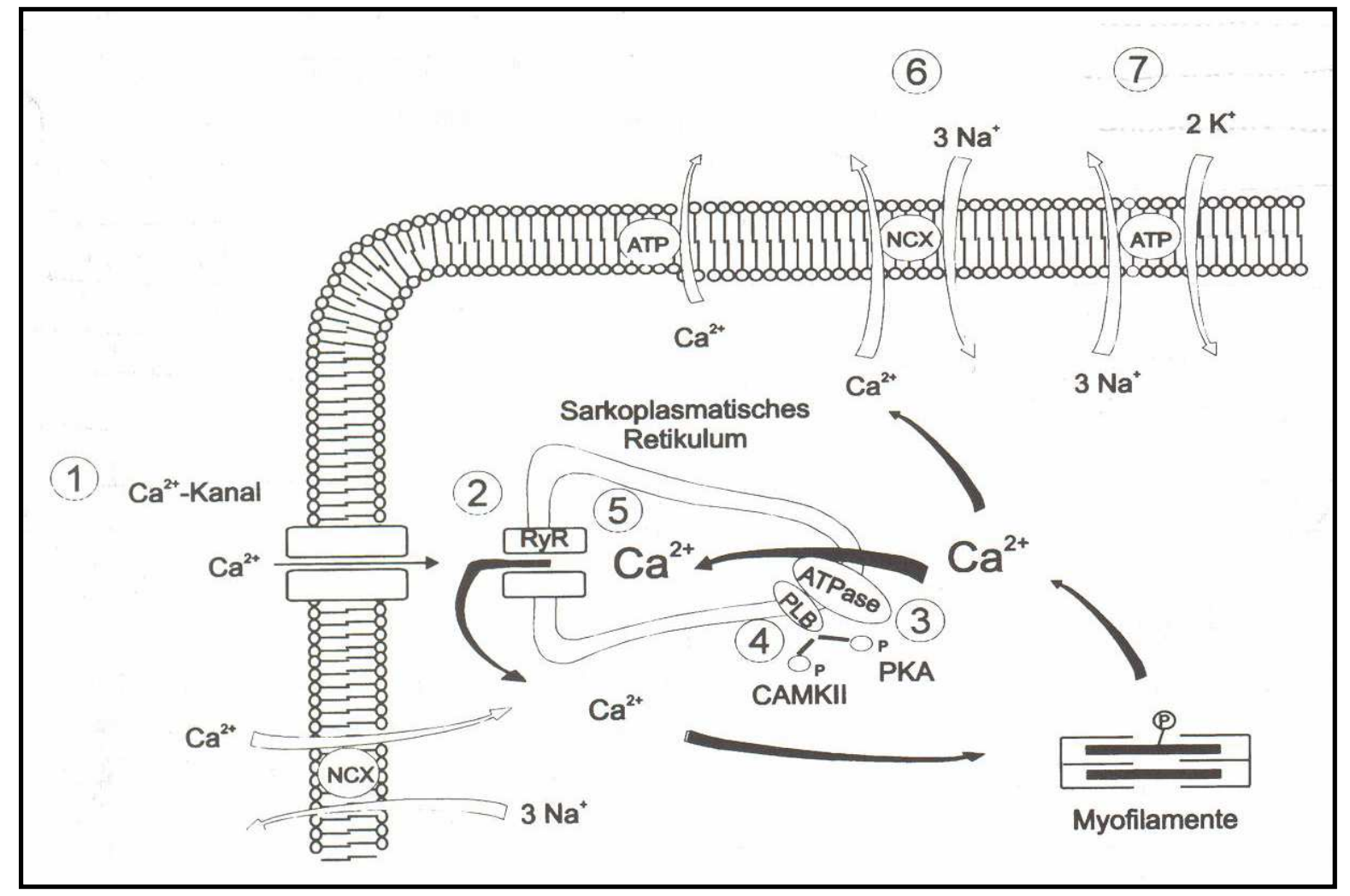

Abb. 1: Elektromechanische Kopplung der menschlichen Herzmuskelzelle, modifiziert aus Pieske und Hasenfuss 2000, S. 286. Kalziumeinstrom über L-Typ Kalziumkanäle (1). Freisetzung von Kalzium aus dem SR via Ryanodin-Rezeptor (2). Rücktransport in das SR über die SERCA (3). Regulation der SERCA durch Phospholamban (PLB) (4). Bindung von Kalzium an Calsequestrin innerhalb des SR (5). Elemination von Kalzium durch den NCX (6). Natrium-Kalium-ATPase (7). 
Unter konstant-stabilen Kontraktionsbedingungen wird in der Diastole die gleiche Menge Kalzium via SERCA zurück in das SR aufgenommen, die zuvor aus dem SR durch die Ryanodin-Rezeptoren freigesetzt worden ist. Gleichzeitig transportiert der NCX genau die Menge nach extrazellulär, die durch die L-Typ-Kalziumkanäle in die Zelle gelangt ist (Bers 2002). Der Anteil Kalzium, der von dem einen oder anderen Transporter aus dem Zytosol eliminiert wird, variiert stark zwischen verschiedenen Spezies. Beim herzgesunden Menschen werden etwa $75 \%$ des zytosolischen Kalziums von der SERCA zurück in das SR gepumpt und etwa $25 \%$ vom NCX nach extrazellulär transportiert (Pieske et al. 1999). Für das Kaninchenmyokard ist das gleiche Verhältnis nachgewiesen (Maier et al. 2000). Dieses Verhältnis verschiebt sich weiter $\mathrm{zu}$ Gunsten der SERCA bei Erhöhung der Stimulationsfrequenz. Dies geschieht erstens durch frequenzbedingte Zunahme der $[\mathrm{Na}]_{\mathrm{i}}$ und dadurch sekundäre Hemmung des NCX, zweitens durch frequenzabhängige Aktivierung der SERCA, aufgrund stärkerer Phosphorylierung des Phospholambans (Bassani RA et al. 1995). Im Rattenmyokard werden schon bei niedrigen Frequenzen etwa $90 \%$ des zytosolischen Kalziums via SERCA eliminiert (Negretti et al. 1993, Maier et al. 2000), was die dominante Rolle der SERCA im Rattenmyokard bei der diastolischen Kalziumelimination unterstreicht (Bassani JWM et al. 1994).

Die Pumpaktivität der SERCA für Kalzium wird durch das Regulatorprotein Phospholamban (PLB) beeinflusst. Unphosphoryliert inhibiert PLB die SERCA und infolge der Phosphorylierung durch eine cAMP-abhängige oder eine Kalzium-Calmodulin-abhängige Proteinkinase wird diese Hemmung aufgehoben (Koss und Kranias 1996).

\subsubsection{Die sarkolemmale Membran und integrale Proteine}

Jede Herzmuskelzelle ist von einer Zellmembran umgeben, in der sich wichtige Proteine für die Zellfunktion befinden. Diese Proteine stellen verschiedene Kanäle und Pumpen dar, durch die bestimmte Ionen passiv entlang eines Konzentrationsgradienten oder aktiv unter Energieverbrauch transportiert werden können. Die Oberfläche der Zellen wird durch Einfältelungen der Membran bis tief ins Zellinnere stark vergrößert. Diese so genannten transversalen ( $\mathrm{T}$ )-Tubuli befinden sich so in unmittelbarer Nähe des intrazellulären Kalziumspeichers der Herzmuskelzelle, dem sarkoplasmatischen Retikulum (SR).

$\mathrm{Zu}$ den Proteinen des Sarkolemms gehören die Ionenkanäle. Das sind spezifische Proteine, welche die Zellmembran quer durchspannen und in geöffnetem Zustand mehr oder weniger selektiv für bestimmte Ionen permeabel sind. Sie sind in der Regel spannungsabhängig, wodurch sie bei bestimmten Membranpotentialen durch Konformationsänderung für 
bestimmte Ionen durchlässig werden. $\mathrm{Zu}$ ihnen gehören Natrium- und Kalium-Ionenkanäle, sowie die L-Typ-Kalziumkanäle. Letztere befinden sich vor allem in den T-Tubuli und sind hauptsächlich für den Kalziumeinstrom während des Aktionspotentials (AP) verantwortlich. Bei hohen intrazellulären Kalziumkonzentrationen werden sie inaktiviert (negative Rückkopplung). Die spannungsabhängigen sarkolemmalen Natriumkanäle, die für den schnellen Natrium-Einstrom zu Beginn des AP und damit für die initiale Depolarisation der Zelle verantwortlich sind, können durch Antiarrhythmika der Klasse I nach Vaughan Williams, wie das in dieser Arbeit untersuchte Flecainid, blockiert werden. Öffnung der sarkolemmalen Kaliumkanäle bewirkt einen Kalium-Auswärtsstrom, der hauptverantwortlich für die Repolarisation der Zelle ist.

Die Natrium/Kalium-ATPase des Sarkolemms tauscht unter ATP-Verbrauch drei Natriumionen gegen zwei Kaliumionen aus und sorgt somit maßgeblich für die NatriumHomöostase und das Aufrechterhalten des Membranpotentials der Herzmuskelzelle.

Über die Expression des L-Typ-Kalziumkanals (Dihydropyridinrezeptor) bei Herzinsuffizienz liegen widersprüchliche Ergebnisse vor. Während eine Arbeitsgruppe eine signifikante Abnahme der mRNA für den L-Typ-Kalziumkanal sowie eine Abnahme der Dihydropyridinrezeptor-Bindungsstellen bei ICM und DCM fand (Takahashi et al. 1992), konnten Rasmussen et al. keine wesentliche Veränderung beobachten (Rasmussen et al. 1990). Die Dichte des Kalziumstroms ist unter elektrophysiologischen Standardbedingungen ebenso nicht verändert (Beuckelmann und Erdmann 1992, Mewes und Ravens 1994). Es konnte aber gezeigt werden, dass der sarkolemmale Kalziumeinstrom über den L-TypKalziumkanal bei steigender Stimulationsfrequenz an Myozyten aus nicht-insuffizienten Herzen zunahm, dies bei Einzelzellen aus terminal insuffizienten Herzen aber nicht mehr der Fall war (Piot et al. 1996). Diese Befunde deuten darauf hin, dass Veränderungen des Kalzium-Einwärtsstroms, insbesondere bei höheren Herzfrequenzen, zu Veränderungen der elektromechanischen Kopplung bei Herzinsuffizienz beitragen können.

Auch bei den Kalium-Ionenkanälen kommt es bei der Herzinsuffizienz zu Veränderungen. So konnte gezeigt werden, dass die Stromdichte der Kaliumauswärtsströme signifikant vermindert ist. Diese tragen wesentlich zur Repolarisation und damit zur AktionspotentialDauer bei (Beuckelmann et al. 1993).

\subsubsection{Der sarkolemmale Natrium-Kalzium-Austauscher (NCX)}

Der NCX ist keine primär Energie verbrauchende Pumpe. Indirekt benutzt sie aber die von der $\mathrm{Na}^{+} / \mathrm{K}^{+}$-ATPase produzierte Energie in Form des Natrium-Konzentrationsgradienten, um 
ein Kalziumion im Austausch gegen drei Natriumionen aus der Zelle zu transportieren (Reuter und Seitz 1986). Dieser während der diastolischen Relaxationsphase wichtige Prozess trägt zur Kalzium-Elimination bei, kann aber auch in umgekehrter Richtung funktionieren und zu einem Kalzium-Einstrom führen, „reverse mode“ (Kimura et al. 1986). Die Transportrichtung des NCX hängt unter anderem vom Natrium- und Kalziumgradienten über der Zellmembran und dem Membranpotential ab (Weber et al. 2002). Deshalb kommt es während der Depolarisationsphase zu einem Kalzium-Einwärtsstrom und so zu einer Unterstützung des Kalzium-Einstroms über die L-Typ-Kalziumkanäle (Gaughan et al. 1999). Diese Befunde deuteten auf den Zusammenhang zwischen Aktionspotential-Dauer (APD) und elektromechanischer Kopplung hin. Der NCX ist am Kardiomyozyten über die gesamte Zellmembran verteilt, inklusive T-Tubuli und Disci intercalares (Kieval et al. 1992).

Bei der Herzinsuffizienz stellt die vermehrte Expression und Aktivität des sarkolemmalen Natrium-Kalzium-Austauschers einen weiteren pathophysiologischen Befund dar (Studer et al. 1994). Dies könnte einer zytosolischen Kalziumüberladung und damit einer diastolischen Dysfunktion entgegenwirken. Es konnte nachgewiesen werden, dass das Ausmaß der diastolischen Dysfunktion am menschlichen Myokard ganz wesentlich von dem Grad der Überexpression des Natrium-Kalzium-Austauschers abhängt (Hasenfuss et al. 1999). So kam es in Herzen mit geringer Zunahme des Natrium-Kalzium-Austauschers zu einer deutlichen diastolischen Dysfunktion, wobei diese in Herzen mit erheblicher Zunahme des Austauschers nicht nachweisbar war. Dies lässt die Schlussfolgerung zu, dass SR-Kalzium-ATPase und Natrium-Kalzium-Austauscher um zytosolisches Kalzium konkurrieren und die gesteigerte Expression des Natrium-Kalzium-Austauschers bei Herzinsuffizienz zu einer weiteren Kalzium-Verarmung des SR beitragen kann und so ebenfalls eine Ursache für die negative KFB darstellen könnte.

Außerdem zeigen neuere Befunde, dass der NCX während der Depolarisationsphase des AP durch einen „reverse-mode“, das heisst Kalzium-Einwärtstransport den Kalzium-Einstrom über die L-Typ-Kalziumkanäle unterstützt und somit eine verlängerte APD bei Herzinsuffizienz auch zu einer Erhöhung der systolischen, zytosolischen Kalziumkonzentration beitragen kann (Weisser-Thomas et al. 2003).

\subsubsection{Das sarkoplasmatische Retikulum (SR)}

Das SR ist ein membranumgebenes intrazelluläres Kompartiment mit der Hauptaufgabe der Speicherung und Ausschüttung von Kalzium. Zur Speicherung besitzt es in seinem Inneren das kalziumbindende Protein Calsequestrin. Das SR besteht aus longitudinalen (L)-Tubuli 
und an ihren Enden den terminalen Zisternen. Diese befinden sich in unmittelbarer Nähe der T-Tubuli der sarkolemmalen Membran. In der Membran der terminalen Zisternen des SR befinden sich die Kalziumfreisetzungskanäle. Der räumlichen Nähe der Freisetzungskanäle des SR und der L-Typ-Kalziumkanäle der T-Tubuli des Sarkolemms wird eine große Bedeutung für die elektromechanische Kopplung zugeschrieben. Das zweite wichtige Protein in der Membran des SR ist die SR-Kalzium-ATPase, die besonders im longitudinalen Abschnitt des SR lokalisiert ist.

\subsubsection{Der Kalziumfreisetzungskanal des SR (Ryanodin-Rezeptor)}

Die kalziumsensitiven Kalziumfreisetzungskanäle haben eine tetramere Struktur und zeichnen sich durch eine hohe Affinität zu dem Pflanzenalkaloid Ryanodin aus, daher auch die Bezeichnung als Ryanodinrezeptor (Inui et al. 1987). Sie werden durch das Kalzium aktiviert, das die Zelle durch die L-Typ-Kalziumkanäle erreicht. Daraufhin öffnen sich die Freisetzungskanäle und setzen Kalzium zur Aktivierung der kontraktilen Proteine aus dem SR frei.

Bei der Herzinsuffizienz liegen über die mRNA-Expression des Ryanodin-Rezeptors widersprüchliche Befunde vor (Brillantes et al. 1992). Auch zur Funktion des Rezeptors gibt es keine einheitlichen Ergebnisse. Go et al. (1995) fanden eine Reduktion der Ryanodinbindungsstellen bei Patienten mit DCM oder ICM um 31 \% (Go et al. 1995), während Meyer et al. (1995) keine signifikanten Unterschiede nachweisen konnten (Meyer et al. 1995). Einige Autoren fanden ein vermindertes Ansprechen der Rezeptoren auf Ryanodin bei DCM und schlossen dadurch darauf, dass der Freisetzungsmechanismus für Kalzium beeinträchtigt ist (Nimer et al. 1995). Es konnte nachgewiesen werden, dass Herzinsuffizienz zu einer gestörten Domainen-Interaktion, über die das Gating des Rezeptors gesteuert wird, führt. Hierdurch kommt es zu einem diastolischen Lecken des Rezeptors, das sowohl zur Auslösung von Arrhythmien als auch zu verringerten systolischen Kalziumtransienten und damit verringerter Kontraktionskraft führt (Oda et al. 2005, Lehnart et al. 2006).

\subsubsection{Die Kalzium-ATPase des SR (SERCA)}

Der Kalziumtransport aus dem Zytoplasma in das SR erfolgt durch die Kalzium-ATPase des sarkoplasmatischen Retikulums, die SERCA. Es handelt sich dabei um einen energieverbrauchenden Prozess, bei dem der Transport von zwei Kalziumionen die Hydrolyse eines energiereichen ATP-Moleküls erfordert. Diese Pumpe ist zusammen mit dem NCXSystem der wesentliche Transportmechanismus zur Entfernung von Kalzium aus dem 
Zytoplasma und leitet so die Relaxation des Myokards ein (Schatzmann 1989). Darüber hinaus füllt es das SR wieder mit Kalzium auf, damit dieses während des nächsten Herzzyklus wieder zur Freisetzung zur Verfügung steht. Während der Wiederaufnahme konkurriert die SERCA mit dem NCX um das zytosolische Kalzium. Die SERCA-Aktivität wird durch das Phosphoprotein Phospholamban reguliert.

Bei der SERCA handelt es sich um ein transmembranes Protein mit einer Molekülgröße von etwa $110 \mathrm{kDa}$. Es konnten bisher fünf verschiedene Isoformen der SERCA identifiziert werden, die durch drei Gene kodiert sind, das SERCA1-, SERCA2- und SERCA3-Gen (Arai et al. 1994). Die beiden zusätzlichen Formen werden weiter durch posttranskriptionale Prozessierung moduliert. Das SERCA1-Gen kodiert die beiden Isoformen SERCA-1a und SERCA-1b. Letztere stellt die adulte Form der SERCA-1a dar. Sie sind im schnell kontrahierenden Skelettmuskel exprimiert und kommen nicht im Myokard vor (Brandl et al. 1986). Das SERCA2-Gen kodiert die beiden Isoformen SERCA-2a und SERCA-2b. Die SERCA-2a ist die primäre Kalziumpumpe des Myokards, kommt aber auch im langsam kontrahierenden Skelettmuskel vor (Zarain-Herzberg et al. 1990). Die SERCA-2b wird vor allem in der glatten Muskulatur exprimiert (Lytton et al. 1989) und die SERCA-3 in epithelialen und endothelialen Zellen von nichtmuskulärem Gewebe (Anger et al. 1994).

Die SERCA-Isoformen unterscheiden sich auch durch ihre Affinität und Pumpraten für Kalzium. So ist für die SERCA-2a zwar eine geringere Affinität für Kalzium als für die SERCA-2b nachgewiesen, die SERCA-2a weist jedoch eine höhere KalziumtransportAktivität auf (Verboomen et al. 1992). Für die SERCA-1a ist im Vergleich zur SERCA-2a eine zweimal größere Kalziumtransport-Aktivität nachgewiesen (Inesi et al. 2000).

Bei der Herzinsuffizienz wurde am menschlichen Myokard eine erhebliche Abnahme der Kalzium-Transportkapazität der SR-Kalzium-ATPase beschrieben (Pieske et al. 1995), die auf zwei Ursachen zurückgeführt werden kann. Erstens kommt es zu einer deutlichen Abnahme der Expression der SR-Kalzium-ATPase auf mRNA- und Protein Ebene (Mercadier et al. 1990). Außerdem führt ein im Rahmen der gestörten ß-adrenergen Signaltransduktion reduzierter cAMP-Gehalt des insuffizienten Myokards (Böhm et al. 1994) zu einer verminderten Phosphorylierung des Regulatorproteins Phospholamban, und es resultiert eine gesteigerte Inhibierung der ohnehin schon reduzierten Kalzium-Pumpen. Somit kann nicht mehr ausreichend Kalzium während der Relaxationsphase im SR akkumuliert werden. Dieser Effekt wird bei höheren Stimulationsfrequenzen verstärkt, da hier die Diastolendauer und damit die Zeit, die für die Pumpprozesse zur Verfügung steht, abnimmt. Es ist ein direkter 
Zusammenhang zwischen dem Ausmaß der kontraktilen Dysfunktion und der verminderten Pumpenexpression der SERCA nachgewiesen (Hasenfuss et al. 1994 b).

\subsubsection{Das Regulatorprotein Phospholamban (PLB)}

Die Pumpaktivität der SERCA für Kalzium wird durch das Regulatorprotein Phospholamban (PLB) beeinflusst. PLB ist ein pentameres Protein, das seine Konformation ändern und in Monomere dissoziieren kann. Diese Monomere sind die aktivere SERCA-hemmende Form. Unphosphoryliert inhibiert PLB die SERCA und durch Phosphorylierung durch eine cAMPabhängige oder eine Kalzium-Calmodulin-abhängige Proteinkinase ändert es seine Konformation und verliert seine Funktion als Inhibitor (Sham et al. 1991, Koss und Kranias 1996). Phosphorylierung von PLB führt so zu einer erhöhten Kalziumsensitivität und einer beschleunigten Pumpfunktion der SERCA.

Bei der Herzinsuffizienz konnte eine geringfügige, nicht signifikante Verminderung von PLB auf Proteinebene nachgewiesen werden (Meyer et al. 1995). Auch andere Autoren finden eine unveränderte Expression von PLB bei schwerer Herzinsuffizienz, sowohl auf mRNA Ebene als auch bei der Proteinexpression (Brillantes et al. 1992). Dies führt bei gleichzeitig deutlicher Abnahme der SERCA zu einer relativ gesteigerten Inhibition der SERCA durch PLB. Verstärkt wird dieser Effekt zusätzlich durch die verminderte intrazelluläre cAMPKonzentration (geringere Phosphorylierung von PLB) durch die verminderte Adenylatzyklase-Aktivität aufgrund der gestörten beta-adrenergen Signaltransduktion.

\subsection{Die Kraft-Frequenz-Beziehung}

Die Steigerung der myokardialen Kontraktionskraft mit zunehmender Herzfrequenz (positive Kraft-Frequenz-Beziehung) ist für die Regulation der Myokard- und Kreislauffunktion ein wichtiger physiologischer Mechanismus (Blinks und Koch-Weser 1961). Das Herzminutenvolumen kann so katecholaminunabhängig bei Belastung gesteigert werden. Dieses kann dem negativ inotropen Effekt, der durch Abnahme der Kammerfüllung (des enddiastolischen Volumens) bei zunehmender Herzfrequenz zustande kommt, entgegen wirken.

Während im nicht-insuffizienten menschlichen Myokard die Kontraktionskraftentwicklung bei steigender Stimulationsfrequenz kontinuierlich ansteigt (positive Kraft-FrequenzBeziehung), ist diese KFB am insuffizienten menschlichen Herzen aufgehoben oder sogar invers (Mulieri et al. 1992). Experimentell konnte die Umkehr der KFB an isolierten 
Muskelstreifen terminal insuffizienter menschlicher Herzen nachgewiesen werden (Feldmann et al. 1988, Mulieri et al. 1992, Pieske et al. 1992). Auch die klinische Relevanz dieser Befunde konnte in Untersuchungen an Patienten bestätigt werden. Bei Patienten mit normaler linksventrikulärer Funktion nahmen mit steigender Schrittmacherfrequenz das Herzminutenvolumen und das Schlagvolumen zu, während diese Potenzierung der Herzleistung bei Patienten mit Herzinsuffizienz fehlte (Hasenfuss et al. 1994 a).

Als subzellulärer Mechanismus konnte gezeigt werden, dass die positive KFB auf einer vermehrten Beladung des SR mit Kalzium beruht und von einer hohen Transportkapazität der SR-Kalzium-ATPase (SERCA) abhängig ist, die zytosolisches Kalzium während der Diastole zurück ins SR pumpt (Pieske et al. 1999). Zusätzliches Kalzium kann in die Zelle gelangen, weil die Offenwahrscheinlichkeit der sarkolemmalen Kalziumkanäle mit steigender Stimulationsfrequenz ansteigt und die Öffnungsdauer der Kalzium-Kanäle in nicht insuffizienten Herzen bei höheren Frequenzen zunimmt, da pro Zeiteinheit mehr Depolarisationen stattfinden. Dieser Befund konnte am insuffizienten Herzen nicht bestätigt werden (Piot et al. 1996). Gleichzeitig kommt es zu einer verringerten Zeit für den KalziumAuswärtstransport durch Verkürzung der diastolischen Relaxationsphase bei höherer Frequenz.

Die Refrakterität der Kalziumfreisetzungprozesse aus dem SR spielt bei der negativen KraftFrequenz-Beziehung des insuffizienten Myokards ebenfalls eine entscheidende Rolle (Pieske et al. 1999). Der gleiche Mechanismus wird auch als Ursache für die negative KraftFrequenz-Beziehung, die das gesunde Rattenmyokard entwickelt, von einigen Arbeitsgruppen beschrieben (Orchard und Lakatta 1985, Diaz et al. 2002).

Eine wichtige Rolle bei der Regulation der KFB spielt auch die intrazelluläre Natriumkonzentration $\left[\mathrm{Na}^{+}\right]_{\mathrm{i}}$. Erhöhung der Stimulationsfrequenz führt zu einem verstärkten Natrium-Einstrom durch die schnellen, spannungsabhängigen Natrium-Kanäle, da die Anzahl der einfallenden Aktionspotentiale pro Zeiteinheit zunimmt (Boyett et al. 1987, Harrison et al. 1992). Als Folge dieser Erhöhung der $\left[\mathrm{Na}^{+}\right]_{i}$ kommt es zu einer sekundären Zunahme der intrazellulären Kalziumkonzentration aufgrund einer stärkeren Aktivierung des NatriumKalzium-Austauschers (Allen 1992, Boyett et al. 1992). 


\subsection{Arrhythmien und antiarrhythmische Therapie bei der Herz- insuffizienz}

Von den Patienten mit chronischer Herzinsuffizienz versterben 30-50\% am plötzlichen Herztod, der Anteil der Patienten mit geringgradiger Herzinsuffizienz in diesem Kollektiv ist relativ sogar größer (Stevenson et al. 1993, Guido et al. 1997, Cleland et al. 2002). Die häufigsten Todesursachen hierbei sind ventrikuläre Tachykardien, die ins Kammerflimmern degenerieren können (Bigger 1987, Krishnan et al. 2002). Bradyarrhythmische Zwischenfälle und Asystolien machen dagegen einen eher kleinen Teil der Todesfälle aus, dies vornehmlich bei fortgeschrittener Herzinsuffizienz (Packer et al. 1991, MERIT-HF Study Group 1999, Cleland et al. 2002). Die häufigste Rhythmusstörung bei Herzinsuffizienz ist Vorhofflimmern, die Prävalenz liegt bei Patienten der NYHA-Klasse II bei 10\% und steigt in der NYHA-Klasse IV auf 40\% (Deedwania et al. 1998), zusätzlich steigt die Prävalenz von Vorhofflimmern mit zunehmendem Alter an (Cleland et al. 2001). Diese Patienten haben eine schlechtere Langzeitprognose, da Vorhofflimmern mit der Verschlechterung der Ventrikelfunktion korreliert und zudem in ventrikuläre Tachykardien bis hin zum Kammerflimmern übergehen kann und auch die Gefahr der Entwicklung von thrombembolischen Komplikationen besteht (Krishnan et al. 2002). Außerdem können persistierende supraventrikuläre Tachyarrhythmien $\mathrm{zu}$ einer Exazerbation der Herzinsuffizienz führen. Die Vorhofkontraktion und damit die Verstärkung der Ventrikelfüllung kann bis zu $25 \%$ des Schlagvolumens ausmachen. Das Fehlen dieses Effekts kann bei Patienten mit eingeschränkter linksventrikulärer Funktion zu einer Verschlechterung der Herzinsuffizienz-Symptome führen. Rhythmusstörungen können somit eine vitale Bedrohung für den herzinsuffizienten Patienten darstellen und sind die häufigste Todesursache bei Patienten mit leichter und mittelschwerer Herzinsuffizienz, NYHA II und III (Krishnan et al. 2002).

Prinzipiell werden bei herzinsuffizienten Patienten alle Antiarrhythmika der Klassen I-IV nach Vaughan Williams (1984) eingesetzt. Neben dem antiarrhythmischen Effekt kommt hierbei dem Einfluss auf die Myokardfunktion des jeweiligen Pharmakons besondere Bedeutung zu, was in dieser Arbeit daher näher untersucht werden soll.

Beta-Rezeptoren-Blocker eignen sich zur Frequenzkontrolle bei tachykardem Vorhofflimmern in Kombination mit Herzglykosiden (Yahalom et al. 1977). Sie antagonisieren die elektrophysiologischen Effekte endogener Katecholamine. Aufgrund ihrer initial negativ inotropen Wirkung sollten sie bei Herzinsuffizienz einschleichend gegeben 
werden. Beta-Rezeptoren-Blocker vermindern das Risiko für einen plötzlichen Herztod herzinsuffizienter Patienten signifikant (Lechat et al. 1998, MERIT-HF Study Group 1999, CIBIS-II Investigators and Committees 1999) und reduzieren auch die Gesamtsterblichkeit von Patienten der Stadien NYHA II-IV. Dieses ist besonders für die drei Beta-RezeptorenBlocker Bisoprolol (CIBIS-II Investigators and Committees 1999), Metoprolol (MERIT-HF Study Group 1999, Hjalmarson et al. 2000) und Carvedilol (Packer et al. 1996 a) nachgewiesen worden.

Kalziumantagonisten spielen in der antiarrhythmischen Therapie herzinsuffizienter Patienten aufgrund ihrer negativ inotropen Wirkungen eine untergeordnete Rolle. Ihre Wirkung entfalten sie durch Blockade des L-Typ-Kalzium-Kanals. Sie können bei Patienten mit eingeschränkter linksventrikulärer Funktion zu einer Verschlechterung der Herzinsuffizienz führen und die Letalität erhöhen (Elkayam et al. 1990, DAVIT-II 1990, Goldstein et al. 1991, Gheorghiade et al. 1991, Cohn et al. 1997). Nur für Amlodipin besteht keine Kontraindikation bei Herzinsuffizienz und es kann bei speziellen Indikationen, wie persistierendem Hypertonus trotz ACE-Hemmer-, Betablocker- und Diuretikatherapie, angewandt werden (Packer et al. 1996 b, de Vries et al. 2000).

Antiarrhythmika der Klasse I und III der Klassifikation nach Vaughan Williams (1984) waren Gegenstand der Untersuchungen in dieser Arbeit, darauf soll im Folgenden näher eingegangen werden.

\subsubsection{Das Klasse-Ic-Antiarrhythmikum Flecainid}

Bei Patienten mit alleinigem Vorhofflimmern (ohne begleitende kardiale Erkrankung), das weniger als 48 Stunden besteht, weist Flecainid (90\%) verglichen mit Propafenon (72\%) und Amiodaron (64\%) die höchste Konversionsrate in den Sinusrhythmus innerhalb der ersten zwölf Stunden auf (Martinez-Marcos et al. 2000). Bei dieser Indikation (,lone atrial fibrillation“) stellt Flecainid das Mittel der ersten Wahl dar (Boriani et al. 1997, Capucci et al. 1999, Hennersdorf et al. 2001). Wichtig ist, dass Flecainid nicht bei Patienten mit Vorhofflimmern und gleichzeitig bestehender Herzinsuffizienz eingesetzt werden darf. Bei bestehender KHK oder abgelaufenem Myokardinfarkt und Vorhofflimmern sollten Medikamente der Klasse IC ebenso nicht eingesetzt werden. Hierbei sind Betablocker die Mittel der ersten Wahl (Hennersdorf et al. 2001). Diese Erkenntnisse erlangte man aus den beiden CAST-Studien (Cardiac Arrhythmia Supression Trial), die unter Flecainid und Encainid eine erhöhte Mortalität nach Myokardinfarkt mit eingeschränkter linksventrikulärer Funktion zeigten (CAST-I 1989, Greene et al. 1992). An der Studie wurde die 
außergewöhnlich niedrige Mortalität der Kontrollgruppe kritisiert. Dennoch wird seither empfohlen, Klasse IC Antiarrhythmika bei diesem Patientenkollektiv nicht mehr einzusetzen (Hennersdorf et al. 2001, Naccarelli et al. 2003).

Zugleich ist ein negativ inotroper Effekt von Flecainid bekannt, die Deutsche Gesellschaft für Kardiologie- Herz- und Kreislaufforschung empfiehlt daher in ihren Leitlinien zu „Therapie der chronischen Herzinsuffizienz“, dass Antiarrhythmika der Klasse I nach Vaughan Williams wegen ihrer potentiell negativ inotropen und proarrhythmischen Wirkungen bei Herzinsuffizienz nicht eingesetzt werden sollten (Hoppe und Erdmann 2001).

\subsubsection{Das Klasse-III-Antiarrhythmikum Amiodaron}

Als Klasse-III-Antiarrhythmikum ist Amiodaron ein sehr effektives Medikament zur Behandlung sowohl supraventrikulärer als auch ventrikulärer Tachykardien (Amiodarone trials-metaanalyses investigators 1997). Da es bei oraler Gabe offenbar nicht negativ inotrop wirkt und sogar geringfügig die linksventrikuläre systolische Pumpfunktion verbessern kann (Massie et al. 1996), stellt es bei der Behandlung von Arrhythmien bei Herzinsuffizienz das Mittel der ersten Wahl dar, dies möglicherweise auch in Zusammenhang mit seinem frequenzstabilisierenden Effekt. Amiodaron kann bei einem Teil herzinsuffizienter Patienten mit Vorhofflimmern den Sinusrhythmus wiederherstellen und erhalten (Gosselink et al. 1992). Die Wirksamkeit einer prophylaktischen Amiodaron Therapie bei Herzinsuffizienz mit ventrikulären Rhythmusstörungen wird in der Literatur kontrovers diskutiert. Zwei große Meta-Analysen von Amiodaron-Studien bei Herzinsuffizienz zeigten jedoch insgesamt einen Überlebensvorteill unter Amiodarontherapie (Amiodarone trials-metaanalyses investigators 1997, Sim et al. 1997).

Die zahlreichen Nebenwirkungen der Therapie machen Amiodaron bei nicht herzinsuffizienten Patienten zu einem Antiarrhythmikum der zweiten Wahl. Als häufigste Nebenwirkungen sind Mikroablagerungen auf der Hornhaut (etwa $90 \%$ ) und die Störungen des Schilddrüsenstoffwechsels $\mathrm{zu}$ nennen. Pneumonitiden und Lungenfibrose stellen seltenere, aber schwerwiegende Nebenirkungen dar (Prayer et al. 1989, Dean et al. 1986). Hautveränderungen, Photosensibilisierung, Leberschädigungen und eine Vielzahl unspezifischer Veränderungen treten bei höheren Dosierungen auf (Stäubli et al. 1983).

Amiodaron und Metaboliten werden praktisch nicht renal eliminiert (Andreasen et al. 1981, Bonati et al. 1983) und reichern sich sehr stark im Fettgewebe an, hier ist die Konzentration dreimal höher ist als im Serum. Dies scheint auch der Grund für die extrem lange und interindividuell stark schwankende Eliminationshalbwertszeit von 30-118 Tagen zu sein (Holt 
und Storey 1983). Seine spezielle Pharmakokinetik macht Amiodaron in der Dauertherapie relativ schlecht steuerbar. Amiodaron ist ein stark hydrophobes Molekül was auch in seiner starken Eiweissbindung im Blutplasma zum Ausdruck kommt. Deshalb muss es in der Injektionslösung zusätzlich mit einem Lösungsvermittler bestehend aus Benzyl-Alkohol und dem Polysorbat „Tween 80“ verwendet werden (Munoz et al. 1988).

\subsection{Ziele und Fragestellungen der vorliegenden Arbeit}

- Ist der negativ inotrope Effekt von Flecainid am isolierten, insuffizienten Myokard kalziumabhängig, wie stark ist dieser Effekt ausgeprägt?

- Vermittelt Amiodaron am isolierten, insuffizienten Myokard einen negativ oder positiv inotropen Effekt, welchen Einfluss darauf hat das verwendete Lösungsmittel?

- Wie ist der Einfluss von Flecainid und Amiodaron auf die diastolische Funktion bei terminaler Herzinsuffizienz?

- Wie ist der Einfluss von Flecainid und Amiodaron auf die Kraft-Frequenz-Beziehung bei terminaler Herzinsuffizienz?

- Wie verhalten sich Flecainid und Amiodaron im nicht-insuffizienten Myokard? Gibt es insbesondere einen Unterschied beim Effekt dieser Substanzen auf die KraftFrequenz-Beziehung im Vergleich zum insuffizienten Myokard? 


\section{Material und Methoden}

\subsection{Untersuchtes Gewebe}

Die in dieser Arbeit durchgeführten Untersuchungen wurden an insgesamt 106 Herzmuskelstreifen-Präparaten durchgeführt. Davon stammten 66 aus 31 terminal insuffizienten humanen Herzen (linker Ventrikel), 40 davon waren Trabekel aus 16 nicht insuffizienten Kaninchenherzen.

\subsubsection{Insuffizientes humanes Myokard}

Alle Präparate dieser Gruppe stammten von Patienten mit terminaler Herzinsuffizienz des klinischen Grades NYHA IV gemäß der Klassifikation der New York Heart Association. Alle diese Patienten mussten sich einer Herztransplantation unterziehen. Diese wurde in orthotoper Operationstechnik durchgeführt. Die Entnahme der Trabekel erfolgte aus dem entnommenen Empfängerherzen. Die Transplantationen fanden im Herzzentrum Nordrhein-Westfalen, Bad Oeynhausen und in der Klinik für Thorax- Herz- und Gefässchirurgie des Universitätsklinikums Göttingen statt. Hinsichtlich der Genese der Herzinsuffizienz konnten die Patienten in eine Gruppe mit ischämischer Kardiomyopathie (ICM) und eine Gruppe mit dilatativer Kardiomyopathie (DCM) eingeteilt werden. Bei $67 \%$ der Patienten war eine ICM, bei $33 \%$ der Patienten eine DCM die zugrundeliegende Erkrankung.

Es lag jeweils eine schriftliche Einverständniserklärung der Patienten vor, sowie die Genehmigung der Experimente durch die Ethik-Kommission der Medizinischen Fakultät der Universität Göttingen.

\subsubsection{Klinische Patientendaten}

Die folgenden Tabellen geben die klinischen Patientendaten für die vier verschiedenen Protokolle (Konzentrations-Wirkungs-Kurve für Flecainid, Kraft-Frequenz-Beziehung für Flecainid, intrazelluläre Kalziumtransienten unter Flecainid sowie Kraft-Frequenz-Beziehung für Amiodaron) mit terminal insuffizientem humanem Myokard wieder.

Patienten-Verschlüsselung (ID), Geschlecht (m/f), Alter (Jahre), Diagnose (ICM oder DCM), Ejektionsfraktion (EF in \%), pulmonalkapillärer Verschlussdruck (PCW in mmHg), cardiac index, Herzindex (CI in $1 / \mathrm{m}^{2}$ ) und die Medikation, die jeweils in folgende Arzneimittelgruppen zusammengefasst wurde: 
Antiarrhythmika (AAR), ACE-Hemmer (ACE), Aldosteron-Antagonisten (Aldact), Angiotensin-II-Rezeptorblocker (ARB), Thrombozytenaggregationshemmer (ASS), BBlocker (Beta), herzwirksame Glykoside (Dig), Schleifendiuretika (Diu), Katecholamine (Kat), Kalziumkanalblocker (KKB), Nitrate und andere Koronardilatanzien (Nit), Phosphodiesterase-Hemmstoffe (PDE).

\section{Flecainid-Konzentrations-Wirkungs-Kurve}

\begin{tabular}{|c||c||c||c||c||c||c||l|}
\hline Patienten & $\mathbf{m} / \mathbf{f}$ & Alter & Diagn. & $\begin{array}{c}\text { EF } \\
(\%)\end{array}$ & $\begin{array}{c}\text { PCW } \\
(\mathbf{m m H g})\end{array}$ & $\begin{array}{c}\mathbf{C l} \\
\left(\mathbf{l} / \mathbf{m}^{\mathbf{2}}\right)\end{array}$ & Medikation \\
\hline K-L.S. & $\mathrm{m}$ & 57 & $\mathrm{ICM}$ & 23 & 16 & 2,14 & AAR, ACE, ASS, Beta, Diu \\
\hline D.F. & $\mathrm{m}$ & 53 & $\mathrm{ICM}$ & 29 & 17 & 3,12 & ACE, Aldact, ASS, Beta, Dig, Nit \\
\hline A.F. & $\mathrm{m}$ & 61 & $\mathrm{DCM}$ & 19 & 18 & 2,01 & AAR, Beta, Diu, Kat, Nit, PDE \\
\hline W.A. & $\mathrm{m}$ & 60 & $\mathrm{ICM}$ & 17 & 19 & 2,11 & ACE, Beta, Dig, Diu, Nit \\
\hline W.F. & $\mathrm{m}$ & 59 & $\mathrm{ICM}$ & 21 & 15 & 1,61 & ACE, Beta, Dig, Diu \\
\hline Mittelwert & & 58,0 & & 21,8 & 17,0 & 2,20 & \\
\hline Standardabw & & 2,83 & & 4,12 & 1,41 & 0,50 & \\
\hline SEM & 1,26 & & 1,84 & 0,63 & 0,22 & \\
\hline
\end{tabular}

\section{Flecainid-Aequorin-Kalziumtransienten}

\begin{tabular}{|c||c||c||c||c||c||c||l|}
\hline Patienten & $\mathbf{m} / \mathbf{f}$ & Alter & Diagn. & $\begin{array}{c}\text { EF } \\
(\%)\end{array}$ & $\begin{array}{c}\text { PCW } \\
(\mathbf{m m H g})\end{array}$ & $\begin{array}{c}\text { Cl } \\
\left(\mathbf{l} / \mathbf{m}^{\mathbf{2}}\right)\end{array}$ & Medikation \\
\hline H-J.S. & $\mathrm{m}$ & 57 & ICM & 19 & 13 & 2,12 & ACE, ASS, Beta, Dig, Diu \\
\hline I.B. & $\mathrm{f}$ & 58 & DCM & 22 & 25 & 1,68 & ARB, Beta, Dig, Diu, Kat, PDE \\
\hline G.K. & $\mathrm{f}$ & 56 & DCM & 23 & 20 & 2,21 & ACE, Dig, Diu, KKB, Nit \\
\hline C.A. & $\mathrm{f}$ & 40 & ICM & 11 & 22 & 3,10 & ACE, Diu, KKB, Nit \\
\hline W.S. & $\mathrm{m}$ & 64 & DCM & 16 & 18 & 1,40 & ACE, Beta, Dig, Diu, Nit \\
\hline Mittelwert & & 55 & & 18,20 & 19,60 & 2,10 & \\
\hline Standardabw & & 8 & & 4,35 & 4,03 & 0,58 & \\
\hline SEM & & 3,58 & & 1,95 & 1,80 & 0,26 & \\
\hline
\end{tabular}

\section{Amiodaron-Konzentrations-Wirkungs-Kurve}

\begin{tabular}{|c||c||c||c||c||c||c||l|}
\hline Patienten & $\mathbf{m} / \mathbf{f}$ & Alter & Diagn. & $\begin{array}{c}\text { EF } \\
(\%)\end{array}$ & $\begin{array}{c}\text { PCW } \\
(\mathbf{m m} \mathbf{m})\end{array}$ & $\begin{array}{c}\mathbf{C l} \\
\left(\mathbf{l} / \mathbf{m}^{\mathbf{2}}\right)\end{array}$ & Medikation \\
\hline P.P. & $\mathrm{m}$ & 67 & DCM & 17 & 18 & 1,63 & AAR, ACE, ASS, Beta, Diu \\
\hline J.S. & $\mathrm{m}$ & 55 & $\mathrm{ICM}$ & 18 & 15 & 2,31 & ACE, Aldact, ASS, Beta, Dig, Nit \\
\hline A.V. & $\mathrm{f}$ & 60 & $\mathrm{DCM}$ & 21 & 21 & 2,43 & AAR, Beta, Diu, Kat, Nit, PDE \\
\hline F.D. & $\mathrm{m}$ & 61 & $\mathrm{ICM}$ & 14 & 20 & 2,36 & ACE, ASS, Beta, Diu, Nit \\
\hline M.B. & $\mathrm{f}$ & 59 & $\mathrm{ICM}$ & 16 & 19 & 2,29 & ACE, Beta, Dig, Diu, Nit \\
\hline Mittelwert & & 60,4 & & 17,2 & 18,6 & 2,2 & \\
\hline Standardabw & & 4,3 & & 2,6 & 2,3 & 0,3 & \\
\hline SEM & & 1,9 & & 1,2 & 1,0 & 0,1 & \\
\hline
\end{tabular}


Amiodaron-Kraft-Frequenz-Beziehung

\begin{tabular}{|c|c|c|c|c|c|c|c|}
\hline Patienten & $\mathbf{m} / \mathbf{f}$ & Alter & Diagn. & $\begin{array}{l}\mathrm{EF} \\
(\%)\end{array}$ & $\begin{array}{c}\text { PCW } \\
(\mathrm{mmHg})\end{array}$ & $\begin{array}{c}\mathrm{Cl} \\
\left(\mathrm{I} / \mathrm{m}^{2}\right)\end{array}$ & Medikation \\
\hline M.L. & $\mathrm{m}$ & 64 & ICM & 21 & 17 & 2,15 & ACE, Beta, Dig, Diu, Nit \\
\hline A-L.H. & $f$ & 59 & DCM & 20 & 18 & 1,01 & ACE, Beta, Dig, Diu \\
\hline D.F. & $\mathrm{m}$ & 56 & ICM & 18 & 27 & 1,12 & ACE, Beta, Dig, Diu, Nit \\
\hline A.G. & $f$ & 60 & ICM & 17 & 15 & 1,60 & ACE, Aldactone, Dig, Diu, Nit \\
\hline G.L. & $\mathrm{m}$ & 63 & ICM & 20 & 25 & 1,82 & Aldact, ARB, Beta, Diu, Nit \\
\hline H.M. & $\mathrm{m}$ & 63 & ICM & 14 & 20 & 1,64 & AAR, ACE, Beta, Diu, Nit \\
\hline G.D. & $\mathrm{m}$ & 61 & DCM & 17 & 18 & 1,80 & AAR, ACE, Beta, Dig, Diu \\
\hline W.F. & $\mathrm{m}$ & 59 & ICM & 16 & 14 & 1,61 & ACE, Beta, Dig, Diu, Nit \\
\hline Mittelwert & & 60,6 & & 17,9 & 19,3 & 1,60 & \\
\hline Standardabw & & 2,50 & & 2,20 & 4,29 & 0,35 & \\
\hline SEM & & 0,88 & & 0,78 & 1,52 & 0,12 & \\
\hline
\end{tabular}

\section{Flecainid-Kraft-Frequenz-Beziehung}

\begin{tabular}{|c|c|c|c|c|c|c|c|}
\hline Patienten & $\mathbf{m} / \mathbf{f}$ & Alter & Diagn. & $\begin{array}{l}\mathrm{EF} \\
(\%)\end{array}$ & $\begin{array}{c}\text { PCW } \\
(\mathrm{mmHg})\end{array}$ & $\begin{array}{c}\mathrm{Cl} \\
\left(\mathrm{l} / \mathrm{m}^{2}\right)\end{array}$ & Medikation \\
\hline H-J.S. & $\mathrm{m}$ & 57 & ICM & 19 & 13 & 2,12 & ACE, ASS, Beta, Dig, Diu \\
\hline W.K. & $\mathrm{m}$ & 60 & ICM & 29 & 17 & 2,01 & ACE, Beta, Dig, Diu, Nit \\
\hline G.K. & $f$ & 56 & ICM & 22 & 24 & 2,21 & ACE, Dig, Diu, KKB, Nit \\
\hline D.T. & $\mathrm{m}$ & 65 & ICM & 29 & 19 & 1,7 & AAR, Aldact, Beta, Dig, Diu \\
\hline F-W.P. & $\mathrm{m}$ & 62 & ICM & 22 & 18 & 0,95 & AAR, ACE, Aldact, Beta, Diu \\
\hline H-P. H. & $\mathrm{m}$ & 48 & ICM & 23 & 16 & 1,95 & ARB, Beta, Dig, Diu, Marc \\
\hline J.W. & $\mathrm{m}$ & 59 & DCM & 26 & 15 & 2,64 & AAR, ACE, Aldact, Dig, Diu \\
\hline D.E. & $\mathrm{m}$ & 51 & DCM & 19 & 15 & 2,02 & ACE, ASS, Beta, Dig, Diu \\
\hline C.A. & $f$ & 45 & ICM & 26 & 14 & 1,8 & AAR, Beta, Dig, Diu, Kat, Nit \\
\hline E.V. & $\mathrm{m}$ & 46 & DCM & 25 & 31 & 1,45 & AAR, Aldact, ASS, Beta, Diu \\
\hline R.D. & $f$ & 54 & DCM & 30 & 15 & 1,91 & ACE, Aldact, Diu, Kat, PDE \\
\hline F.W. & $\mathrm{m}$ & 62 & DCM & 26 & 22 & 2,47 & ACE, Beta, Dig, Diu, Nit \\
\hline A.M. & $\mathrm{m}$ & 67 & $\mathrm{ICM}$ & 27 & 20 & 2,24 & ACE, Aldact, Beta, Dig, Diu, Nit \\
\hline H.M. & $f$ & 57 & $\mathrm{ICM}$ & 20 & 18 & 2,69 & ACE, Aldact, Beta, Dig, Diu, Nit \\
\hline Mittelwert & & 56,4 & & 24,5 & 18,4 & 2,01 & \\
\hline Standardabw & & 6,62 & & 3,58 & 4,61 & 0,44 & \\
\hline SEM & & 1,77 & & 0,96 & 1,23 & 0,12 & \\
\hline
\end{tabular}

\subsubsection{Transport und Präparation}

\section{Transport}

Das explantierte Herz wurde unmittelbar nach der Organentnahme in eine kardioprotektive Tyrodelösung (Zusammensetzung siehe 2.2.1.) überführt. Diese war gekühlt und durch Carbogen (95\% Sauerstoff; $5 \%$ Kohlendioxid) präoxigeniert. Als kardioplegen Wirkstoff enthielt die Lösung 2,3-Butandion-Monoxim (BDM) in einer Konzentration von $30 \mathrm{mmol} / \mathrm{l}$. 
Herzen, die im Universitätsklinikum Göttingen explantiert wurden, konnten daraufhin innerhalb von zehn Minuten in das kardiologische Labor gebracht werden. Das im Herzzentrum NRW, Bad Oeynhausen, entnommene Myokard konnte innerhalb eines etwa zweistündigen Transportes in das Labor im Göttinger Klinikum gebracht werden. Während dieses Transportes befand sich das Gewebe in gekühlter, präoxigenierter, ButanedionMonoxim haltiger $(30 \mathrm{mM})$, kardioplegischer Lösung in einem luftdichten Gefäss. Zum Transport diente ein spezieller Koffer, der temperaturisoliert war und über Kühlakkus eine Temperatur von $4^{\circ} \mathrm{C}$ konstant hielt.

Die Aufbewahrung des Myokards im Labor erfolgte in einem auf $4^{\circ} \mathrm{C}$ gekühlten Organbad in Butandion-Monoxim-haltiger Tyrodelösung, die permanent mit Carbogen durchperlt wurde. Diese Lösung wurde alle vier Stunden erneuert.

\section{Präparation}

Die Präparation erfolgte in einer Präparierschale, die ebenfalls mit der für den Transport verwendeten BDM-haltigen Tyrodelösung gefüllt war, gekühlt und permanent mit Carbogen durchperlt wurde. Zur besseren Visualisierung wurde ein Stereomikroskop mit zehnfacher Vergrößerung (VMT; Olympus) verwendet. Ziel war es, möglichst unverzweigte und freiliegende Trabeculae carneae mit parallelem Faserverlauf, durch Schnitte an beiden Enden eines fünf bis zehn Millimeter langen Stückes, vom Restmyokard zu isolieren.

Dazu wurde der linke Ventrikel zunächst septumnah - per Schnittführung durch das Lumen der Aorta - bis zur Herzspitze - eröffnet, da hier im Bereich des Ausflusstraktes des linken Ventrikels das Innenrelief sehr glatt ist und hier wenig intakte Trabekel traumatisiert werden. Die Trabekel wurden möglichst langstreckig, unter strenger Vermeidung von Dehnung, mit Hilfe von mikrochirurgischen Scheren aus der Ventrikelwand geschnitten. Zur Erleichterung des atraumatischen Einspannens des Muskels in der Anlage wurde an beiden Enden des Trabekels Myokardreste (ein so genanntes meat-end) belassen, an denen der Muskelstreifen dann in den Klemmen eingespannt wurde.

Die speziellen Anforderungen an das Trabekel-Präparat waren je nach Experimentierprotokoll unterschiedlich:

Für die Aequorinexperimente war hinsichtlich des Makroinjektionsverfahrens ein intaktes Endokard - über die gesamte Trabekellänge - erforderlich. Dieses dient bei der Injektion als ein Widerlager für den injizierten Aequorin-Bolus. Die Querschnittsfläche der Präparate sollte hierbei $0,6 \mathrm{~mm}^{2}$ nicht überschreiten, da nur so eine ausreichende Oxigenierung durch Diffusion des Sauerstoffes aus der Tyrode in das Innere des Präparates gewährleistet ist 
(Koch-Weser und Blinks 1963; Paradise et al. 1981). Fibrosierte Trabekel wurden nicht verwendet.

Für die Messung der KWK sowie der Kraft-Frequenz-Beziehung an der Viereranlage wurde auf möglichst geringe Querschnittsflächen geachtet.

Nach der Präparation verblieben die Muskelstreifen noch mindestens fünfzehn Minuten in der kardioplegischen Tyrode, um den Zellschaden zu minimieren, der präparationsbedingt durch eine massive myozytäre Kalziumfreisetzung entstehen könnte.

\subsubsection{Nicht-insuffizientes Kaninchenmyokard}

Die Präparate dieser Gruppe stammten ausschließlich von weiblichen Kaninchen der Rasse New Zealand Bastard, geliefert im Alter von 6 Wochen. Alle untersuchten Herzen stammten von Tieren, deren Alter zwischen acht und zehn Wochen lag. Gehalten wurden die Tiere in der Zentralen Tierexperimentellen Einrichtung (ZTE) des Universitätsklinikums Göttingen, wobei alle Tiere einer Lieferung in gemeinsamer Bodenhaltung, getrennt von anderen Kaninchen, gehalten wurden. Die Untersuchungen wurden von der Ethik-Kommision der medizinischen Fakultät genehmigt.

\section{Präparation}

Alle Tiere wurden mit Hilfe einer intravenösen Phenobarbital-Narkose anästhesiert, wobei der venöse Zugang von der Ohrvene aus gewählt wurde. Nach Zuwarten von mindestens fünf Minuten und unter sicherem Feststellen von Schmerzlosigkeit, Bewusstlosigkeit und Muskelrelaxation (fehlender Kornealreflex, keine Schmerzempfindung an der Sohlenseite des Laufes und erloschener Muskeltonus), wurde zunächst das Fell an der Bauchseite abpräpariert, dann die Schichten der muskulären Bauchdecke einzeln durchtrennt. Dann erfolgte die Eröffnung des Thoraxraumes durch Abpräparation des Zwerchfelles von der ventralen und lateralen Thoraxwand. Daraufhin wurden die Rippen mit einer kräftigen Knochenschere jeweils zwei Zentimeter lateral des Sternums in cranialer Richtung durchtrennt. Somit konnte das Sternum am kaudalen Rand mit einer chirurgischen Pinzette gefasst und nach kranial gehalten werden, so dass jetzt das Herz - noch schlagend - im Thorax sichtbar wurde. Nach Eröffnung des Perikards wurde nun in zügiger Abfolge die Herzspitze mit einer feinen chirurgischen Pinzette gefasst, die untere Hohlvene durchtrennt, das Herz luxiert und anschliessend die dorsal gelegenen Pulmonalvenen, Pulmonalarterie, obere Hohlvene sowie die Aorta ascendens durchtrennt. 
Unmittelbar daraufhin wurde das Herz in eine Präparierschale gelegt und die Koronararterien über den verbliebenen Aortenstumpf antegrad mit 300 Milliliter Butandion-Monoxim-haltiger Tyrodelösung für etwa zehn Minuten perfundiert.

Die Lösung war gekühlt und permanent mit Carbogen durchperlt. Ein sofortiges Erblassen des gesamten Myokardes zeigte den Erfolg der Perfusion an. Somit konnte sichergestellt werden, dass das gesamte Myokard ausreichend mit kardioplegischer Lösung versorgt worden war.

Die weitere Präparation erfolgte in einer Präparierschale, die ebenfalls mit kardioplegischer Tyrode gefüllt und mit Carbogen durchperlt war, unter Verwendung eines Stereomikroskops (VMT; Olympus) mit zehnfacher Vergrösserung. Nach Eröffnung des Ventrikels, entsprechend der oben beschriebenen Technik, wurden auch hier Trabeculae carneae mit möglichst geringem Durchmesser entnommen. Diese wurden möglichst langstreckig unter Vermeidung von Dehnung mit Hilfe mikrochirurgischer Scheren aus der Wand des Ventrikels geschnitten und anschließend noch fünfzehn Minuten in der BDM-haltigen Tyrode belassen. Auch Papillarmuskeln aus dem rechten Ventrikel wurden bei geeignetem Durchmesser verwendet.

\subsection{Lösungen und Substanzen}

\subsubsection{Tyrodelösung}

Die Tyrodelösung, die für den Transport, die Präparation und alle Experimente verwendet wurde, entspricht einem modifizierten Krebs-Henseleit-Puffer und hatte folgende Zusammensetzung:

$152 \mathrm{mM} \mathrm{Na}^{+}, 3,6 \mathrm{mM} \mathrm{K}^{+}, 135 \mathrm{mM} \mathrm{Cl}^{-}, 25 \mathrm{mM} \mathrm{NaHCO}_{3}, 0,6 \mathrm{mM} \mathrm{Mg}^{2+}, 1,3 \mathrm{mM} \mathrm{H}_{2} \mathrm{PO}^{-}$, $0,6 \mathrm{mM} \mathrm{SO}_{4}{ }^{2+}, 2,5 \mathrm{mM} \mathrm{Ca}^{2+}, 11,2 \mathrm{mM}$ Glukose sowie $10 \mathrm{IE} / \mathrm{l}$ Altinsulin (H-Insulin, Hoechst AG).

Die Tyrodelösung war stets mit Carbogen (95\% Sauerstoff, 5\% Kohlenstoffdioxid) begast, um die Oxigenierung zu gewährleisten und den pH-Wert konstant bei 7,4 zu halten. Bis zum Beginn des Experimentes enthielt die Tyrode $30 \mathrm{mM}$ Butandion-Monoxim. Sie wurde an jedem Experimentiertag frisch angesetzt. 


\subsubsection{Kardioplegie}

Für den Transport sowie die Präparation enthielt die Tyrodelösung zusätzlich 30 mM BDM (2,3-Butandion-Monoxim). Dabei handelt es sich um eine Phosphatase, deren Wirkung auf einer reversiblen Hemmung der Querbrückeninteraktion (Blanchard et al. 1984; Blanchard et al. 1990; Mulieri und Alpert 1984) und auf einer Herabsetzung der Sensitivität der kontraktilen Proteine für Kalzium (Fryer et al. 1988 a; Mulieri et al. 1989) in der Herzmuskelzelle beruht. Die Kalziumsensitivität des Troponin C (Gwathmey et al. 1991) und die Aufnahme von Kalzium in das Sarkoplasmatische Retikulum (SR) (Phillips und Altschuld 1996) bleiben dabei unbeeinflusst. BDM hat darüber hinaus keinen Einfluss auf das Membranpotential, auch nicht auf den Verlauf von Aktionspotentialen (Fryer et al. 1988 b).

Die Inhibition der Querbrückeninteraktion durch BDM ist konzentrationsabhängig. Eine vollständige Hemmung der Kraftentwicklung der Herzmuskelzellen ist bei einer Konzentration von $30 \mathrm{mM}$ beobachtet worden (Perreault et al. 1992 a). Die in dieser Arbeit verwendete Konzentration von $30 \mathrm{mM}$ hat sich unter gleichen Versuchsbedingungen als optimal erwiesen (Mulieri et al. 1992).

Der Grund für die Verwendung von BDM lag darin, dass das Myokard während des Transportes ins Labor vor hohem Energieverbrauch zu schützen war, um so Hypoxieschäden zu vermeiden. Außerdem kommt es während der Präparation durch die Gewebsdefekte zu einer teilweise massiven Freisetzung von Kalzium aus den zerstörten Zellen, die ohne Schutz zur Kontraktur des gesamten Präparates führen würde.

Alle Effekte von BDM sind durch einfaches Auswaschen mit BDM-freier Tyrode vollständig reversibel. Das und die oben beschriebenen Eigenschaften von BDM machen es zur idealen kardioprotektiven Substanz für die Versuchbedingungen in dieser Arbeit.

\subsubsection{Verwendete Substanzen}

Die folgenden Substanzen wurden in Ihrer Wirkung auf die Kraftentwicklung und intrazelluläre Kalziumtransienten (nicht Amiodaron) sowie bezüglich der Wirkung auf die Kraft-Frequenz-Beziehung (KFB) untersucht. Alle in dieser Arbeit verwendeten Substanzen wurden, wenn nicht anders angegeben, bei der Firma Sigma Chemical Co., Deutschland, bezogen und waren von bestmöglich erwerblichem Reinheitsgrad.

Alle Substanzen wurden in Pulverform - entsprechend den Angaben des Herstellers aufbewahrt und unmittelbar vor Beginn des Experimentes in Lösung gebracht. 


\section{Flecainid}

Flecainid wurde als Flecainid-Hydrochlorid verwendet. Zunächst wurde eine $10^{-2} \mathrm{M}$ Stammlösung angesetzt, hierbei diente als Lösungsmittel Aqua dest. Für die weitere Verdünnungsreihe konnte dann Tyrodelösung verwendet werden.

Die für eine Konzentrations-Wirkungs-Kurve verwendeten Konzentrationen waren: $10^{-8} \mathrm{M}, 10^{-7} \mathrm{M}, 10^{-6} \mathrm{M}, 3^{*} 10^{-6} \mathrm{M}, 10^{-5} \mathrm{M}$ und $10^{-4} \mathrm{M}$.

Für die Messung der Kalziumtransienten und den Einfluss auf die KFB wurde die Konzentration $3 * 10^{-6} \mathrm{M}$ verwendet.

\section{Amiodaron}

Amiodaron wurde ebenfalls in Hydrochlorid-Form verwendet. Die stark hydrophoben Stoffeigenschaften von Amiodaron (AM) liessen ein Lösen allein in Tyrodelösung oder Aqua dest. nicht zu. Als zusätzliche Lösungsmittel mussten Benzyl-Alkohol sowie das Polysorbat „Tween 80“" verwendet werden (Munoz et al. 1988).

In umfangreichen Vorversuchen wurde die minimal nötige Lösungsmittelmenge der beiden Komponenten ermittelt, die es erlaubte, AM bei Zimmertemperatur in Lösung zu halten. Es wurde ermittelt, dass hierzu $10 \%$ vol. Benzyl-Alkohol, $10 \%$ vol. Tween 80 sowie $80 \%$ vol. destilliertes Wasser nötig waren. Es wurde so eine Stammlösung hergestellt, mit der Konzentration von $10^{-2} \mathrm{M}$ Amiodaron. Die Versuche zur KFB wurden mit einer Konzentration von $10^{-4} \mathrm{M}$ Amiodaron in der Experimentiertyrode durchgeführt. Stets gleichzeitig wurden mit Trabekeln aus demselben Ventrikel Lösungsmittelkontrollen durchgeführt, denen die entsprechende Menge Lösungsmittel zugesetzt wurde. Hiermit sollten kardiotoxische Effekte des Lösungsmittelgemisches eruiert werden.

\subsubsection{Aequorin}

Aequorin diente in der vorliegenden Arbeit als Indikator für intrazelluläres Kalzium. Dabei handelt es sich um ein Photoprotein, das aus der freilebenden Salzwasser-Hydromeduse Aequorea forskolea gewonnen wird. Erstmals wurde das 21 kDa schwere Molekül 1962 von Shimomura, Johnson und Saiya isoliert und wird seit 1970 als intrazellulärer Kalziumindikator verwendet. Aufgrund seiner Größe gelangt es nur durch Mikroinjektion, temporäre Permeabilisierung oder die Makroinjektionsmethode in die Zelle; intrazelluläre Kompartimentierung ist unwahrscheinlich. Eine Aktivitätsminderung kommt nur durch Kalziumbindung und somit durch den Verbrauch zustande (Cobbold und Rink 1987). 
Das Molekül besitzt drei Kalzium-Bindungsstellen gleicher Affinität. Es kommt zur Lichtemission (blaues Licht der Wellenlänge $469 \mathrm{~nm}$ ) wenn alle drei Bindungsstellen besetzt sind. Bei dieser Lumineszenz-Reaktion ändert sich die Konformation des Moleküls und es werden Photonen freigesetzt. Das Apoprotein Coelenterazin des Aequorin-Moleküls wird oxidiert, ändert dabei seine Konformation in irreversibler Weise. Daher verbraucht sich das Aequorin bei dieser Reaktion - ein Molekül kann nur einmal aktiviert werden (Blinks 1992).

Die Lichtemission ist der Anzahl der Moleküle direkt proportional, deren drei Bindungsstellen besetzt sind (Blinks 1989).

Aequorin bietet sich aus einigen Gründen für die Messung intrazellulären Kalziums in Herzmuskelzellen an: Es ist in physiologischen Konzentrationen spezifisch für Kalzium. Darüber hinaus hat es eine sehr schnelle Reaktionskinetik und damit auch eine sehr schnelle Lichtemission, die den zeitlichen Verlauf des Kalziumtransienten in der Herzmuskelzelle wiedergeben kann (Cobbold und Rink 1987). Auch benötigt diese Reaktion keinen zusätzlichen Sauerstoff, dieser ist selbst Bestandteil des Aequorin-Moleküls. Es interagiert nicht mit Kalzium-regulierten Zellfunktionen, hat eine sehr lange Halbwertszeit im Zytosol und ist gegenüber Bewegungsartefakten wenig anfällig (Miller et al. 1994).

Stellt man die Reaktionskurve im doppelt logarithmischen Masstab dar, so verläuft sie im Bereich von physiologischen Kalziumkonzentrationen der Herzmuskelzelle $\left(10^{-7}-10^{-5} \mathrm{M}\right)$ linear (kompletter Verlauf ist sigmoid); besonders während der Systole sind so Änderungen der Kalziumkonzentration semiquantitativ zu erfassen. Es sind keine toxischen Effekte des Aequorinmoleküls auf die Zelle bekannt. Aequorin ist gegenüber $\mathrm{pH}-\mathrm{Wert}$ Schwankungen im physiologischen Beriech unempfindlich (Prasher et al. 1985).

Nachteile von Aequorin als intrazellulärer Kalzium-Indikator sind die oftmals geringe Lumineszenzintensität, eine relative Unempfindlichkeit im diastolischen Konzentrationsbereich und schwierig quantifizierbare Messdaten (Cobbold und Rink 1987).

Das für diese Arbeit benutzte Aequorin wurde von Prof. Dr. J. Blinks (Friday Harbour, Washinhgton, USA) in lyophilisierter Form bezogen. $1 \mathrm{mg}$ Aequorin wurde in $700 \mu \mathrm{g}$ kalziumfreiem Aqua dest. (Kalziumkonzentration <0,005 ppm) gelöst und in einzelnen Portionen von $35 \mu \mathrm{l}$ bei $-80^{\circ}$ Celsius eingefroren. So konnten bei Bedarf jeweils kleine Mengen des Aequorins aufgetaut und verwendet werden. Zur Vermeidung einer Kontamination mit Kalzium wurden alle verwendeten Utensilien (Eppendorf Cups, Pipettenspitzen, usw.) zuvor gründlich mit 10mM EDTA, einem Komplexbildner für mehrwertige Ionen und quarzdestilliertem Wasser, gespült (Blinks 1989). Die tiefgefrorene Aequorinlösung war etwa drei Monate ohne Qualitätseinbußen verwertbar. Das hochsensitive 
Aequorin toleriert mehrere „Gefrier-Auftau-Zyklen“ ohne signifikanten Aktivitätsverlust (Blinks 1982).

\subsection{Messapparaturen}

\subsubsection{Aequorinanlage - Versuchsaufbau und verwendete Geräte}

Zentrales Element dieser Anlage ist das Organbad, in dem sich das Muskelstreifenpräparat während des Versuches befindet. Dieses besteht hier aus einer 1,2 cm langen Quarzküvette, deren Lumen (Durchmesser $4 \mathrm{~mm}$ ) während des Versuches mit Tyrode durchspült wird. Die Küvette ist an einem Ende mit einem Thermoblock fest verbunden, auf der anderen Seite endet sie offen. Innerhalb des Küvettenlumens befinden sich auch zwei gegenüberliegende Muskelklemmen, zwischen denen das Muskelstreifenpräparat eingespannt werden kann. Diese sind über Kabel mit der elektrischen Stimulation verbunden und können jeweils über Mikrometerschrauben in ihrer Distanz zueinander verstellt werden. Die linke Klemme am offenen Ende der Küvette ist direkt mit dem Kraftaufnehmer verbunden. Zum Einspannen des Muskels kann die Küvette mit dem Thermoblock auf einem beweglichen Schlitten nach rechts - in Längsachse des Muskels - verschoben werden, so dass nun die beiden Klemmen frei zugänglich sind. Ebenso wird bei der Injektion des Kalzium-Indikators verfahren, um den Muskelstreifen gut erreichen zu können. Direkt über der Küvette befindet sich ein Stereomikroskop, das durch zehnfache Vergrößerung das Einspannen und die Injektion erleichtert. Hierbei wird das gesamte Organbad mit Hilfe einer Kaltlichtquelle beleuchtet. Nach erfolgter Aequorininjektion wird das Mikroskop durch den Photomultiplier ersetzt, der nun seinerseits unmittelbar über der Küvette positioniert ist. Direkt unter die Küvette wird ein runder Hohlspiegel gelegt, der auftretendes Streulicht in den Photomultiplier reflektieren soll. Die beschriebene Versuchsanordnung befindet sich während des Experimentes in einem lichtundurchlässigen Metallgehäuse, wobei alle während des Versuches zu verändernden Parameter von außen beeinflusst werden können.

Die Experimentier-Tyrodelösung wird außerhalb des Dunkelbereiches in einem Wasserbad auf $39^{\circ}$ Celsius vorgewärmt, mit Carbogen oxigeniert und durch das darin enthaltene Kohlendioxid auch auf einen physiologischen $\mathrm{pH}$-Wert von 7,4 eingestellt. Von einer Rollpumpe angetrieben wird die Tyrodelösung durch Tygonschläuche zum Thermoblock geleitet, durchfließt dann die Küvette und wird am offenen Ende von einer Kanüle abgesaugt und wiederum durch Tygonschläuche zum Wasserbad zurückgeleitet. Bevor die Tyrode in die Küvette eintritt, durchfließt sie den Thermoblock (das Peltier-Element) und wird hier auf 
genau $37^{\circ}$ Celsius abgekühlt. Exakt diese Temperatur hat dann die Tyrode, während sie den in der Küvette eingespannten Muskel umspült. Hier wird die Temperatur durch eine Sonde während des gesamten Experimentes gemessen und angezeigt.

Die Vorwärmung der Tyrode im Wasserbad hat sich als vorteilhaft erwiesen, weil sie eine Gasblasenbildung in der Küvette verhindert, wenn diese im Thermoblock abgekühlt wird. Da Gase bei höheren Temperaturen schlechter in Flüssigkeiten lösbar sind, könnte es zu einer Gasblasenbildung kommen, wenn die mit Sauerstoff und Kohlendioxid begaste Tyrode im Thermoblock von Zimmertemperatur auf $37^{\circ}$ Celsius erwärmt werden würde. Gasblasen innerhalb der Küvette, welche die Lichtmessung beeinträchtigen können, treten somit durch die Vorwärmung der Tyrode nicht auf.

Die Messignale für Kontraktionskraft und das Aequorin-Lichtsignal wurden mit einem Thermoschreiber, sowie auf einem Speicheroszilloskop gesammelt. Zusätzlich konnten die Parameter der isometrischen Kontraktion über eine Analog-Digital-Wandlerkarte auch auf dem Personalkomputer mit Hilfe des LabView Programmes ausgewertet werden.

Die folgende Abbildung 2 zeigt den Aufbau der Aequorin-Anlage.

\section{Verwendete Geräte}

- Basisgerät zur Messung isometrischer Kontraktionskraft, Typ OPTIL mit Kraftaufnehmer KG 3 (Scientific Instruments, Heidelberg)

- Stimulator STM1 (Scientific Instruments, Heidelberg)

- Temperaturkontrolleinheit (Scientific Instruments, Heidelberg)

- Einheit zur Messung des Aequorin-Lichtsignals mit Photomultiplier: Philips XP2802/Thorn EMI 9635A

- Rollpumpe MC MS (Ismatec Zürich, Schweiz)

- Stereomikroskop VMT (Olympus, Tokio, Japan)

- Thermostat Lauda MS/2

- Oszilloskop: Digital-Speicheroszilloskop 400 Pro 10 (Nicolet)

- Personalkomputer (Adams Soft)

- Auswertprogramm LabView (National Instruments Corporation, Austin, Australien)

- Dreikanal Thermoschreiber Graphtec Lineacorder Mark VII, WR 3310 (Hugo Sachs Elektronik, Hugstetten)

- Kaltlichtquelle KL 1500 Electronic (Schott, Mainz) 


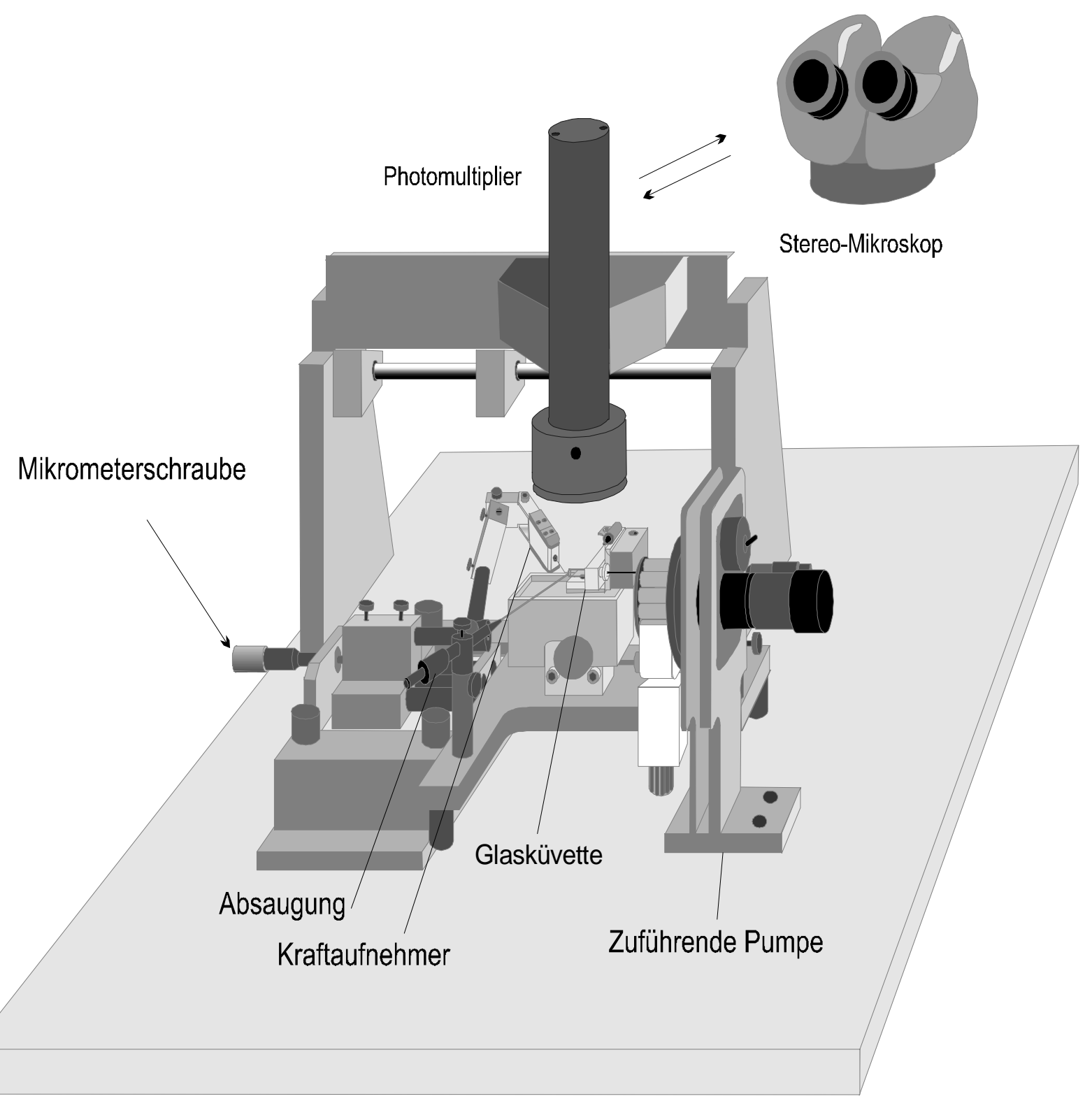

Abb. 2: Die Abbildung zeigt den Aufbau der Aequorin-Anlage, die zusätzlich komplett in einem lichtundurchlässigen Metallgehäuse untergebracht war (nicht abgebildet). Dieses wurde nach erfolgter Aequorininjektion während der Messungen geschlossen. Die während des Versuchs zu verändernden Parameter konnten von außen reguliert werden.

Die oben abgebildete Gerätekonfiguration wurde in unserer Arbeitsgruppe, in Zusammenarbeit mit Prof. K. Güth, Scientific Instruments, Heidelberg, für Messungen am menschlichen Herzmuskelgewebe entwickelt und zusammengestellt. 


\subsubsection{Aequorinanlage - Versuchsvorbereitung}

Nach der oben beschriebenen Präparation des Muskelstreifens wurde dieser, mit Hilfe mikrochirurgischer Pinzetten, zwischen den beiden Klemmelektroden fixiert. Anschließend wurde die Küvette über das Präparat geschoben, die Absaugkanüle befestigt und das Präparat für zehn Minuten mit oxigenierter BDM-haltiger Tyrode umspült, um den durch das Einspannen bedingten Zellschaden infolge einer Kalziumüberladung zu minimieren. Beim Einhängen des Muskels musste darauf geachtet werden, dass dieser schlaff (ohne Vorspannung) zwischen den Klemmen hing, um eine künstlich geschaffene Ruhespannung des Präparates auszuschließen. Ausgehend von diesem Zustand wurde an allen Messgeräten (Thermoschreiber, Oszilloskop und Personalkomputer) die so gemessene Kraft als Nullpunkt der entwickelten Muskelspannung geeicht, wobei hier in BDM keine Muskelspannung entwickelt wird, sondern die entstehende Kraft aus Retraktionskräften der elastischen Trabekelanteile besteht. Nun wurde die BDM-haltige Tyrodelösung durch $150 \mathrm{ml}$ Experimentier-Tyrode ausgetauscht und somit die noch im Schlauchsystem befindliche kardioplege Tyrode ausgewaschen, indem die abgeleitete Flüssigkeit in ein separates Auffanggefäß (Messzylinder) ausgeleitet wurde. Es wurden nun 50ml ausgeleitet; anschliessend befanden sich $100 \mathrm{ml}$ Tyrodelösung im Wasserbad, die nun in rezirkulierender Weise durch das Schlauchsystem gepumpt wurde.

Jetzt wurde mit der elektrischen Stimulation des Muskelstreifens begonnen. Bei einer Frequenz von $1 \mathrm{~Hz}$ und einer Impulsdauer von $5 \mathrm{~ms}$ wurde die Spannung langsam hochreguliert, bis die erste Kontraktion registriert werden konnte (Schwellenspannung). Ausgehend von diesem Betrag wurde die Spannung um weitere $20 \%$ erhöht, um während des gesamten Experimentes eine stabile Stimulation zu gewährleisten. In den folgenden Minuten konnte eine langsame Kraftzunahme des Muskelstreifens beobachtet werden. Nach Erreichen eines stabilen Kraft-Niveaus wurde nun mit der Vordehnung des Präparates begonnen. In Schritten von 0,05 mm wurde der Muskel nun über die Mikrometerschrauben bis $1_{\max }$ vorgedehnt; $1_{\max }$ ist hierbei definiert als die Vordehnung, bei der der Muskel die maximale isometrische Kraft entwickelt, die auch bei weiterer Dehnung nicht mehr zunimmt. Die isometrische Kontraktionskraftamplitude ist definiert als die Differenz zwischen systolischer und diastolischer Spannungsentwicklung der Präparate.

Nach vollständiger mechanischer Stabilisierung des Präparates wurde die Stimulation für fünf Minuten ausgeschaltet und währenddessen die Aequorininjektion vorbereitet. 


\section{Aequorin-Makroinjektion}

Das bei $-80^{\circ}$ Celsius eingefrorene Aequorin wurde bei Raumtemperatur aufgetaut, dann wurden $5 \mu \mathrm{l}$ Aequorinlösung eine feine Glaspipette (Injektionskanüle) pipettiert. Zur Vermeidung einer Verunreinigung mit Kalzium wurden die Injektionskanüle und die Pipettenspitze zur Abmessung der Aequorinlösung vorher von außen und innen mehrfach mit EDTA-Lösung und kalziumfreiem Aqua dest. gespült, dreimalig mit EDTA (10mM), danach dreimal mit kalziumfreiem Aqua dest.

Nun wurde die Pumpe abgestellt und die Quarzküvette zurückgeschoben, um unter mikroskopischer Sicht das Aequorin subendokardial zu injizieren. Ergab sich am Schnittrand des eingespannten Trabekels kein endokardfreier Bereich, so musste mit einer feinen Kanüle (26 Gauge) eine kleine Inzision am Endokard vorgenommen werden, durch diese wurde dann die aequorinhaltige Injektionskanüle möglichst langstreckig streng subendokardial vorgeschoben, dann der Muskel unter langsamen Zurückziehen der Kanüle beladen. Eine weitere Perforation des Muskelstreifens war unbedingt $\mathrm{zu}$ vermeiden. Eine erfolgreiche Injektion war an einem Aufblähen des Endokards mit darauffolgendem kleinperligen Ausschwitzen der Lösung an der Muskeloberfläche nachzuvollziehen. Durch die Injektion mit leichtem Überdruck in das vitale Präparat kommt es wahrscheinlich zu einer kurzfristigen Erhöhung der Membranpermeabilität und zur Aufnahme des Aequorins in die kardialen Myozyten (Blinks 1992).

Diese Art der Aequorininjektion (Makroinjektion) ist von Kihara und Morgan detailliert beschrieben worden (Kihara und Morgan 1989). Nach Ende der Injektion wurde die Küvette wieder über den Muskel geschoben und die Pumpe in Betrieb genommen. Nach weiteren fünf Minuten wurde auch die Stimulation mit der vorher festgelegten Spannung wieder angestellt. In Dunkelheit wurden nun der Photomultiplier und der Hohlspiegel positioniert, anschließend das Gehäuse um die Anlage geschlossen. Von außen konnte nun das Netzgerät des Photomultipliers in Betrieb genommen werden, durch das dieser mit einer Spannung von 1100 Volt betrieben wurde.

Die sichtbaren Aequorinsignale stabilisierten sich im Laufe von etwa 30 Minuten, da das Protein entweder aus dem Extrazellularraum gespült und verbraucht oder in die Herzmuskelzelle aufgenommen wurde. Auch die entwickelte Kraft erreichte schnell wieder ein konstantes Niveau, woraufhin mit dem eigentlichen Versuchsprotokoll begonnen wurde. 


\subsubsection{Anlage zur Messung der isometrischen Kontraktionskraft (4er-}

\section{Anlage) - Versuchsaufbau und verwendete Geräte}

Das zentrale Element dieser Anlage stellt das Organbad dar. Es besteht aus einer rechteckigen, $0,8 \mathrm{~cm}$ tiefen, $1,0 \mathrm{~cm}$ breiten und 3,0 $\mathrm{cm}$ langen Vertiefung, die in das umgebene Material glattrandig hineingefräst ist. An den kurzen Enden wird mit Hilfe von Kanülen die Experimentiertyrode zu- und abgeleitet. Der zulaufende Schenkel befindet sich am rechten Ende am Boden des Organbades, als Absaugung dient eine gebogene Kanüle, die am linken Ende von oben die Tyrodelösung wieder aus dem Organbad absaugt. Beide Kanülen sind mit Silikonschläuchen verbunden. Über diese wird die Tyrode, von einer Rollpumpe angetrieben, durch das Organbad geleitet. Reservoir der Tyrode ist ein Wasserbad, in dem diese auf $39^{\circ}$ Celsius vorgewärmt und mit Carbogen präoxigeniert wird. Da die Temperatur der Tyrode wieder abgenommen hat, wenn sie durch die Silikonschläuche das Organbad erreicht hat, ist das Organbad zusätzlich in ein Thermoelement eingelassen, über das die Temperatur der Tyrode im Organbad geregelt werden kann. Mit einem digitalen Thermometer, dessen dünne Messonde permanent im Organbad liegt, kann die Temperatur kontrolliert werden. Das Thermoelement wird dann so eingestellt, dass die Tyrodelösung im Organbad eine Temperatur von $37^{\circ}$ Celsius erreicht.

An den beiden Enden des Organbades befinden sich auch die Aufhängvorrichtungen für den Muskelstreifen. Diese bestehen auf beiden Seiten aus Nadeln aus Platindrähten mit einem Durchmesser von 0,1 mm, die zum Ende hin spitz zulaufen. Sie sind so gebogen, dass sie senkrecht nach oben weisen, so dass die Muskelstreifen mit ihrem fleischigen Ende - fast ohne Traumatisierung - auf diese gespießt werden können. Die rechte Aufhängnadel ist direkt mit dem Kraftaufnehmer verbunden und diese Einheit ist zum Organbad hin auch nicht verschiebbar. Die linke Aufhängnadel ist mit der elektrischen Stimulation sowie mit einer Mikrometerschraube verbunden, mit deren Hilfe diese Aufhängnadel in Längsrichtung des Organbades und damit auch des Muskelstreifenpräparates verschoben werden kann.

Neben jedem Organbad befindet sich eine Haltevorrichtung aus Stahl, auf die ein Stereomikroskop mit zehnfacher Vergrößerung aufgesetzt werden kann, welches das Einhängen des Muskelstreifens erleichtert. Dies geschieht mit Hilfe von zwei mikrochirurgischen Pinzetten.

An dieser Anlage ist es möglich, vier Organbäder gleichzeitig zu nutzen (,4er-Anlage“). Jedes einzelne ist wie oben beschrieben aufgebaut. Sie werden jedoch aus getrennten Kreisläufen mit Tyrodelösung versorgt, so dass die Möglichkeit besteht, jeden Muskelstreifen im Organbad einer anderen Intervention auszusetzen. Bei Verwendung von Trabekeln aus 
dem gleichen Herzen und Ventrikel bestehen so optimale Vergleichsmöglichkeiten. Die Stimulation wird von einem Stimulator simultan auf alle Muskelstreifenpräparate zeitgleich übertragen, somit sind gut vergleichbare Versuchsbedingungen hergestellt, die optimal kontrollierbar sind.

Das Messignal aller vier Präparate wird während des Versuches auf einem VierkanalThermoschreiber registriert, zusätzlich mit Hilfe des LabView-Programmes mit dem Personalkomputer.

\section{Verwendete Geräte}

- 4-Kanal-Thermoschreiber Linearcorder WR 3320 (Graphtec; Vertrieb durch Hugo Sachs Elektronik, Hugstetten)

- Mikrometerschraube (Mituyo, Japan)

- Peristaltische Rollenpumpe Ismatec MS-CA (Ismatec, Zürich, Schweiz)

- Kraftaufnehmer und Verstärker (Scientific Instruments, Heidelberg)

- Stimulationseinheit (Scientific Instruments, Heidelberg)

- Stereomikroskop SD 30 (Olympus, Taiwan)

- Thermometer Digi-Sense (Cole-Parmer, Vernon-Hills, USA)

- Umwälzthermostat Haake K 15 (Haake, Karlsruhe)

\subsubsection{4er-Anlage - Versuchsvorbereitung}

Nach der oben beschriebenen Präparation des Muskelstreifens aus dem Ventrikel (Trabekel aus humanen bzw. Kaninchenherzen) wurde dieser, mit Hilfe mikrochirurgischer Pinzetten, zwischen den beiden Nadelelektroden fixiert, indem die großzügig herauspräparierten fleischigen Enden des Präparates jeweils auf eine Haltenadel aufgespießt wurden. Der weitere Versuchsablauf geschah entsprechend der in Kapitel 2.3.1. geschilderten Weise, hier ohne die beschriebene Injektion von Aequorin.

Nach Erreichen eines stabilen Kraftniveaus aller Muskelstreifenpräparate konnte mit dem eigentlichen Experimentierprotokoll begonnen werden. 


\subsection{Versuchsprotokolle}

\subsubsection{Flecainid-Konzentrations-Wirkungs-Kurve (KWK)}

In dieser Versuchsreihe sollte der Einfluss einer kumulativen Konzentrations-WirkungsKurve von Flecainid auf die Kontraktionskraft des Muskelstreifens untersucht werden. Die Messungen wurden an der 4er-Anlage durchgeführt.

Nach vollständiger Stabilisierung der Kraftsignale aller Präparate wurde mit dem Experiment begonnen. Es wurden die Konzentrationsschritte $10^{-8}, 10^{-7}, 10^{-6}, 3 * 10^{-6}, 10^{-5}$ und $10^{-4} \mathrm{~mol} / \mathrm{L}$ untersucht. Nach jeder Konzentrationserhöhung wurde gewartet, bis sich die Kraftentwicklung aller Präparate stabilisiert hatte, diese Zeit betrug etwa 25 Minuten. Dann wurden jeweils einzelne Signale mit dem Thermoschreiber im Schnellschrieb $(50 \mathrm{~mm} / \mathrm{s})$ aufgezeichnet, zusätzlich wurden jeweils zwanzig gemittelte Kraftsignale mit Hilfe des LabView Programms gespeichert.

Die Konzentrations-Wirkungs-Kurve für Flecainid wurde an insgesamt zehn Trabekeln aus fünf terminal insuffizienten, menschlichen Herzen ermittelt.

\subsubsection{Wirkung von Flecainid auf die Kontraktionskraft mit simultaner Registrierung intrazellulärer Kalzium-Transienten}

Diese Messungen wurden an der Aequorin-Anlage durchgeführt. Nach vollständiger Stabilisierung von Kraft- und Lichtsignal bei einer Stimulationsfrequenz von $1 \mathrm{~Hz}$ wurden diese Beträge als Ausgangswerte (AGW) gemessen. Anschließend wurde der Effekt der Konzentration $3 * 10^{-6}$ M Flecainid auf die Kontraktionskraft und auf das Aequorin-Lichtsignal untersucht (Konzentration mit halbmaximaler Wirkung, siehe Ergebnisteil). Diese Konzentration entspricht in vivo dem therapeutischen Plasmaspiegel von Flecainid (Boriani et al. 1997, Capucci et al. 1999, Hennersdorf et al. 2001). Nach Zugabe der Substanz wurde solange gewartet bis sich Kontraktionskraft und Lichtsignal wieder stabilisiert hatten, dann wurden jeweils einzelne Signale mit dem Thermoschreiber im Schnellschrieb $(50 \mathrm{~mm} / \mathrm{s})$ aufgezeichnet und zusätzlich 50 gemittelte Licht- und Kraftsignale mit dem Oszilloskop und dem Komputer registriert. Diese Untersuchung wurde an fünf Präparaten aus fünf verschiedenen Herzen durchgeführt. 


\subsubsection{Amiodaron-Konzentrations-Wirkungs-Kurve (KWK)}

Diese Messungen wurden ebenfalls als kumulative Konzentrations-Wirkungs-Kurve (KWK) an der 4er-Anlage durchgeführt. Aufgrund der Notwendigkeit von Benzylalkohol und Tween 80 als Lösungsmittel für Amiodaron wurden parallel $\mathrm{zu}$ der eigentlichen KWK Kontrollversuche mit dem Lösungsmittel durchgeführt, wobei der Lösungsmittelanteil kumulativ dem jeweiligen Konzentrationsschritt entsprechend erhöht wurde. Als Konzentrationsschritte dienten $10^{-8}, 10^{-7}, 10^{-6}, 10^{-5}, 10^{-4}$ und $10^{-3} \mathrm{~mol} / \mathrm{L}$. Die KonzentrationsWirkungs-Kurve für Amiodaron und Lösungsmittel wurde an insgesamt zehn Trabekeln aus fünf terminal insuffizienten, menschlichen Herzen ermittelt.

\subsubsection{Einfluss von Flecainid auf die Kraft-Frequenz-Beziehung des terminal insuffizienten humanen Myokards}

Der Einfluss von Flecainid auf die Kontraktionskraft humaner Herzmuskelstreifen in Abhängigkeit von der Stimulationsfrequenz (Kraft-Frequenz-Beziehung: KFB), wurde an je 19 Trabekel-Paaren aus 12 Herzen an der 4er-Anlage untersucht. Um den Vergleich zu unbehandelten Trabekeln aus demselben Ventrikel $\mathrm{zu}$ ermöglichen, wurde wie folgt verfahren:

Es wurden möglichst lange Trabekel aus der Ventrikelwand präpariert (1-1,5 cm Länge), so dass diese in der Mitte geteilt werden konnten. Damit war auch ein nahezu identischer Durchmesser der Präparate garantiert. Diese wurden dann in getrennte Organbäder der oben beschriebenen Anlage zur simultanen Kraftmessung eingespannt. Zur Tyrode der einen Trabekel wurde zu Versuchsbeginn - nach Stabilisierung der Kontraktionskraft - Flecainid als Einzeldosis gegeben, mit einer erreichten Konzentration von $3 * 10^{-6} \mathrm{M}$ in der Experimentiertyrode. Nach erneutem Erreichen eines stabilen Kraftniveaus wurde mit der Untersuchung der Kraft-Frequenz-Beziehung (KFB) begonnen. $\mathrm{Zu}$ Beginn wurde die Frequenz auf 0,5 Hz gesenkt und danach über die Schritte 1,0 - 1,5 - 2,0 - 2,5 - und 3,0 Hz wieder erhöht. Bei jeder einzelnen Frequenz wurde wiederum eine Kraftstabilisierung abgewartet und dann die Kraftsignale wie oben beschrieben aufgezeichnet und gespeichert.

Durch die beschriebene Methode erhielt man durch jeden Versuch also eine KFB unter Flecainid und eine KFB eines identischen Kontroll-Muskels aus demselben Ventrikel, der unbehandelt war. 


\subsubsection{Einfluss von Amiodaron auf die Kraft-Frequenz-Beziehung des terminal insuffizienten humanen Myokards}

Der Einfluss von Amiodaron auf die Kontraktionskraft des Herzmuskelstreifens in Abhängigkeit von der Stimulationsfrequenz (KFB), wurde an 18 Trabekeln aus 6 Herzen an der 4er-Anlage untersucht. Wie oben beschrieben, ist es nötig Amiodaron in einem Lösungsmittelgemisch bestehend aus Benzyl-Alkohol, dem Polysorbat „Tween 80“ und Wasser, zu lösen. Bei der Untersuchung des Einflusses von Amiodaron auf die KFB sollte nun eruiert werden, ob auch das beschriebene Lösungsmittelgemisch Effekte auf die Inotropie und die KFB des Herzmuskelstreifens hat. Hierzu wurde wie folgt verfahren:

Es wurden möglichst lange Trabekel aus der Ventrikelwand präpariert, die in drei gleichlange Stücke geschnitten werden konnten. Diese wurden dann in getrennte Organbäder der oben beschriebenen Anlage zur simultanen Kraftmessung eingespannt. Von einer $10^{-2} \mathrm{M}$ Stammlösung Amiodaron wurde nun die Menge zur Tyrode einer Trabekel pipettiert, durch die eine Konzentration von $10^{-4} \mathrm{M}$ in der Experimentiertyrode erreicht wurde. In die Tyrode der zweiten Trabekel wurde nun nur die äquivalente Menge an Lösungsmittelgemisch gegeben. Eine dritte Trabekel blieb als Kontrollmuskel unbehandelt. Nachdem alle drei Muskelstreifen ein stabiles Kraftniveau erreicht hatten wurde mit der Untersuchung der KFB begonnen. Zunächst wurde die Frequenz auf $0,5 \mathrm{~Hz}$ gesenkt und dann über die Schritte 1,0 $\mathrm{Hz}, 1,5 \mathrm{~Hz}, 2,0 \mathrm{~Hz}, 2,5 \mathrm{~Hz}$ und 3,0 Hz gesteigert. Bei jeder einzelnen Frequenz wurde wiederum eine Kraftstabilisierung abgewartet und dann die Kraftsignale wie oben beschrieben aufgezeichnet und gespeichert.

Durch dieses Vorgehen erhielt man also eine KFB eines unbehandelten Muskels und die eines Muskels aus demselben Ventrikel, der mit Amiodaron behandelt war, sowie einen, der als Lösungsmittel-Kontrolle diente.

\subsubsection{Einfluss von Flecainid und Amiodaron auf die Kraft-Frequenz- Beziehung des nicht-insuffizienten Kaninchen-Myokards}

Diese Versuchsreihen wurden nach den oben beschriebenen Protokollen für insuffizientes humanes Herzmuskelgewebe durchgeführt, mit dem Unterschied, dass hier Trabekel aus dem linken Ventrikel, bzw. Papillarmuskeln aus dem rechten Ventrikel eines Kaninchenherzens verwendet wurden. Es wurden die Frequenzschritte von 1,0 bis 5,0 Hz untersucht. Um für die Amiodaronversuche drei vergleichbare Präparate zu bekommen, war es hier nicht möglich, eine Trabekel zu teilen, sondern es wurden drei Muskelstreifen mit möglichst identischem 
Durchmesser aus der Ventrikelwand präpariert. Diese wurden dann den oben beschriebenen Interventionen zugeführt.

Die Versuche für Flecainid wurden an 15 Trabekeln aus 5 Kaninchenherzen, die Versuche für Amiodaron und Lösungsmittel an 24 Muskelstreifen aus 8 Kaninchenherzen durchgeführt.

\subsection{Auswertung der Versuche}

\subsubsection{Untersuchte Parameter}

Bei alle Messungen wurden die folgenden Parameter erhoben:

- F $\quad(\mathrm{mN})$ Amplitude der isometrischen Kontraktion

- $\mathrm{F}_{\text {diast. }} \quad(\mathrm{mN})$ diastolische Spannung

- TPT (ms) Zeit vom Beginn der Kontraktion bis zur maximal entwickelten Kraft

- $\mathrm{RT}_{50 \%} \quad(\mathrm{~ms})$ Zeit vom Zeitpunkt der maximal entwickelten Kraft bis zur 50\%igen Relaxation

- $\mathrm{RT}_{90 \%} \quad$ (ms) Zeit vom Zeitpunkt der maximal entwickelten Kraft bis zur 90\%igen Relaxation

- $+\mathrm{dF}_{\mathrm{dt}} \mathrm{max}_{\max }(\mathrm{mN} / \mathrm{s})$ maximale Kraftanstiegsgeschwindigkeit

- $-\mathrm{dF}_{\mathrm{d}} \mathrm{dt}_{\max }(\mathrm{mN} / \mathrm{s})$ maximale Relaxationsgeschwindigkeit

Alle Kraftdaten wurden auf die Querschnittsfläche der Präparate normiert.

Für die Aequorinmessungen wurden zusätzlich erhoben:

- $\mathrm{L}_{\max } \quad(\mathrm{mV})$ Amplitude der Verstärkerspannung des Aequorinlichtsignals

- $\mathrm{RL}_{50 \%} \quad(\mathrm{~ms}) \quad$ Zeit vom Zeitpunkt des maximalen Lichtsignals bis zur 50\%igen Abnahme des Signals

- RL ${ }_{90 \%}$ (ms) Zeit vom Zeitpunkt des maximalen Lichtsignals bis zur 90\%igen Abnahme des Signals

\subsubsection{Bestimmung der Querschnittsfläche}

Die Querschnittsfläche des Muskelstreifenpräparates wurde nach dem Vordehnen bestimmt, indem der Durchmesser der Trabekel mit Hilfe einer Millimeter-Strichplatte im Okular des 
Stereomikroskops ausgemessen wurde. Die Querschnittsfläche in $\mathrm{mm}^{2}$ berechnete sich hierbei - unter Annahme einer zylindrischen Form der Trabekel - nach der Formel:

\section{(Radius des Muskelstreifens) $^{2} * \pi$}

\subsubsection{Normierung der Daten}

Die Parameter der Kraftentwicklung wurden jeweils auf die Querschnittsfläche des entsprechenden Präparates bezogen $\left(\mathrm{mN} / \mathrm{mm}^{2}\right)$. Die Messwerte der Kraft, des Lichtsignals und die jeweiligen Zeitparameter der isometrischen Kontraktion und des Lichtsignals wurden auch jeweils in Prozent des Ausgangswertes (AGW) angegeben, um die Änderungen der Parameter besser in Bezug zueinander und zum AGW setzten zu können. Außerdem ermöglicht dies einen Vergleich zwischen den verschiedenen Substanz-Gruppen (beispielsweise zwischen der Amiodaron- und Lösungsmittel-Gruppe).

Bei den Experimenten zur Kraft-Frequenz-Beziehung wurden die Parameter für jedes Frequenzprotokoll auf den Ausgangswert von 0,5 Hz (Mensch) oder 1,0 Hz (Kaninchen) der jeweiligen Messreihe bezogen.

\subsubsection{Statistische Auswertung}

Alle in dieser Arbeit angegebenen Daten wurden mit dem Programm Exel 2000 der Firma Microsoft (USA) gesammelt und mit dem Statistikprogramm Statistica 6.0, Studentenversion der Firma Statsoft (Tulsa, USA) ausgewertet.

Alle Ergebnisse sind als Mittelwert \pm Standardfehler des Mittelwertes (SEM) angegeben. Die Testung auf Signifikanz erfolgte mittels des ANOVA-Tests für wiederholte Messungen und nachfolgend mit dem Student-Newman-Keuls-Post-Hoc-Test. Unterschiede mit einer Irrtumswahrscheinlichkeit von $\mathrm{p}<0,05$ wurden als signifikant anerkannt. 


\section{Ergebnisse}

\subsection{Basale funktionelle Effekte von Flecainid: Untersuchungen am menschlichen, terminal insuffizienten Myokard}

\subsubsection{Konzentrations-Wirkungs-Kurve (KWK)}

Die KWK für Flecainid wurde nach dem im Methodenteil erläuterten Protokoll durchgeführt.

Der untersuchte Konzentrationsbereich lag zwischen $10^{-8}$ und $10^{-4} \mathrm{M}$.

\section{Flecainid - K W K}

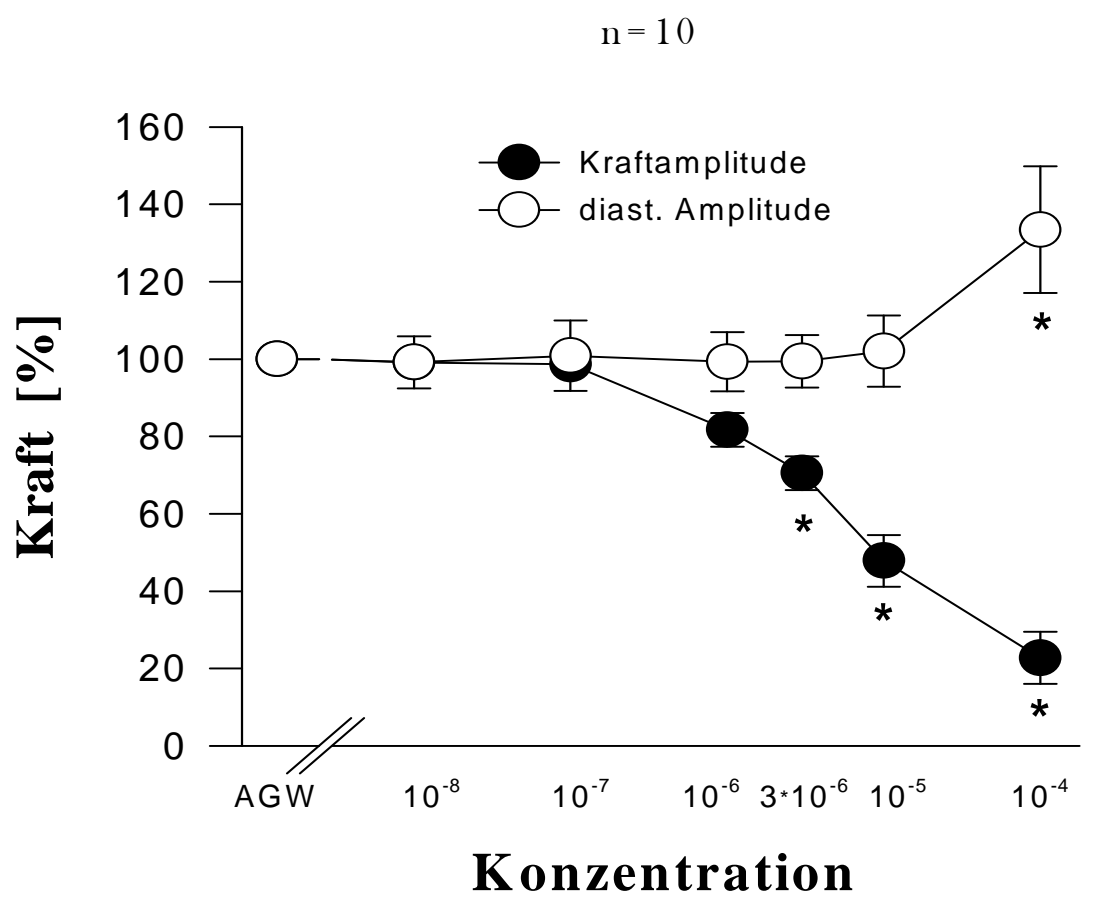

Abb. 3: Die Abbildung zeigt auf der Ordinate die Werte der Amplitude der Kontraktionskraft und der Diastole in Prozent des Ausgangswertes. Sie zeigt die konzentrationsabhängige Abnahme der Kontraktionskraft und die nahezu konstant bleibende diastolische Spannung der Muskelstreifen bis zur Konzentration von $10^{-5} \mathrm{M}$. Die Stimulationsfrequenz betrug $1,0 \mathrm{~Hz} . \mathrm{n}=10$. $\quad *=\mathrm{p}<0,05$ vs. AGW 
Abbildung 3 zeigt den konzentrationsabhängigen negativ inotropen Effekt von Flecainid, sowie den Einfluss auf die diastolische Spannung der Muskelstreifenpräparate. Die Werte zu den Abbildungen sind zusätzlich im Tabellenanhang (Tabelle 1) $\mathrm{zu}$ finden. $\mathrm{Ab}$ einer Konzentration von $10^{-6} \mathrm{M}$ erkennt man einen beginnenden negativen inotropen Effekt, der mit zunehmender Konzentration stärker wird. Bis einschließlich $10^{-5} \mathrm{M}$ lässt sich kein Effekt auf die diastolische Spannung beobachten. Erst ab $10^{-4} \mathrm{M}$ tritt auch ein Anstieg der diastolischen Spannung hinzu. Eine weitere Erhöhung der Konzentration war aufgrund wahrscheinlich toxischer Effekte auf den Muskelstreifen nicht durchführbar.

Zur näheren Untersuchung der Kraft-Frequenz-Beziehung sollte eine Konzentration bestimmt werden, bei der Flecainid eine submaximale Wirkung auf die Muskelstreifenpräparate hat, ohne toxische Effekte zu zeigen. In Anbetracht dieser Kriterien wurde die Konzentration $3 * 10^{-6} \mathrm{M}$ gewählt. Diese entspricht auch dem therapeutischen Plasmaspiegel von Flecainid in vivo (Boriani et al. 1997, Capucci et al. 1999, Hennersdorf et al. 2001) und hat darüber hinaus einen gut reproduzierbaren inotropen Effekt auf die Muskelstreifen.

\section{Zeitparameter der isometrischen Kontraktion während der Flecainid-KWK}

Abbildung 4 zeigt den konzentrationsabhängigen Einfluss von Flecainid auf die Zeitparameter der isometrischen Kontraktion. Dargestellt sind die Werte der TPT, der $\mathrm{RT}_{50 \%}$ sowie der $\mathrm{RT}_{90 \%}$, jeweils in Millisekunden (ms). Man erkennt deutlich, dass Konzentrationen bis einschließlich $10^{-5} \mathrm{M}$ Flecainid, keinen Einfluss auf die Zeitparameter der Kontraktion haben, bei dieser Konzentration kommt es lediglich zu einer dezenten Zunahme der $\mathrm{RT}_{90 \%}$. $\mathrm{Ab}$ einer Konzentration von $10^{-4} \mathrm{M}$ kommt es $\mathrm{zu}$ einem Anstieg der drei genannten Parameter, im Vergleich zum AGW (alle Werte siehe Tabelle 1).

\section{$\pm \mathbf{d F} / \mathbf{d t}_{\max }$ unter Flecainid}

Abbildung 5 zeigt die maximale Kraft-Anstiegs-Geschwindigkeit $\left(+\mathrm{dF} / \mathrm{dt}_{\max }\right)$ und die maximale Relaxationsgeschwindigkeit $\left(-\mathrm{dF}_{\mathrm{dt}} \mathrm{dt}_{\max }\right)$ der Muskelstreifenpräparate während der Flecainid-KWK in \% des Ausgangswertes. 


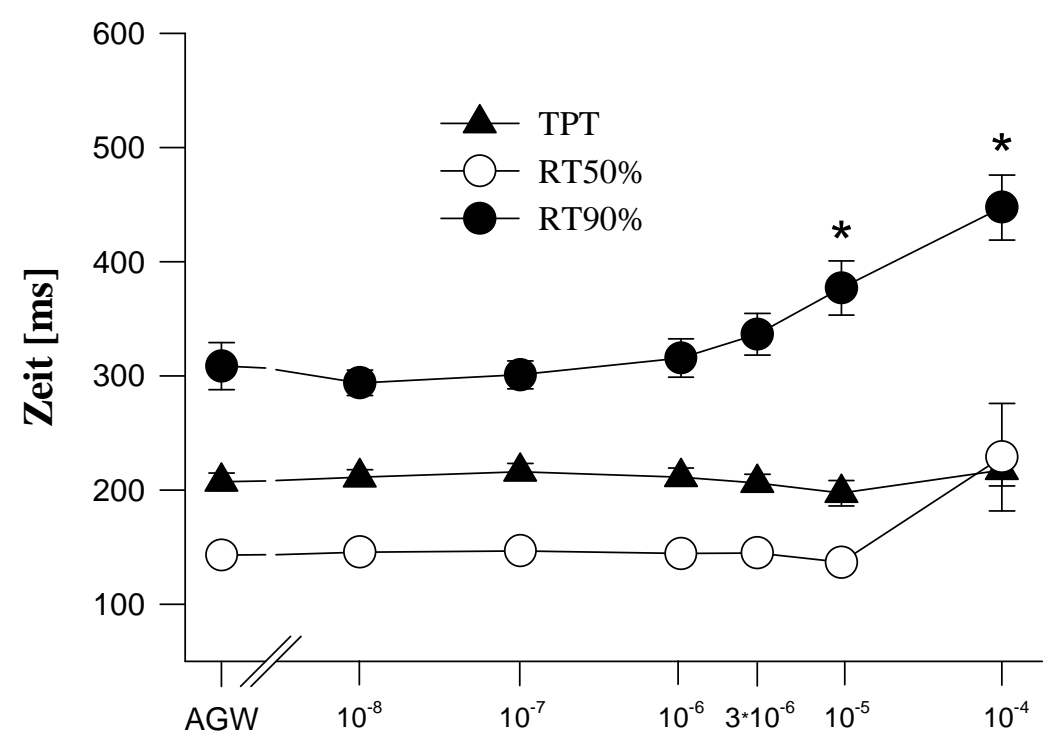

Konzentration

Abb. 4: Dargestellt ist der Verlauf der Zeitparameter der isometrischen Kontraktion. Es zeigt sich keine signifikante Änderung der untersuchten Parameter, mit Ausnahme der maximalen Konzentration von $10^{-4}$ M. $\quad *=\mathrm{p}<0,05$ vs. AGW $\quad \mathrm{n}=10$

\section{Flecainid- KWK}
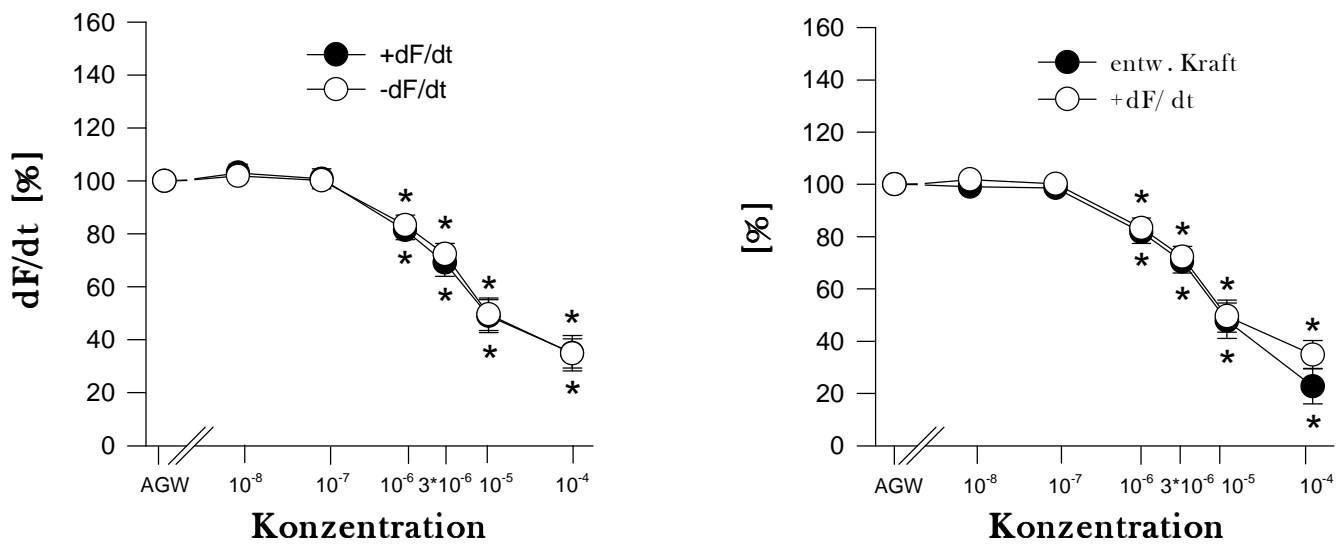

Abb. 5: Der linke Teil der Abbildung zeigt den parallelen Verlauf von $+d F / d t_{\max }$ und $-d F / d t_{\max }$ während der KWK mit Flecainid. Der rechte Teil der Abbildung verdeutlicht die Korrelation der maximalen Kraft-Anstiegs-Geschwindigkeit und der inotropen Effekte von Flecainid in allen untersuchten Konzentrationsbereichen. $\quad *=\mathrm{p}<0,05 \quad \mathrm{n}=10$. 
Die Werte bei halbmaximaler Konzentration von $3 * 10^{-6}$ M Flecainid:

Abnahme der Kontraktionskraft auf 70,5 \pm 4,4 \%, Abnahme der maximalen Kraft-Anstiegsgeschwindigkeit $\left(+\mathrm{dF}^{2} / \mathrm{dt}_{\max }\right)$ auf $72,3 \pm 4,1 \%$, sowie Abnahme der maximalen Relaxationsgeschwindigkeit $\left(-\mathrm{dF}_{\mathrm{dt}} \mathrm{max}\right)$ auf $69,1 \pm 5,1 \%$ (zu den weiteren Werten siehe Tabelle 1).

\subsubsection{Registrierung intrazellulärer Kalzium-Transienten}

Die Registrierung der intrazellulären $\mathrm{Ca}^{2+}$-Transienten erfolgte nach dem im Methodenteil erläuterten Protokoll der Aequorin-Methode. Auf den stabil schlagenden Muskelstreifen wurde die wie oben beschrieben ermittelte Konzentration $3 * 10^{-6} \mathrm{M}$ Flecainid gegeben.

Wie Abbildung 6 zeigt, entspricht die Abnahme der Kontraktionskraft bei Applikation der Flecainid-Einzelkonzentration, der Kraftabnahme der Vorversuche mit kumulativer Titration von Flecainid (siehe oben). Außerdem zeigt die Abbildung, dass die Abnahme der Kraftamplitude auf 65,7 \pm 7,6 \%, von einer parallelen Abnahme der Amplitude des Kalziumtransienten auf $67,5 \pm 7,2 \%$ begleitet wird. Die Einzelwerte dazu sind in Tabelle 2 zusammengefasst.

\section{Abnahme der Kontraktionskraft und des Lichtsignals unter Flecainid}

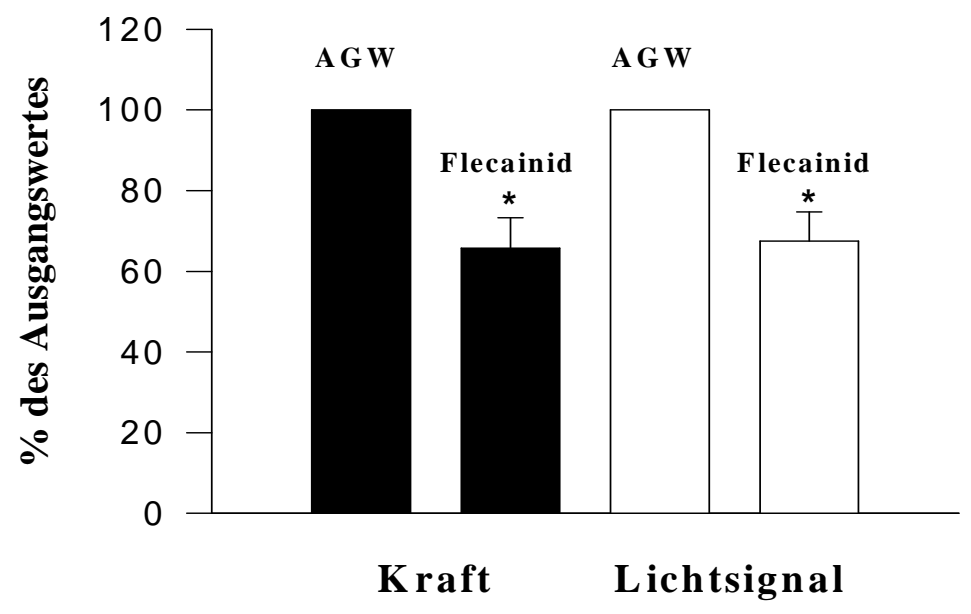

Abb. 6: Die beiden linken Balken zeigen die Kraftabnahme in \% nach Applikation der Flecainid-Einzel-Dosis. Die beiden rechten Balken zeigen die dazugehörige Abnahme des Aequorin-Lichtsignales. Es ist die nahezu identische prozentuale Abnahme der beiden Parameter zu erkennen. $\mathrm{AGW}=$ Ausgangswert. $*=\mathrm{p}<0,05$ vs. AGW $\mathrm{n}=5$ 


\subsection{Basale funktionelle Effekte von Amiodaron: Untersuchungen am menschlichen, terminal insuffizienten Myokard}

Wie im Methodenteil dargestellt ist es nötig, Amiodaron in einem Gemisch aus BenzylAlkohol und dem Polysorbat Tween 80 in Wasser zu lösen. Um die inotropen Effekte von Amiodaron und solche, die auf das Lösungsmittel zurückzuführen, sind zu testen, wurden kumulative KWK und Lösungsmittel-Kontrollen durchgeführt, bei denen kumulativ exakt die Mengen Lösungsmittel appliziert wurde, die zur Herstellung der jeweils aufsteigenden Amiodaron-Konzentrationen bei der KWK notwendig sind.

Wie Abbildung 7 zeigt, kam es unter alleinigem Lösungsmittel zu einer deutlichen Abnahme der Kontraktionskraft. Dieser negativ inotrope Effekt war konzentrationsabhängig und ab $10^{-5}$ mol/L signifikant. Unter Amiodaron zeigte sich ein nahezu identischer Kurvenverlauf mit signifikanter Kraftabnahme ab $10^{-4} \mathrm{~mol} / \mathrm{L}$ (siehe Tabelle 3 und 4).

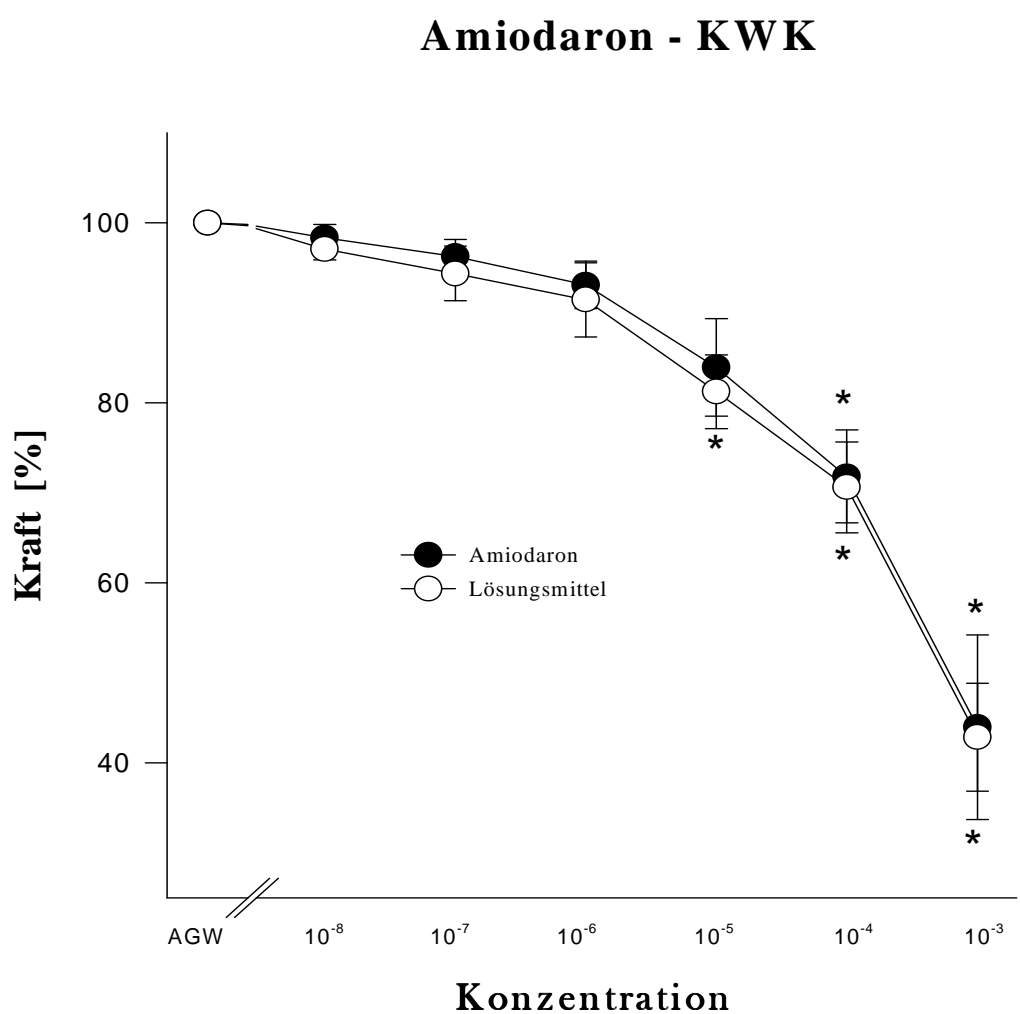

Abb. 7: Die beiden Kurven zeigen die konzentrationsabhängige Kraftabnahme in \% nach Applikation von Amiodaron und alleinigem Lösungsmittel. Die nahezu identische prozentuale Abnahme der Kontraktionskraft in beiden Kurven ist zu erkennen. * ${ }^{*}<0,05$ vs. AGW $\mathrm{n}=10$ 
Die diastolische Spannung zeigte unter Lösungsmittel einen parallelen Verlauf zur Kontraktionsamplitude, die konzentrationsabhängige Abnahme erreichte hier bereits ab $10^{-8}$ mol/L das Signifikanzniveau ( $\mathrm{p}$ 0,05). Unter Amiodaron fiel der Verlauf der diastolischen Spannung vergleichbar aus (Abbildung 8). Zu den Einzelwerten siehe Tabelle 3 und 4.

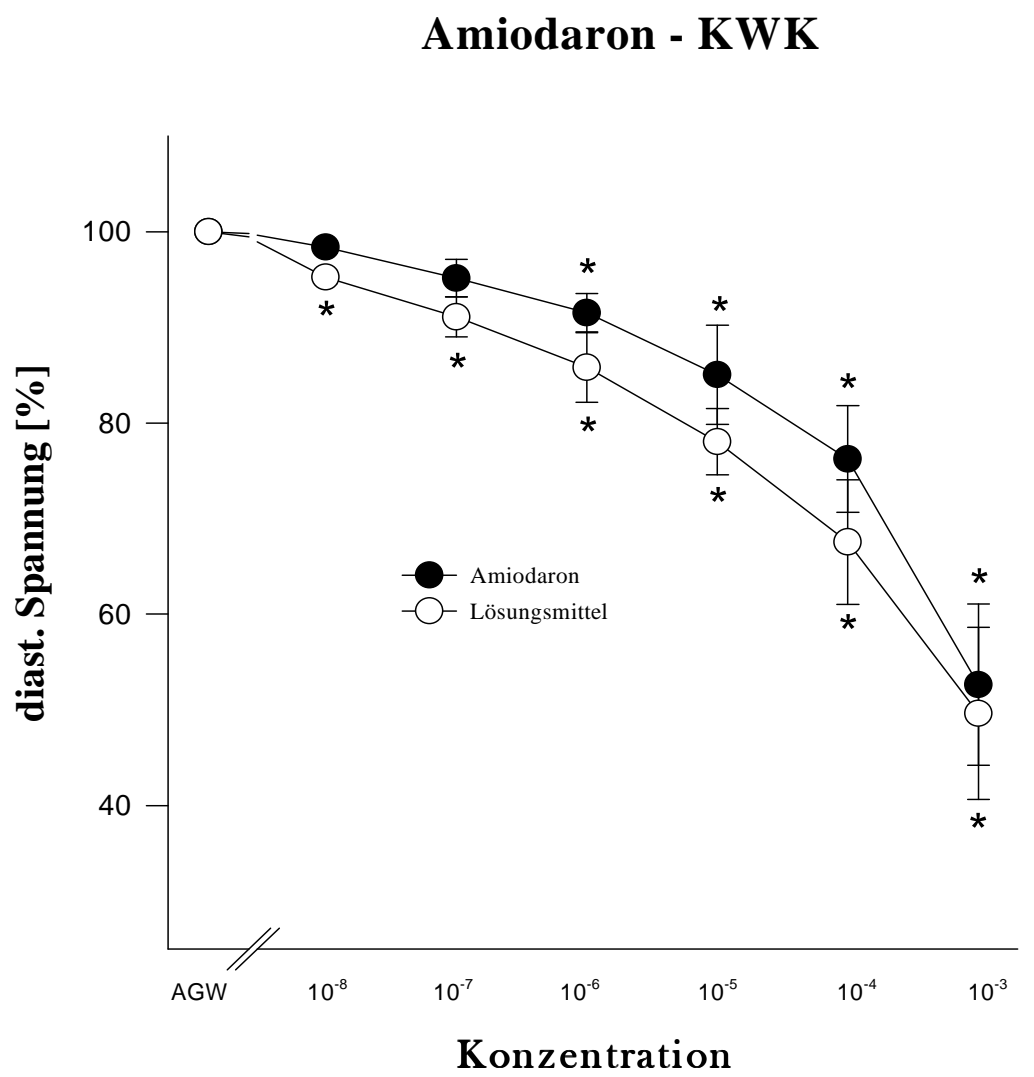

Abb. 8: Die beiden Kurven zeigen die konzentrationsabhängige Abnahme der diastolischen Spannung in \% nach Applikation von Amiodaron und alleinigem Lösungsmittel. Die nahezu identische prozentuale Abnahme in beiden Kurven ist zu erkennen. $*=\mathrm{p}<0,05 \mathrm{vs.}$ AGW $n=10$

\section{$\pm \mathbf{d F} / \mathbf{d t}_{\max }$ unter Amiodaron}

Der Verlauf der maximalen Kraftanstiegsgeschwindigkeit $+\mathrm{dF} / \mathrm{dt}_{\max }$ und der maximalen Relaxationsgeschwindigkeit $-\mathrm{dF}^{\mathrm{dt}} \mathrm{t}_{\max }$ zeigte sich sowohl unter Amiodaron als auch unter alleinigem Lösungsmittel im Verlauf der KWK annähernd parallel zum Verlauf der Kraftamplitude. Die konzentrationsabhängige Abnahme beider Parameter zeigte einen signifikanten Unterschied ab der Konzentration $10^{-4} \mathrm{M}$ (Abbildung 7 und 9, Tabelle 3 und 4). 

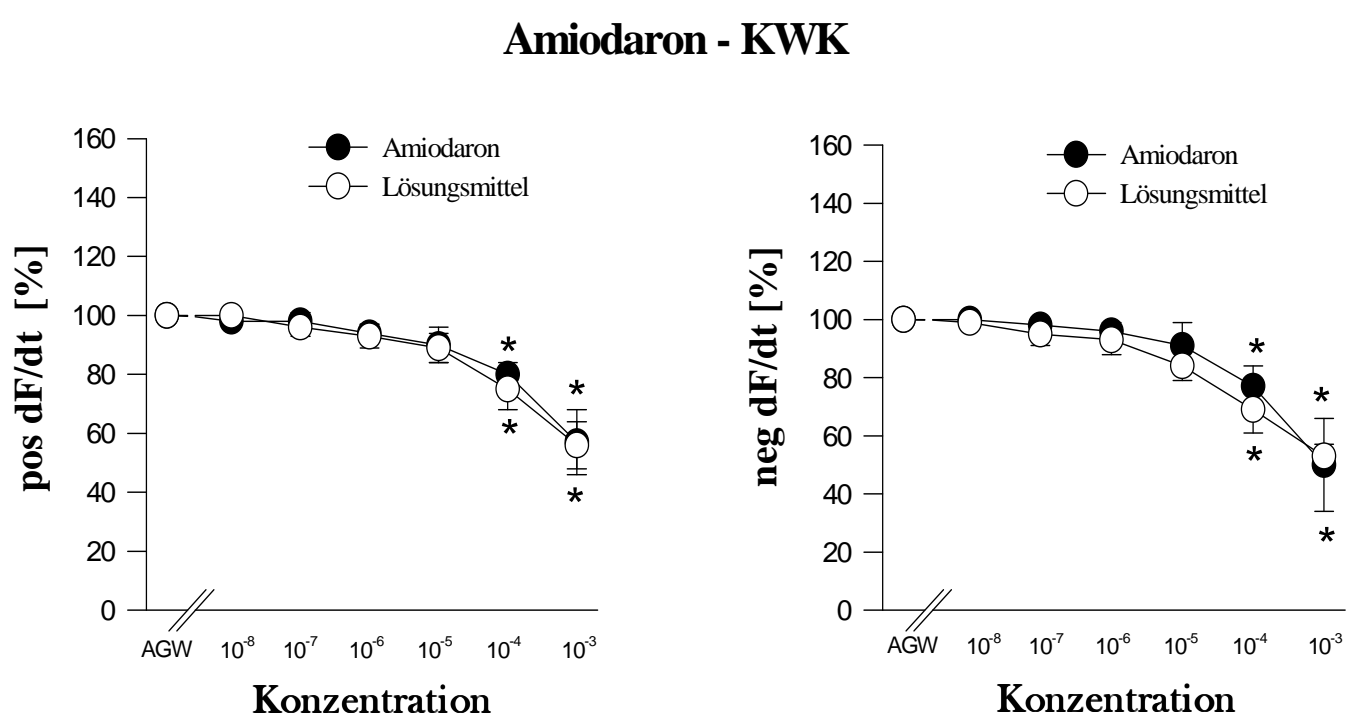

Abb. 9: Die Abbildung zeigt den parallelen, konzentrationsabhängigen, abnehmenden Verlauf der maximalen Kraft-AnstiegsGeschwindigkeit $+\mathrm{dF}^{-\mathrm{dt}_{\max }}$ und der maximalen Relaxationsgeschwindigkeit $-\mathrm{dF} / \mathrm{dt}_{\max }$ während der KWK sowohl mit Amiodaron als auch mit dem Lösungsmittel. $\quad *=\mathrm{p}<0,05$ vs. AGW $\mathrm{n}=10$.

\section{Zeitparameter der isometrischen Kontraktion während der Amiodaron-KWK}

Die Kontraktionszeiten (TPT, der $\mathrm{RT}_{50 \%}$ und $\mathrm{RT}_{90 \%}$ ) wurden sowohl unter Lösunsgmittel als auch unter Amiodaron im Verlauf der KWK nicht signifikant verändert (siehe Tabelle 3 und 4). Die geringen Veränderungen der Kontraktionszeiten entsprechen etwa denen der Flecainid KWK (siehe auch Abbildung 4). Daher wird auf eine separate graphische Darstellung hier verzichtet.

\subsection{Kraft-Frequenz-Beziehung unter Flecainid und Amiodaron am terminal insuffizienten humanen Myokard}

\subsubsection{Kraftamplitude unter Flecainid und Amiodaron}

Zur Bestimmung des Einflusses auf die KFB von terminal insuffizientem Herzmuskelgewebe wurde die oben ermittelte Konzentration von $3 * 10^{-6} \mathrm{M}$ Flecainid und $10^{-4} \mathrm{M}$ Amiodaron verwendet. Die Amiodaron-Konzentration von $10^{-4} \mathrm{M}$ wurde gewählt, da sie dem therapeutisch wirksamen Plasmaspiegel entspricht, wie er als Gewebespiegel im Myokard nachgewiesen werden kann (Latini et al. 1983). Für Amiodaron wurden jeweils ein unbehandelter Kontrollmuskel, ein mit Lösungsmittel behandelter und ein mit Amiodaron 
behandelter Muskel aus dem identischen Herzen miteinander verglichen. Für Flecainid wurde ein Kontrollmuskel mit einem Flecainid behandelten Muskel verglichen. Hierbei waren keine Lösungsmittelkontrollen notwendig, da sich Flecainid gut in Tyrodelösung löst (siehe Methodenteil).

\section{Flecainid}

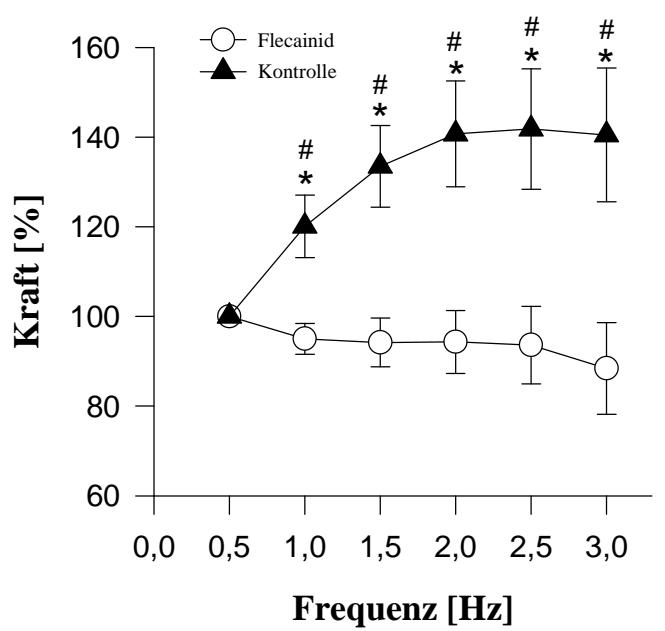

Amiodaron

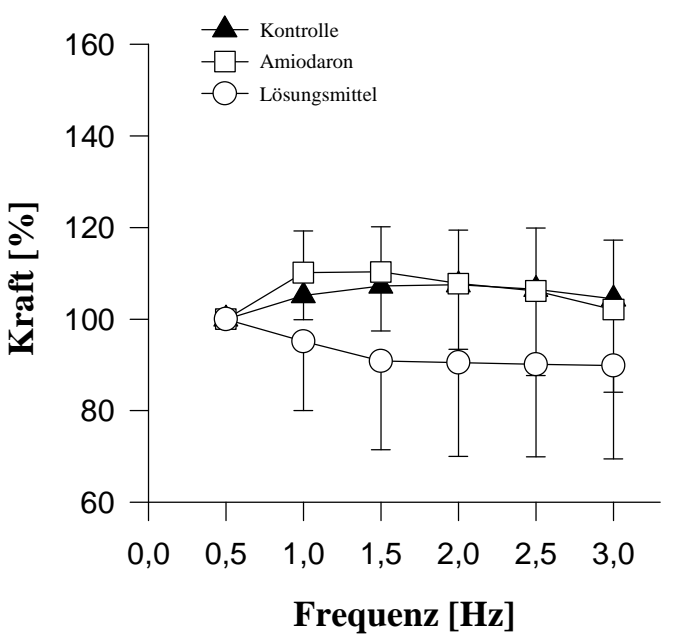

\begin{abstract}
Abb. 8: In der linken Abbildung ist die KFB unter Flecainid $3 * 10^{-6} \mathrm{M}$ im Vergleich zu der Kontrollgruppe dargestellt. Es sind die Werte der isometrischen Kontraktionskraft in \% des Ausgangswertes bei 0,5 Hz aufgetragen. Die Kontrollmuskeln weisen eine dezent positive KFB auf, wohingegen die KFB unter Flecainid in eine negative umgekehrt wird. Die rechte Abbildung zeigt die KFB unter $10^{-4} \mathrm{M}$ Amiodaron. Dargestellt ist die Kontraktionskraft in \% des Ausgangswertes bei 0,5 Hz. Die drei Gruppen weisen untereinander keinen signifikanten Unterschied auf. Zu beachten ist der unterschiedliche Verlauf der KFB der jeweiligen Kontrollgruppen (siehe Diskussion Kapitel 4.3.3.) $*=\mathrm{p}<0,05$ vs. $0,5 \mathrm{~Hz} \quad \#=\mathrm{p}<0,05$ vs. Flecainid, in der Amiodaron-Reihe waren Unterschiede zwischen den Gruppen n.s.
\end{abstract}

Wie in Abbildung 8 zu erkennen ist, war der Verlauf der KFB der Kontrollmuskeln in beiden Gruppen dezent positiv (Unterschiede n.s.); links mit einer Optimumfrequenz bei 2,5 Hz und einer Kraftsteigerung auf 141,8 \pm 13,4 \% im Vergleich zum Ausgangswert (AGW) bei 0,5 Hz. In der rechten Kontrollgruppe zeigte sich ein Maximum bei 2,0 Hz (Optimumfrequenz) mit 110,3 $\pm 11,7 \%$ des AGW.

Unter Flecainid zeigte sich eine signifikante Änderung des Verlaufes der KFB. Mit Erhöhung der Stimulationsfrequenz kam es $\mathrm{zu}$ einem kontinuierlichen Abfall der isometrischen Kontraktionskraft (negative Kraft-Frequenz-Beziehung) auf minimal 88,4 \pm 10,2 \% des AGW bei 3,0 Hz. Die Optimumfrequenz lag bei $0,5 \mathrm{~Hz}$. Unter Amiodaron änderte sich der Verlauf der KFB nicht signifikant. Bis $1,5 \mathrm{~Hz}$ verlief sie positiv, danach nahm die Kontraktionskraft mit zunehmender Stimulationsfrequenz wieder ab, ohne bei hohen Frequenzen unter den AGW zu sinken. Die Optimumfrequenz lag bei 1,5 Hz mit Steigerung 
der Kontraktionskraft auf 110,3 \pm 9,9 \% des AGW. Die KFB der Lösungsmittelkontrollen verlief von Beginn an negativ, die Optimumfrequenz lag bei 0,5 Hz. Die Kontraktionskraft sank auf minimal 89,8 \pm 20,3\% des AGW bei 3,0 Hz. Alle Einzelwerte sind in den Tabellen

5 bis 9 zusammengefasst.

\section{Kontrolle}

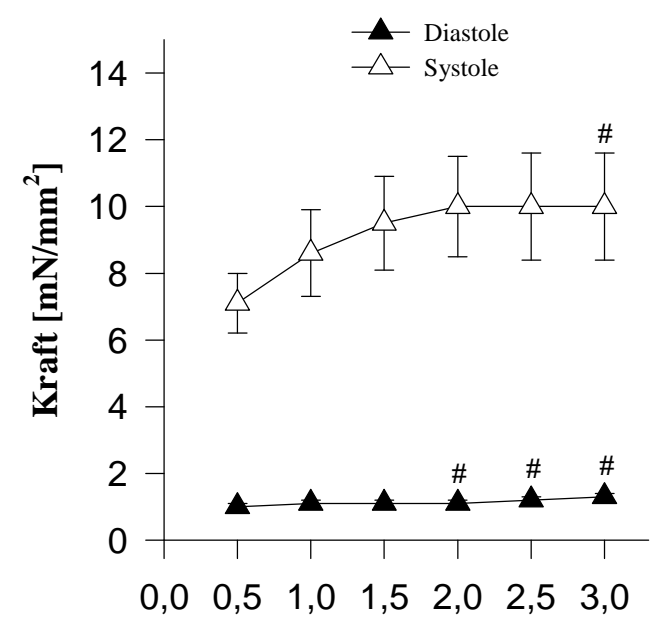

Frequenz [Hz]

\section{Flecainid}

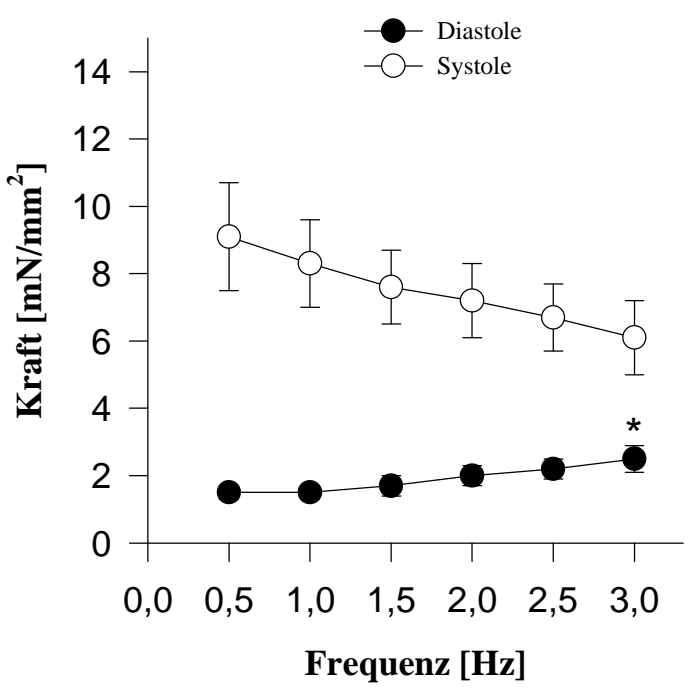

\begin{abstract}
Abb. 9: Der linke Teil der Abbildung stellt den Verlauf von systolischer Kraftentwicklung und diastolischer Spannung der Kontrollmuskeln während der KFB dar. Der rechte Teil beschreibt den gleichen Sachverhalt für die Flecainid Muskeln. In der rechten Abbildung ist zu erkennen, dass die negative KFB sowohl aus einer Abnahme der systolischen Kraftentwicklung als auch aus einer Zunahme der diastolischen Spannung resultiert. Identische Ausgangskraft der beiden Gruppen bei $1 \mathrm{~Hz}$, jeweils $\mathrm{n}=19 . \quad * \quad * \mathrm{p}<0,05 \mathrm{vs} .0,5 \mathrm{~Hz} \quad \#=\mathrm{p}<0,05 \mathrm{vs}$. Flecainid
\end{abstract}

In der oben gezeigten Abbildung 9 sind für Flecainid und die korrespondierende Kontrollgruppe jeweils systolische Kraftentwicklung und diastolische Spannung in einem Diagramm wiedergegeben. Die isometrische Kraft ist definiert als die Amplitude, das heisst als die Differenz aus der systolischen Kraftentwicklung und diastolischer Spannung. Die Ergebnisse zeigen, dass die negative KFB unter Flecainid auf einem Abfall der systolischen Kraft und einem Anstieg der diastolischen Spannung beruht. Die positive KFB der Kontrollmuskeln resultiert aus einer Zunahme der systolischen Kraftentwicklung, bei nahezu unveränderter diastolischer Spannung, bei Erhöhung der Stimulationsfrequenz. 


\section{Kraft-Frequenz-Beziehung}
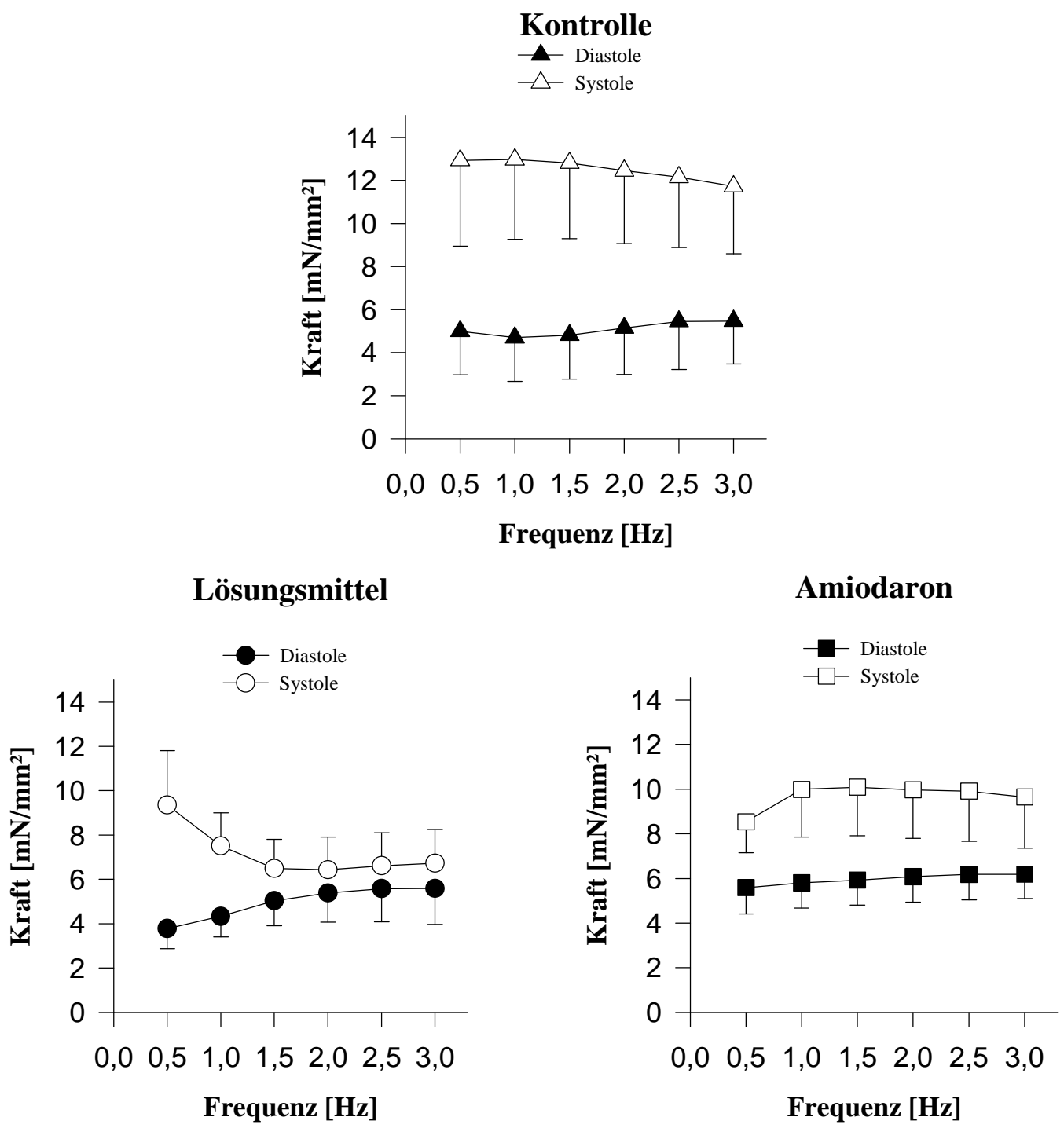

Abb. 10: Die Abbildung stellt den Verlauf von systolischer Kraftentwicklung und diastolischer Spannung der Kontrollmuskeln (oben), der Amiodaron-Muskeln (rechts unten) und der Lösungsmittel-Muskeln (links unten) während der KFB dar. Jeweils $n=7$. Unterschiede zwischen den Gruppen waren jeweils nicht signifikant.

Die oben aufgeführte Abbildung 10 zeigt den Verlauf der systolischen und diastolischen Kraftentwicklung für Amiodaron, Lösungsmittel und der Kontrollgruppe. Es ist deutlich zu erkennen, dass die Abnahme der Kraftamplitude in der Lösungsmittel Gruppe sowohl auf einer Abnahme der systolischen als auch einer Zunahme der diastolischen Kraftentwicklung beruht. Im Gegensatz dazu findet sich sowohl in der Kontrollgruppe als auch für Amiodaron ein annähernd stabiler Verlauf der Kraftentwicklung. 


\subsubsection{Diastolische Spannung unter Flecainid und Amiodaron}

Die folgende Abbildung 11 zeigt den Verlauf der diastolischen Spannung der Muskelstreifenpräparate der Flecainid- und Amiodaron-Experimente während der KFB (zu den Einzelwerten siehe auch Tabellen 5 bis 9).

Flecainid

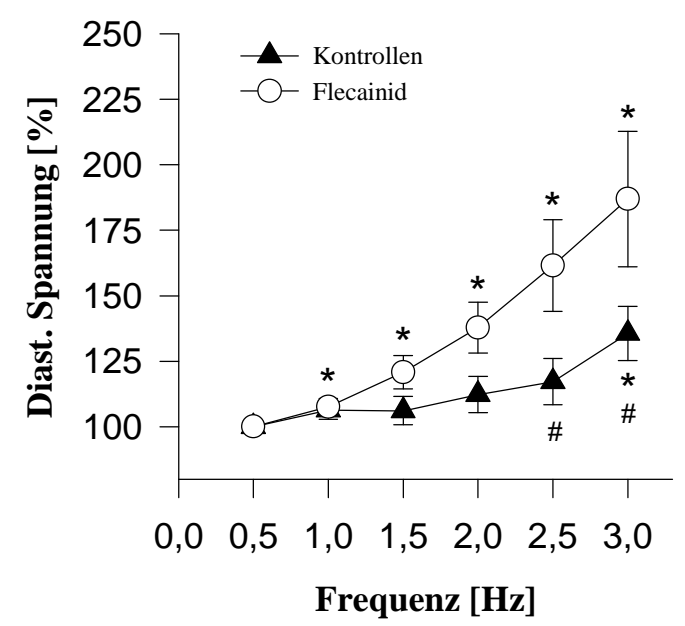

Amiodaron

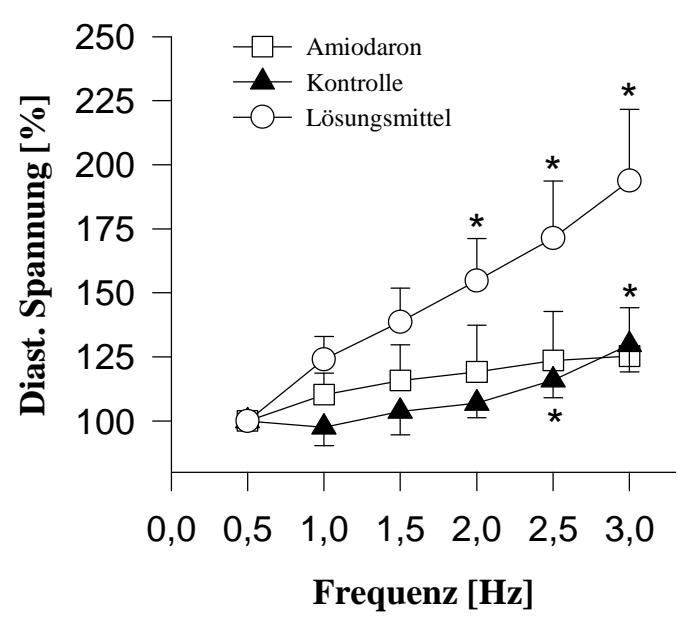

Abb. 11: Die Abbildung zeigt die Änderungen der diastolischen Spannung im Verlauf der KFB in \% in Bezug zum Ausgangswert bei einer Frequenz von 0,5 Hz. Im linken Teil sind die Ergebnisse der Flecainid Experimente dargestellt, im rechten Teil die Amiodaron-Experimente. $*=\mathrm{p}<0,05$ vs. $0,5 \mathrm{~Hz} \#=\mathrm{p}<0,05$ vs. Flecainid, in der Amiodaron-Reihe waren die Unterschiede zwischen den Gruppen nicht signifikant

Die diastolische Spannung änderte sich bei den Kontrollmuskeln für Flecainid im Verlauf der KFB ab $3 \mathrm{~Hz}$ signifikant. In der Kontrollgruppe für Amiodaron stieg die Spannung frequenzabhängig von $4,99 \pm 2,0 \mathrm{mN} / \mathrm{mm}^{2}$ bei $0,5 \mathrm{~Hz}$ auf maximal $5,47 \pm 2,0 \mathrm{mN} / \mathrm{mm}^{2}$ bei 3,0 Hz dezent an. Bei den Flecainid-Muskeln nahm die diastolische Spannung im Verlauf der KFB kontinuierlich zu und erreichte ein Maximum von 186,9 $\pm 25,8 \%$ des AGW bei 3,0 Hz, das sich signifikant vom AGW bei $0,5 \mathrm{~Hz}$ unterschied. In der Lösungsmittelgruppe war ebenso ein signifikanter Anstieg auf 193,7 $\pm 27,9 \%$ des AGW zu sehen, von 3,81 \pm 0,9 $\mathrm{mN} / \mathrm{mm}^{2}$ auf $6,02 \pm 1,3 \mathrm{mN} / \mathrm{mm}^{2}$ bei $3,0 \mathrm{~Hz}$. In der Amiodarongruppe jedoch blieb die diastolische Spannung weitgehend konstant. $5,58 \pm 1,2 \mathrm{mN} / \mathrm{mm}^{2}$ bei $0,5 \mathrm{~Hz}$ und $6,191,1$ $\mathrm{mN} / \mathrm{mm}^{2}$ bei $3,0 \mathrm{~Hz}$ (n.s.). 


\subsubsection{Zeitparameter der isometrischen Kontraktion unter Flecainid und}

\section{Amiodaron}

Die Zeitparameter der isometrischen Kontraktion, $\mathrm{TPT}, \mathrm{RT}_{50 \%}$ und $\mathrm{RT}_{90 \%}$ verkürzten sich in allen untersuchten Gruppen mit Zunahme der Stimulationsfrequenz. Innerhalb der Flecainid Gruppe unterschieden sich die Kontroll-Muskeln nicht von den Flecainid-Muskeln. Die Abnahme der Zeitparameter der Kontraktion entsprach sich qualitativ und quantitativ in beiden Gruppen. Ebenso waren in der Amiodaron Gruppe keine Unterschiede zwischen Kontroll-, Amiodaron- und Lösungsmittel-Muskeln festzustellen. Die dazu gehörigen Werte sind in den Tabellen 5 bis 9 jeweils in Millisekunden (ms) angegeben.

\subsection{4. $\mathbf{d F} / \mathrm{dt}_{\max }$ unter Flecainid und Amiodaron}

Die maximale Kraftanstiegs- und Relaxationsgeschwindigkeit stiegen in Abhängigkeit von der Stimulationsfrequenz bei allen Gruppen an. In der Kontrollgruppe für Flecainid stiegen beide Parameter nahezu parallel bis auf einen maximalen Wert von 191,95 $\pm 15,3 \%$ $\left(+\mathrm{dF} / \mathrm{dt}_{\max }\right)$ bzw. 193,81 $\pm 16,0 \%\left(-\mathrm{dF}_{\mathrm{dt}}\right.$ max $)$ bei 3,0 Hz an (siehe Abbildung 12).

$$
\mathrm{dF}_{\mathbf{d t}} \mathbf{m a x}_{\max }
$$

$$
\text { Flecainid } \quad-\overbrace{}^{\text {neg dF/dt } \max \mathrm{m}_{\text {max }} \mathrm{dt}_{\max }} \quad \text { Kontrolle }
$$

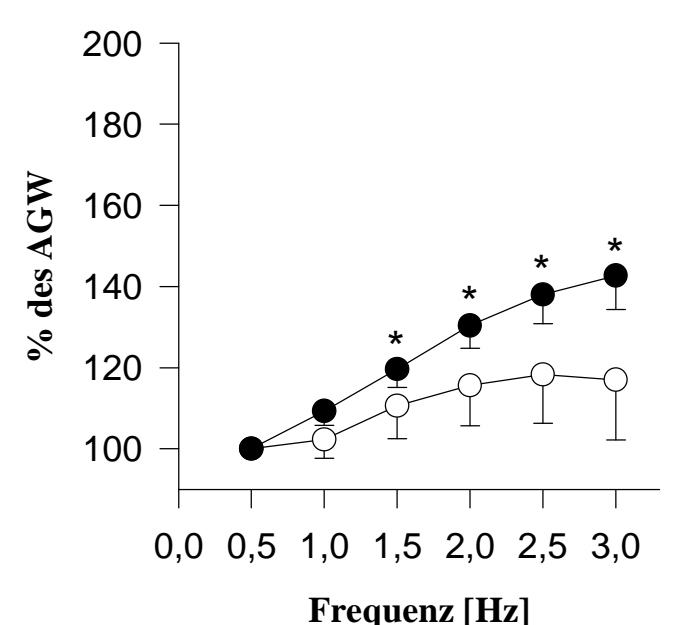

Frequenz [Hz]

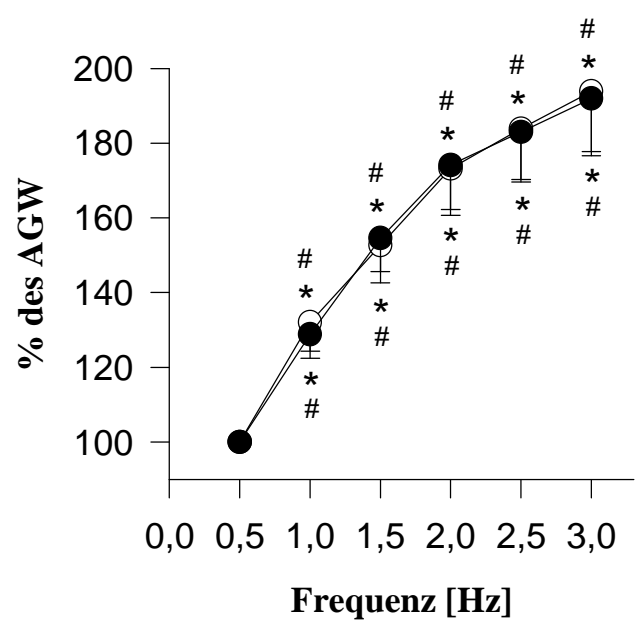

Abb. 12: Die linke Abbildung zeigt den Verlauf der maximalen Kraftanstiegs- und Relaxationsgeschwindigkeit bei Erhöhung der Stimulationsfrequenz unter Flecainid, die rechte Abbildung zeigt die gleichen Werte für die Kontrollgruppe.

$*=\mathrm{p}<0,05$ vs. $0,5 \mathrm{~Hz} \quad \#=\mathrm{p}<0,05$ vs. Flecainid 
Im Vergleich dazu stiegen diese Parameter in der Flecainid-Gruppe auf 142,7 \pm 8,4 \% $\left(+\mathrm{dF} / \mathrm{dt}_{\max }\right)$ bzw. nur 117,0 $\pm 14,8 \%\left(-\mathrm{dF} / \mathrm{dt}_{\max }\right)$ bei 3,0 Hz. Der Anstieg der Kurven ist hierbei auch nicht mehr parallel. Die maximale Relaxationsgeschwindigkeit bleibt gegenüber dem Anstieg der maximalen Kraftanstiegsgeschwindigkeit zurück (Abbildung 12). Zu den Einzelwerten siehe Tabellen 5 bis 9.

In der Amiodaron-Gruppe imponiert ebenfalls ein abgeschwächter Anstieg der beiden Parameter im Vergleich zur Kontrollgruppe. Hierbei kommt es aber, anders als in der Flecainid-Gruppe, zu einem weiterhin parallelen Anstieg der beiden Werte. Auch ist hierbei der Effekt des Lösungsmittels auf maximale Kraftanstiegs- und Relaxationsgeschwindigkeit $\mathrm{zu}$ beachten. In dieser Gruppe nimmt die maximale Kraftanstiegsgeschwindigkeit nur dezent auf $113,93 \pm 23,3 \%$ des AGW bei 3,0 Hz zu. Die maximale Relaxationsgeschwindigkeit steigt hier nicht wie in allen anderen untersuchten Gruppen an, sondern fällt sogar ab, auf $95,66 \pm 21,34 \%$ des AGW bei 3,0 Hz (Abbildung 13). $\mathrm{Zu}$ den Einzelwerten siehe auch Tabellen 5 bis 9. 


\section{Kraft-Frequenz-Beziehung $\mathbf{d F} / \mathbf{d t}_{\max }$}

\section{Kontrolle}
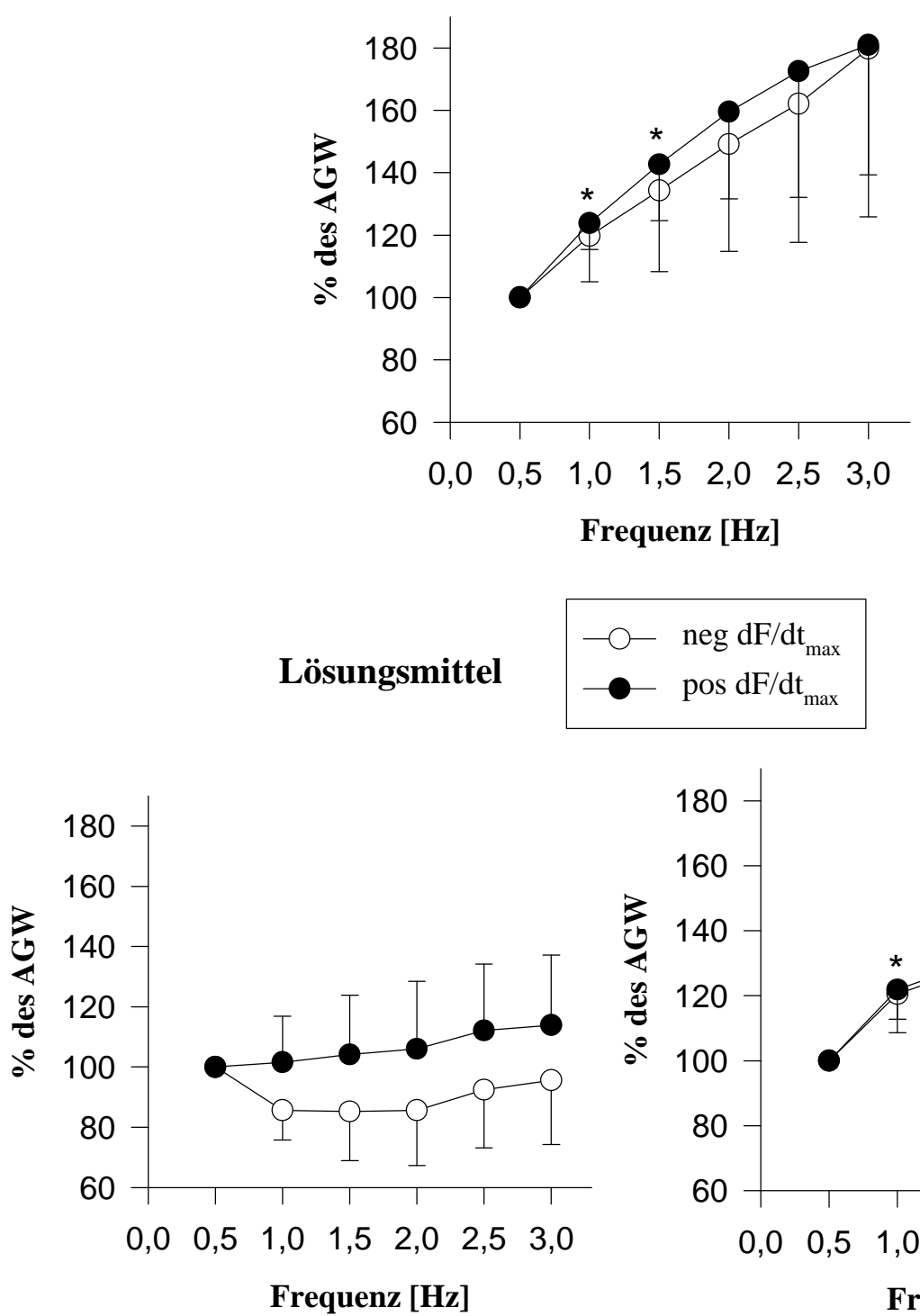

Amiodaron

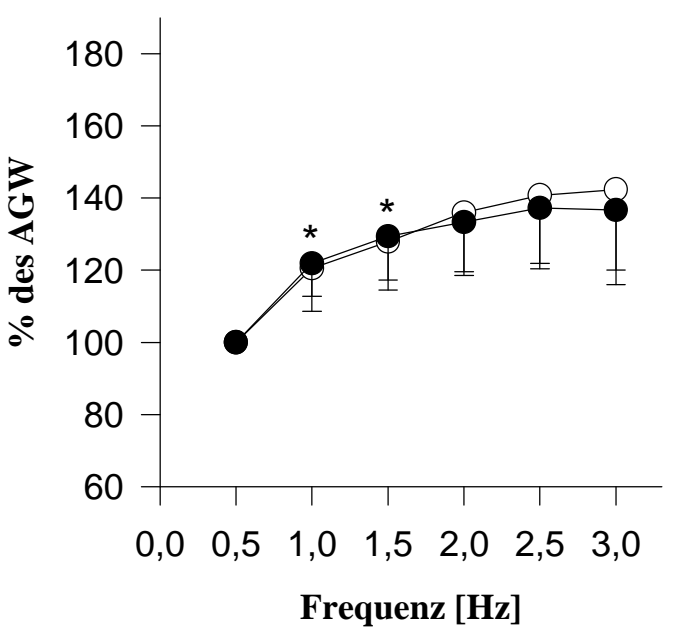

Abb. 13: Die Abbildung zeigt den Verlauf der maximalen Kraftanstiegs- und Relaxationsgeschwindigkeit bei Erhöhung der Stimulationsfrequenz unter Amiodaron (unten rechts), unter Lösungsmittel (unten links) und in der Kontrollgruppe (oben).

$*=\mathrm{p}<0,05$ vs. $0,5 \mathrm{~Hz}$ Unterschiede zwischen den Gruppen jeweils nicht signifikant 


\subsubsection{Querschnittsflächen der Muskelstreifenpräparate}

Der Durchmesser der Muskelstreifenpräparate der einzelnen Gruppen betrug für die Flecainid-Muskeln 0,47 \pm 0,03 mm (Querschnittsfläche: 0,19 $\pm 0,03 \mathrm{~mm}^{2}$ ) und für die Kontrollmuskeln 0,45 $\pm 0,03 \mathrm{~mm}$ (Querschnittsfläche: 0,17 $\pm 0,03 \mathrm{~mm}^{2}$ ). Die Unterschiede der beiden Gruppen waren nicht signifikant.

Die Durchmesser in der Amiodaron-Reihe: Kontrollmuskeln $0,36 \pm 0,04 \mathrm{~mm}$

(Querschnittsfläche: $\quad 0,11 \pm 0,02 \mathrm{~mm}^{2}$ ), Amiodaron-Muskeln $0,39 \pm 0,02 \mathrm{~mm}$ (Querschnittsfläche: 0,12 $\pm 0,01 \mathrm{~mm}^{2}$ ) und Lösungsmittel-Muskeln 0,37 $\pm 0,04 \mathrm{~mm}$ (Querschnittsfläche: 0,11 $\pm 0,02 \mathrm{~mm}^{2}$ ), die Unterschiede waren jeweils nicht signifikant (siehe auch Abbildung 14).

\section{Mittlerer Durchmesser der Muskelstreifen in $\mathbf{m m}$}

Muskeln der Flecainid Experimente

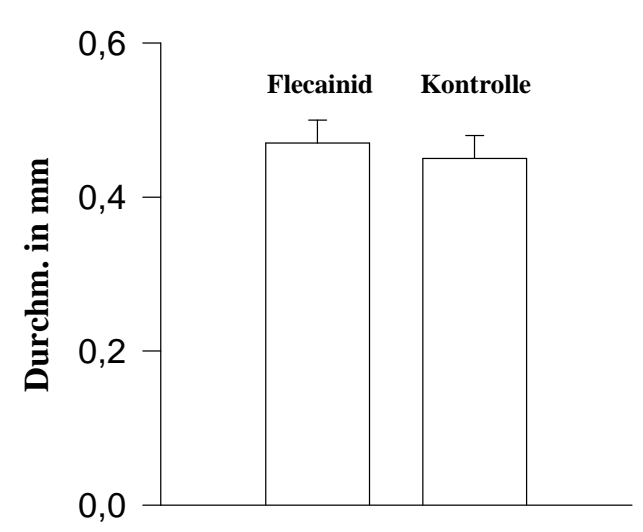

Muskeln der Amiodaron Experimente

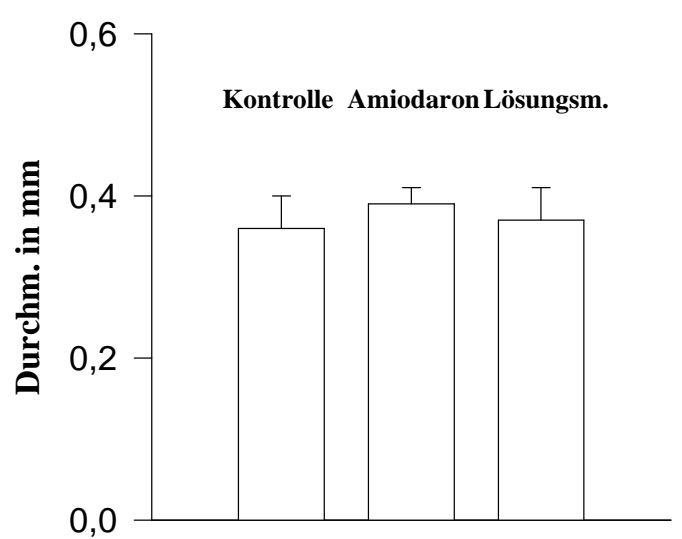

Abb. 14: Die linke Abbildung zeigt, dass die verwendeten Muskelstreifen für die KFB unter Flecainid in beiden Gruppen identische Durchmesser hatten. Unterschiede waren nicht signifikant. Gleiches gilt für die rechte Abbildung, in der die Durchmesser der Muskelstreifen für die KFB unter Amiodaron dargestellt sind. 


\subsection{Kraft-Frequenz-Beziehung unter Flecainid und Amiodaron am nicht-insuffizienten Kaninchen-Myokard}

Entsprechend dem Protokoll am menschlichen Myokard wurde auch die KFB am Herzmuskelgewebe des Kaninchens mit einer Flecainidkonzentration von von $3^{*} 10^{-6} \mathrm{M}$ und einer Amiodaronkonzentration von $10^{-4} \mathrm{M}$ durchgeführt.

Wie im Methodenteil beschrieben, wurden im Anschluss an die Stabilisierungsphase die Messungen zur Kraft-Frequenz-Beziehung (KFB) durchgeführt. Hierbei wurde die Stimulationsfrequenz ausgehend von $1,0 \mathrm{~Hz}$ bis auf einschließlich 5,0 Hz gesteigert, um dem physiologischen Spektrum des Kaninchens zu entsprechen.

\subsubsection{Kraftamplitude unter Flecainid und Amiodaron}

Abbildung 16 zeigt links die Ergebnisse für Flecainid und rechts für Amiodaron. Bei den Kontrollmuskeln der Flecainidexperimente zeigte die KFB einen ausgeprägten positiven Verlauf mit einer maximalen Zunahme auf $312 \pm 19 \%$ des Ausgangswertes bei 4 Hz. Im Gegensatz hierzu nahm die Kraft unter Flecainid signifikant schwächer zu und fiel bereits ab $3 \mathrm{~Hz}$ wieder ab (Maximum bei $3 \mathrm{~Hz}$ mit $236 \pm 20 \%$ des Ausgangswertes). Somit zeigt Flecainid auch im nicht-insuffizienten Myokard eine Verschlechterung der KFB. Wie in Abbildung 16 rechts zu erkennen ist, war der Verlauf der KFB der Kontrollmuskeln der Amiodaronexperimente ebenso deutlich positiv, mit einer maximalen Kraftsteigerung bei 5,0 $\mathrm{Hz}$ auf $341 \pm 22 \%$ des AGW. Unter Amiodaron zeigte sich im Vergleich keine signifikante Änderung des Verlaufes der KFB. Die Kontraktionskraft erreichte ein Maximum von $372 \pm$ $17 \%$ des Ausgangswertes bei 5,0 Hz.

Unter Lösungsmittel alleine kam es auch zu keiner signifikanten Veränderung der KFB. So lag die maximale Steigerung der Kontraktionskraft bereits bei 4,0 Hz (309 $\pm 18 \%$ des Ausgangswertes) und damit bei einer niedrigeren Frequenz als bei der Kontrollgruppe (5,0 Hz). Insgesamt scheinen sich die KFB der drei Gruppen nicht zu unterscheiden. Alle Einzelwerte sind in den Tabellen 10 bis 14 zusammengefasst. 


\section{Kraft-Frequenz-Beziehung (Kaninchenmyokard)}

Flecainid

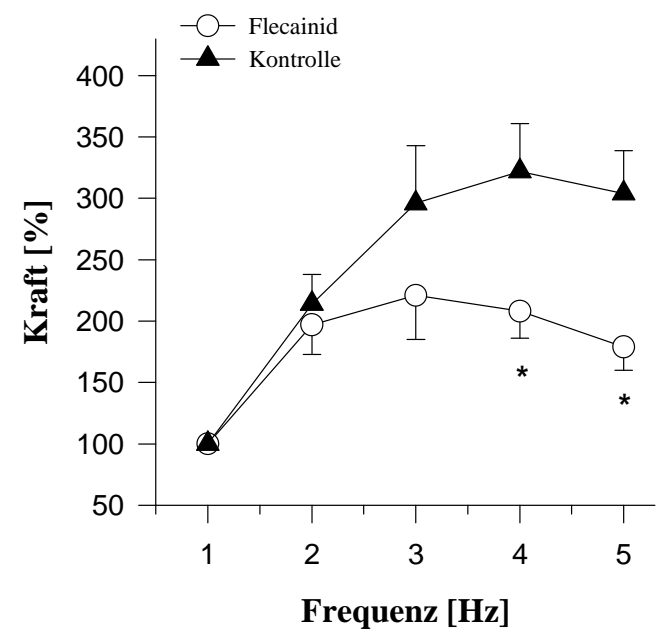

Amiodaron

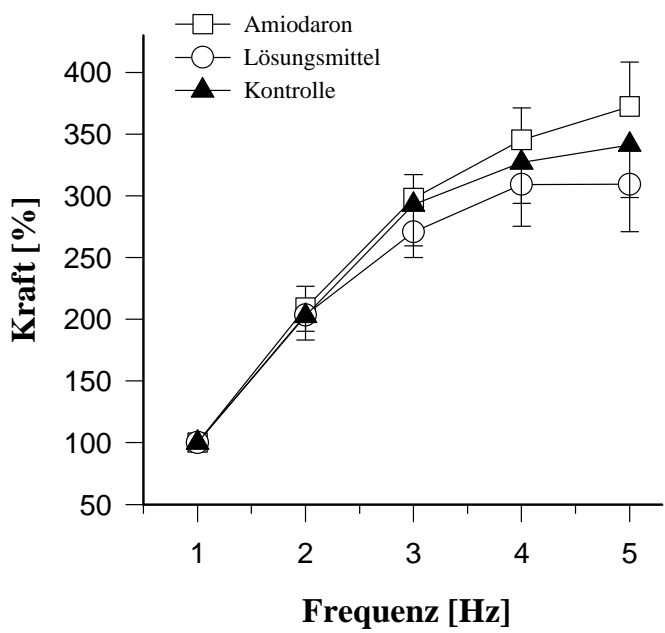

Abb. 16: Die Abbildung zeigt den Verlauf der KFB des nicht-insuffizienten Kaninchenmyokards in \% der Ausgangskraft links für Flecainid und rechts für Amiodaron gegen die jeweiligen Kontrollgruppen. Zu beachten ist die signifikante Verschlechterung der KFB durch Flecainid. $*=\mathrm{p}<0,05$ vs. Kontrolle jeweils $\mathrm{n}=8$

\subsubsection{Diastolische Spannung unter Flecainid und Amiodaron}

Wie Abbildung 17 zeigt, wiesen die Kontrolltrabekel aus Kaninchenmyokard in den durchgeführten Messungen im Gegensatz zum insuffizienten Humanmyokard auch bei hohen Frequenzen keinen signifikanten Anstieg auf. Dieses Verhalten wurde durch Amiodaron nicht negativ beeinflusst, wohingegen sowohl Flecainid als auch das Lösungsmittel einen deutlichen frequenzabhängigen Anstieg der diastolischen Spannung aufwiesen (Flecainid auf $153 \pm 12 \%$ bei $5 \mathrm{~Hz}$ und Lösungsmittel auf $136 \pm 10 \%$ bei $5 \mathrm{~Hz}, \mathrm{p}<0,05)$. 
Flecainid

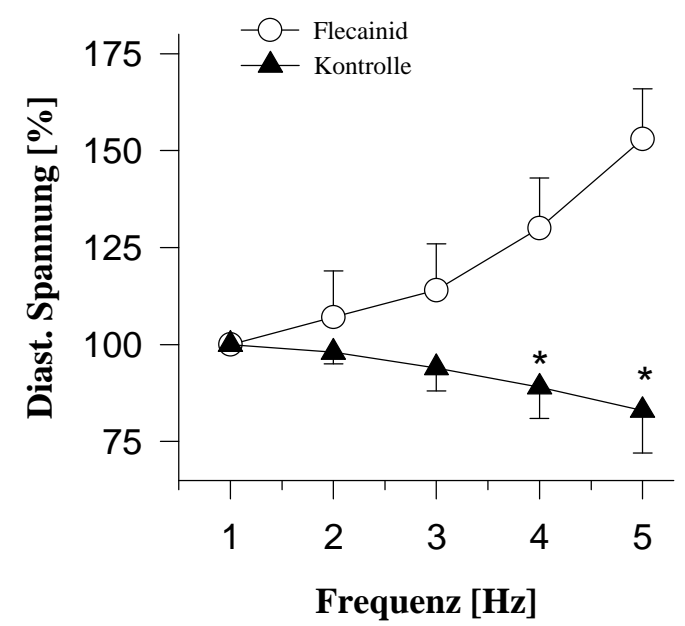

Amiodaron

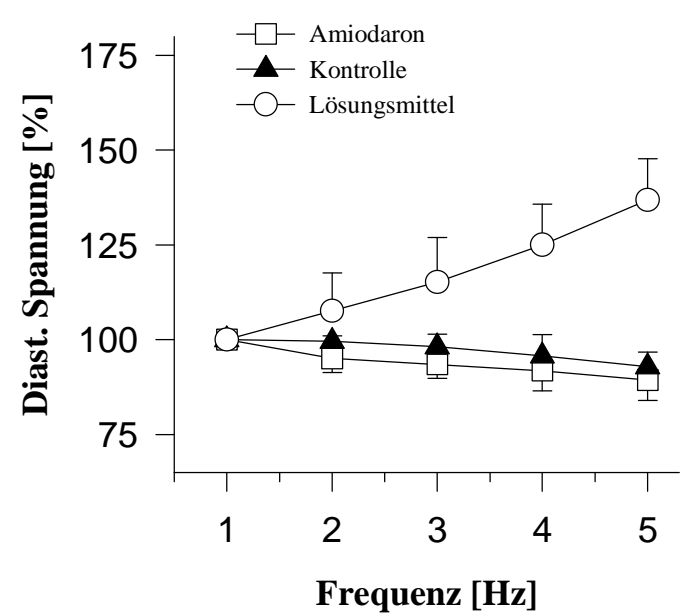

Abb. 17: Die Abbildung zeigt den Verlauf der diastolischen Spannung bei der KFB des nicht-insuffizienten Kaninchenmyokards in \% der Ausgangsspannung, links für Flecainid und rechts für Amiodaron gegen die jeweiligen Kontrollgruppen. Zu beachten ist die signifikante Zunahme der diastolischen Spannung während der KFB durch Flecainid im Vergleich zur Kontrollgruppe. $*=\mathrm{p}<0,05$ vs. Kontrolle jeweils $n=8$

\subsubsection{Zeitparameter der isometrischen Kontraktion unter Flecainid und}

\section{Amiodaron}

Die Effekt der untersuchten Substanzen auf die Zeitparameter der isometrischen Kontraktion (TPT, $\mathrm{RT}_{50 \%}$ und $\mathrm{RT}_{90 \%}$ ) waren sowohl in der Flecainid- als auch in der Amiodaron-Reihe vergleichbar zu denen im Humanmyokard (kein signifikanten Unterschiede) und sind in den Tabellen 10 bis 14 jeweils in Millisekunden (ms) aufgeführt. Auf eine graphische Darstellung wurde daher verzichtet.

\subsection{4. $\mathbf{d F} / \mathbf{d t}_{\max }$ unter Flecainid und Amiodaron}

Die maximale Kraftanstiegs- und Relaxationsgeschwindigkeit stiegen mit zunehmender Stimulationsfrequenz sowohl in der Flecainid-Gruppe als auch in der Kontroll-Gruppe nahezu parallel an. In der Flecainid-Gruppe stieg die maximale Relaxationsgeschwindigkeit ($\mathrm{dF} / \mathrm{dt}_{\max }$ ) bis auf einen maximalen Wert von $251 \pm 24 \%$ bei $5 \mathrm{~Hz}$ an. In der Kontroll-Gruppe stieg die maximale Relaxationsgeschwindigkeit bis auf den maximalen Wert von $253 \pm 20 \%$ bei $5 \mathrm{~Hz}$ an. Die maximale Kraftanstiegsgeschwindigkeit $(+\mathrm{dF} / \mathrm{dt})$ verlief in beiden Gruppen 
ebenfalls parallel, mit einem Maximum von $224 \pm 20 \%$ bei $3 \mathrm{~Hz}$ in der Flecainid-Gruppe, sowie von $223 \pm 21 \%$ bei $4 \mathrm{~Hz}$ in der Kontroll-Gruppe (siehe Abbildung 18).

\section{$\mathrm{dF} / \mathrm{dt}_{\max }$}

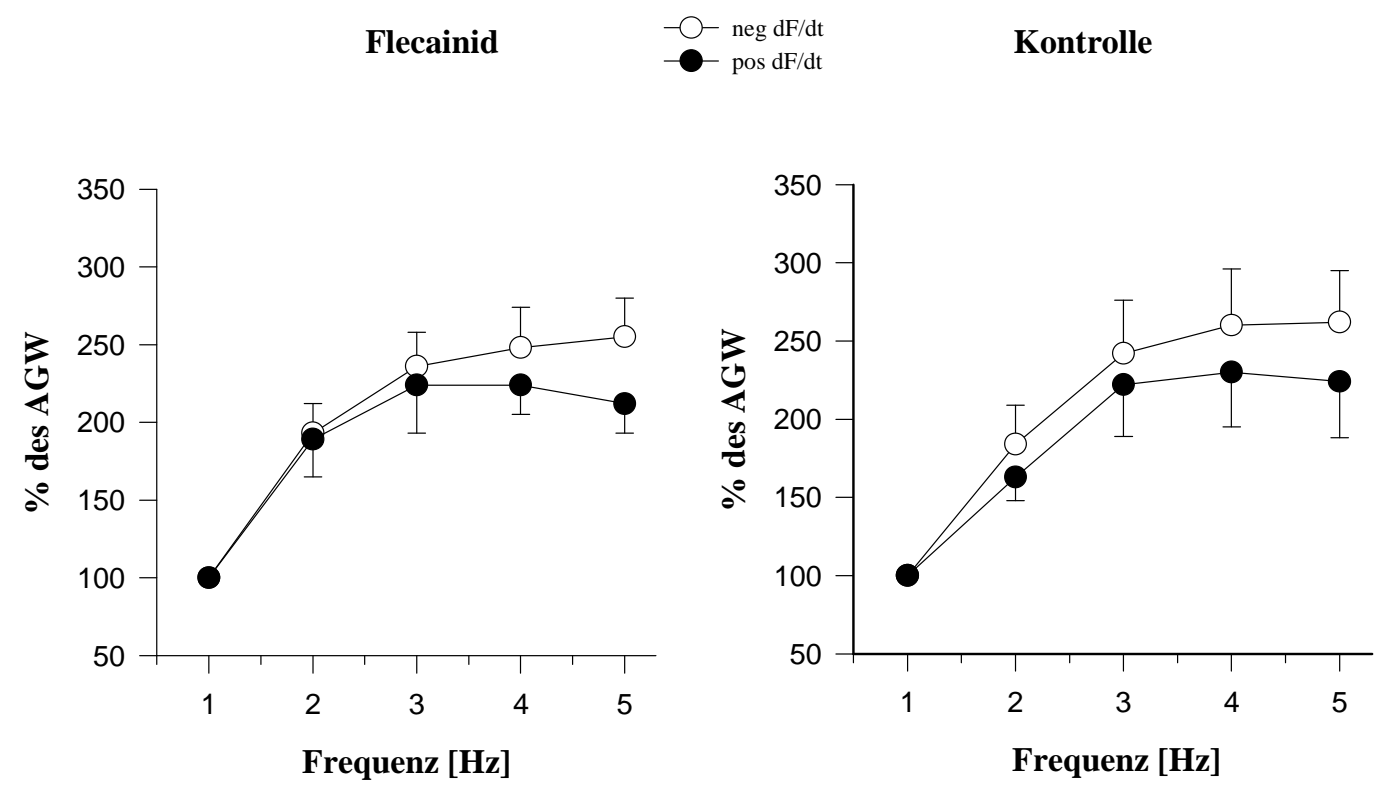

Abb 18.: KFB des Kaninchen-Myokards. Die linke Abbildung zeigt den Verlauf der maximalen Kraftanstiegs- und Relaxationsgeschwindigkeit bei Erhöhung der Stimulationsfrequenz unter Flecainid, die rechte Abbildung zeigt die gleichen Werte für die Kontroll-Gruppe. Es ergeben sich im Verlauf der KFB keine signifikanten Unterschiede zwischen den beiden Gruppen.

Bei den Amiodaron Experimenten stiegen die maximale Kraftanstiegs- und Relaxationsgeschwindigkeit in Abhängigkeit von der Stimulationsfrequenz bei allen drei Gruppen an. In der Kontroll-Gruppe stiegen beide Parameter exakt parallel bis auf einen maximalen Wert von $298 \pm 35 \%\left(+\mathrm{dF}^{2} \mathrm{dt}_{\max }\right)$ bzw. $293 \pm 34 \%\left(-\mathrm{dF}^{\mathrm{dt}} \mathrm{max}_{\max }\right)$ bei $5 \mathrm{~Hz}$ an. Im Vergleich dazu stiegen diese Parameter in der Amiodaron-Gruppe auf $447 \pm 15 \%\left(+\mathrm{dF} / \mathrm{dt}_{\max }\right)$ und $448 \pm 12 \%\left(-\mathrm{dF}^{2} \mathrm{dt}_{\max }\right)$ bei $5 \mathrm{~Hz}$ an. In der Lösungsmittel-Gruppe erreichte die Kraftanstiegsgeschwindigkeit bei $5,0 \mathrm{~Hz}$ das Maximum mit $365 \pm 17 \%$ und die Relaxationsgeschwindigkeit schon bei $4,0 \mathrm{~Hz}$ mit $357 \pm 16 \%$ des Ausgangswertes (nicht mit abgebildet). Die Abbildung 19 zeigt den Verlauf dieser Parameter über die Frequenzbereiche. $\mathrm{Zu}$ erkennen ist, dass der Anstieg in der Amiodaron-Gruppe tendenziell stärker ausfällt, als in der Kontroll-Gruppe. Die Unterschiede zwischen den Gruppen waren statistisch jedoch nicht signifikant. 


\section{$\mathbf{d F} / \mathbf{d t}_{\max }$}
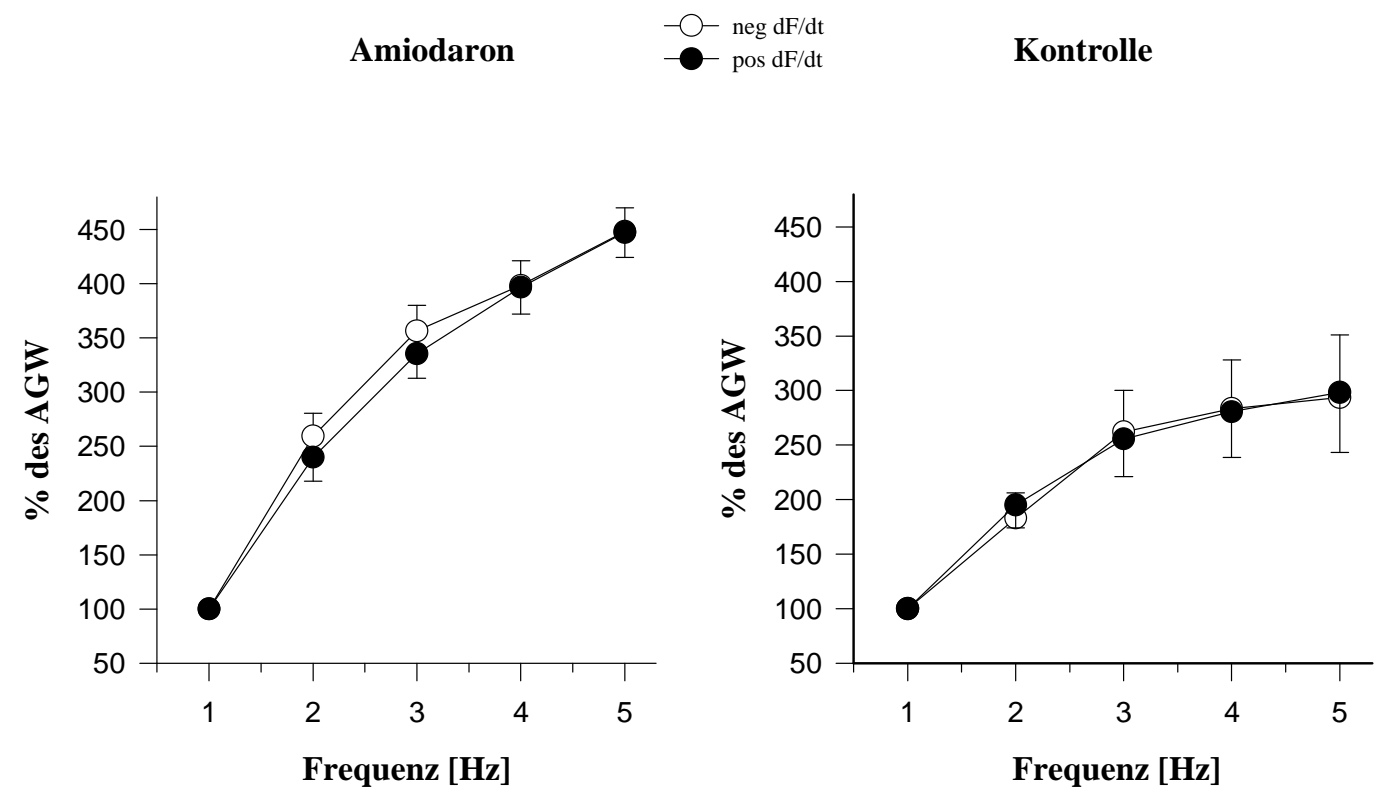

Abb 19.: KFB des Kaninchen-Myokards. Die linke Abbildung zeigt den Verlauf der maximalen Kraftanstiegs- und Relaxationsgeschwindigkeit bei Erhöhung der Stimulationsfrequenz unter Amiodaron, die rechte Abbildung zeigt die gleichen Werte für die Kontrollgruppe. Es ergeben sich im Verlauf der KFB keine signifikanten Unterschiede zwischen den beiden Gruppen, jeweils $\mathrm{n}=8$.

Die Abbildung 20 soll zum direkten Vergleich die unterschiedlichen Verläufe der maximalen Kraftanstiegs- und maximalen Relaxationsgeschwindigkeiten während der KFB des Kaninchen-Myokards unter Flecainid im Vergleich zu Amiodaron verdeutlichen (Graphen aus den Abbildung 18 und 19). Bei den Frequenzschritten 4 und $5 \mathrm{~Hz}$ ergaben sich signifikante Unterschiede zwischen den beiden Gruppen. Die Einzelwerte zu den obigen Abbildungen sind in den Tabellen 10 bis 14 einzusehen. 


\section{$\mathbf{d F} / \mathbf{d t}_{\text {max }}$}

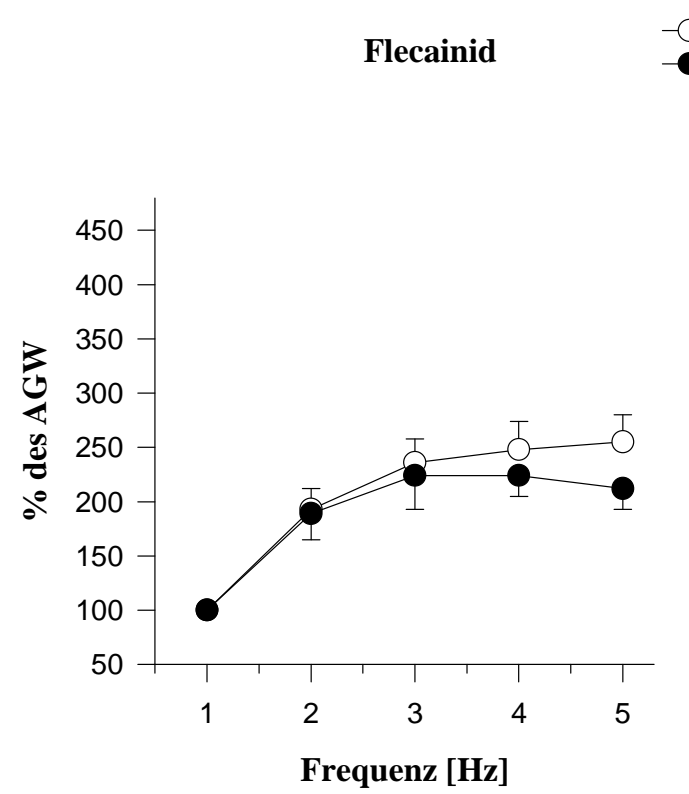

$-\operatorname{neg} \mathrm{dF} / \mathrm{dt}$
$-\operatorname{pos} \mathrm{dF} / \mathrm{dt}$

Amiodaron

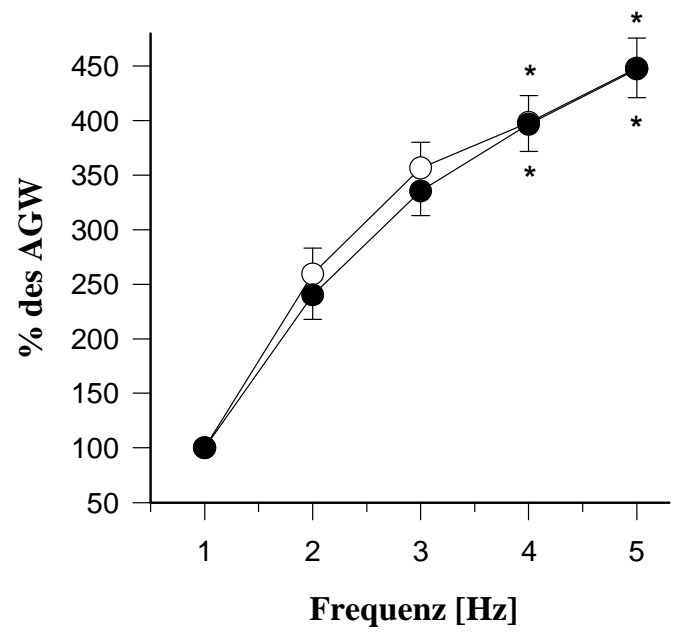

Abb. 20: Die Abbildung stellt den Verlauf von maximaler Kraftanstiegs- und Relaxationsgeschwindigkeit der Flecainid-Gruppe (links) im Vergleich zur Amiodaron-Gruppe (rechts) während der KFB dar. Bei den Frequenzen 4 und 5 Hz ergaben sich signifikante Unterschiede. $*=\mathrm{p}<0,05$ vs. Flecainid, jeweils $\mathrm{n}=8$ 


\section{Diskussion}

\subsection{Verwendung von multizellulären Muskelstreifenpräparaten}

In dieser Arbeit wurden multizelluläre, ventrikuläre Muskelstreifenpräparate aus explantierten menschlichen Herzen oder gesundem Kaninchenmyokard untersucht. Durch die in dieser Arbeit durchgeführten Messanordnungen konnten pharmakologische Effekte an isometrisch kontrahierenden Herzmuskelpräparaten unter konstanter Vor- und Nachlast untersucht werden. Die Frequenz konnte konstant gehalten oder in genau definierten und reproduzierbaren Schritten verändert werden, wie es bei der KFB gewünscht ist (Kennedy et al. 1987). Aufgrund der geringen Verfügbarkeit von nicht-insuffizientem humanem Myokard wurde als nicht-insuffizientes Gewebe daher gesundes Kaninchenmyokard verwendet.

\subsection{Registrierung intrazellulärer Kalzium-Transienten}

In der vorliegenden Arbeit wurde Aequorin, ein Indikator für intrazelluläres Kalzium, verwendet. Es bietet sich aus folgenden Gründen für die Messung des intrazellulären Kalziumtransienten an multizellulären Muskelstreifenpräparaten an:

Aequorin ist unter physiologischen Bedingungen kalziumspezifisch, und seine Reaktionskinetik ist sehr schnell. Die Lichtemission kommt im Millisekundenbereich zustande, abhängig von den Reaktionsbedingungen (Temperatur) um 10 ms (Hastings et al. 1969, Blinks 1992). Die lichtemittierende Reaktion benötigt keinen externen Sauerstoff, dieser ist Bestandteil des Aequorinmoleküls. Die doppellogarithmisch aufgetragene Aequorin-Reaktionskurve für Kalzium zeigt einen sigmoiden Verlauf, wobei der Kurvenanteil zwischen $10^{-7}$ und $10^{-5} \mathrm{M}\left[\mathrm{Ca}^{2+}\right]$ nahezu linear verläuft. Besonders während der Systole sind so Änderungen der Kalziumkonzentration gut zu erfassen, wobei niedrige Konzentrationen während der Diastole nur ungenau beurteilt werden können (Blinks et al. 1982). Aequorin ist zudem gegenüber pH-Wert-Schwankungen im physiologischen Bereich unempfindlich (Prasher et al. 1985), es hat keine toxischen Effekte auf die Zellen und besitzt eine lange Halbwertszeit im Zytosol (Miller et al. 1994). Für Aequorin wird kein toxisches Lösungsmittel benötigt. Es ist für Bewegungsartefakte, wie sie bei simultaner Messung der isometrischen Kontraktionskraft vorkommen, unempfindlich (Blinks 1992). 
Die in der vorliegenden Arbeit verwendete Makroinjektionstechnik ist der früher verbreiteten Mikroinjektionstechnik vergleichbar oder überlegen. Bei letzterer muss der Indikator mittels einer Mikropipette in etwa einhundert Myozyten einzeln injiziert werden, was mit einem großen technischen und zeitlichen Aufwand verbunden ist (Kihara et al. 1989).

Es gibt allerdings auch Nachteile bei der Verwendung von Aequorin als Kalziumindikator:

Die lichtemittierende Reaktion ist irreversibel, das Aequorin verbraucht sich also während des Experimentes. Die Abnahme der Intensität des Lichtsignals, in der Literatur als „,run down“ bezeichnet, beträgt z.B. für das Froschmyokard bei Raumtemperatur 4\% pro Stunde (Blinks 1992). Weitere Nachteile sind die oftmals geringe Lumineszenzintensität, eine relative Unempfindlichkeit im diastolischen Konzentrationsbereich und schwierig quantifizierbare Messdaten (Cobbold und Rink 1987). Auf die Kalibirierung der Messdaten und Umrechnung in Kalzium-Konzentrationen (Allen und Blinks 1978) wurde wegen der technischen Komplexität und der unbefriedigenden Genauigkeit (Neering und Prendergast 1980, Urthaler et al. 1993) daher verzichtet.

Der Mechanismus, durch den Aequorin in die Zellen gelangt, ist noch nicht hinreichend geklärt. Ein Erklärungsmodell nimmt an, dass Aequorin durch bestimmte permeable Membranbereiche in die Zelle eindringen kann (Mullins 1966). Andere Arbeitsgruppen zeigten die Möglichkeit einer transienten, reversiblen Permeabilitätserhöhung der Zellmembran durch den mechanischen Reiz der Beladung (Perreault et al. 1992 b, Fabiato 1981). Belegt ist auch, dass kein aktiver Transportmechanismus für die Aufnahme des Aequorins ins Zellinnere nötig ist, da auch bei Temperaturen, die aktive Transportmechanismen unmöglich machen, Zellen mit Aequorin beladen werden können (Morgan et al. 1984). Das Aequorin-Molekül kann die Zelle nicht mehr verlassen, nachdem es einmal ins Zytosol eingedrungen ist. 


\subsection{Wirkungen von Flecainid und Amiodaron an terminal insuffizientem humanem Myokard}

\subsubsection{Inotrope Effekte von Flecainid am humanen Myokard}

Die erstellte KWK für Flecainid zeigte einen dosisabhängigen negativ inotropen Effekt, mit halbmaximaler Wirkung von Flecainid bei $3 * 10^{-6} \mathrm{M}$. Dabei nahmen die maximale Kraftanstiegsgeschwindigkeit und die maximale Relaxationsgeschwindigkeit der Kontraktion parallel mit der Amplitude der entwickelten Kraft ab. Gleiche Ergebnisse erhielten auch Schulze und Knops bei Untersuchungen von Flecainid an ventrikulären Trabekeln gesunder Kälber. Sie zeigten einen dosisabhängigen, frequenzunabhängigen negativ inotropen Effekt von Flecainid. Dabei verlangsamte sich die maximale Anstiegssteilheit des Aufstriches des Aktionspotentials. Die Plateau-Höhe des Aktionspotentials und die APD änderten sich unter Flecainid nicht (Schulze und Knops 1982). Daraus leiteten die Autoren eine Hemmung auf den schnellen depolarisierenden Natrium-Kanal aber keine Wirkung auf den Kalium- oder Kalziumausstrom ab. Einflüsse auf diese Ströme würden die Dauer des AP verändern. Ito et al. (1996) wiesen ebenfalls einen konzentrationsabhängigen negativ inotropen Effekt von Flecainid an isolierten Kaninchen- und Rattenherzen nach (Ito et al. 1996). Durch Kombination von schnellen Kühlungskontrakturen, Post-Pausen-Kontraktionen und Blockade des Ryanodinrezeptors unter Flecainid und Vergleich der beiden Spezies, konnten sie insgesamt eine Abnahme des Kalziumgehaltes des SR nachweisen. Sie schlossen somit daraus, dass die Hauptwirkung der Klasse-I-Antiarrhythmika, die Blockade des schnellen Natrium-Kanals, letztendlich auch zu einer Reduktion des SR-Kalziums führt. Diese Ergebnisse stehen im Einklang mit hämodynamischen Wirkungen von Flecainid am Kaninchen-Modell in vivo (Twidale et al. 1994) und bei Patienten (Greene et al. 1992).

Die Abnahme der Kontraktionskraft durch Flecainid konnte in dieser Arbeit in Versuchen mit gleichzeitiger Bestimmung der intrazellulären Kalzium-Transienten als kalziumabhängig bestätigt werden. Die Amplitude des Kalzium-Transienten nahm um den gleichen Betrag wie die Kraftamplitude auf etwa $65 \%$ des Ausgangswertes ab. Damit konnte erstmals auch am humanen terminal insuffizienten Myokard gezeigt werden, dass der negativ inotrope Effekt von Flecainid kalziumabhängig ist. Die Zeitverläufe der Kraftentwicklung und des AequorinLichtsignals änderten sich nach Zugabe von Flecainid nicht und der Abfall von Licht- und Kraftsignal war proportional. Dies läßt die Schlussfolgerung zu, dass die Sensibilität der Myofilamente für Kalzium durch Flecainid nicht verändert wird. 


\subsubsection{Wirkmechanismus von Flecainid}

Flecainid ist ein Antiarrhythmikum der Klasse IC. Die Klasse-I-Antiarrhythmika entfalten ihre Wirkung durch Blockade des schnellen, spannungsabhängigen Natrium-Kanals, der nach Überschreiten des Schwellenpotentials der Herzmuskelzelle die Depolarisation und damit das Aktionspotential einleitet. Folge der Natrium-Kanalhemmung ist eine Verlängerung der relativen Refraktärzeit, also der Zeit, bis sich der Natrium-Kanal von seiner Inaktivierung wieder völlig erholt hat. Frühzeitig einfallende Extrasystolen können so unterdrückt werden (Forth et al. 2001). Flecainid besitzt die längste Kinetik der Klasse-I-Antiarrhythmika. Das heisst, die Erholung des Ionenkanals von seiner Inaktivierung durch Flecainid dauert am längsten, verglichen mit den übrigen Klasse-I-Antiarrhythmika (Roden und Woosley 1986). Flecainid besitzt keine Wirkung auf den repolariserenden Kalium-Kanal, somit hat es keinen Einfluss auf die Dauer des Aktionspotentials (APD), wie etwa Chinidin oder Procainamid (Klasse IA); diese verlängern die APD.

Durch die Blockade des schnellen, spannungsabhängigen Natrium-Kanals und damit des Natriumeinstromes ins Zellinnere während der Depolarisation, wird die Natriumkonzentration an der Zellmembran-Innenseite durch Flecainid reduziert. Durch diese Änderung des Natriumgradienten kommt es zu einer Aktivierung des sarkolemmalen Natrium-KalziumAustauschers (NCX) in Richtung des Exports von Kalzium und des Einwärtstransportes von Natrium. Somit verliert das Zytosol Kalzium, wodurch sekundär auch weniger Kalzium vorhanden ist, das in das SR zurück aufgenommen werden kann. So steht bei den folgenden Erregungs-Kontraktionszyklen weniger Kalzium zur Bindung an die kontraktilen Proteine zur Verfügung. Dass die Aktivität des Natrium-Kalzium-Austauschers den Kalziumgehalt des SR beeinflusst, ist von mehreren Autoren belegt (Sutko et al. 1986, Bers und Bridge 1989, Bassani RA und Bers 1994). Bedenkt man den Befund der vermehrten Expression und Aktivität des sarkolemmalen Natrium-Kalzium-Austauschers bei Herzinsuffizienz (Studer et al. 1994, Hasenfuss et al. 1999), so wird deutlich, warum der negativ inotrope Effekt von Flecainid im insuffizienten Myokard stärker ausgeprägt sein könnte als in gesunden Herzen und warum Flecainid bei Herzinsuffizienz nebenwirkungsreicher ist.

Es ist für Flecainid nachgewiesen, dass es am Froschmyokard sarkolemmale Kalzium-Kanäle blockiert (Scamps et al. 1989). Außerdem konnten Kihara et al. zeigen, dass Flecainid am Hundemyokard sarkolemmale L-Typ-Kalziumkanäle hemmt und damit den langsamen Kalziumeinstrom in die Zelle (Kihara et al. 1996). Der Effekt zeigte sich jedoch erst deutlich bei Konzentrationen von $10^{-4} \mathrm{M}$ Flecainid, wobei die optimale Plasmakonzentration zur Unterdrückung von Arrhythmien zwischen $3 * 10^{-7}$ und $10^{-6} \mathrm{M}$ beschrieben ist (Woosley et al. 
1984, Toyama et al. 1989). Die Hemmung der L-Typ-Kalziumkanäle könnte also auch eine Erklärung der negativ inotropen Wirkung von Flecainid sein. Zu bedenken ist aber, dass der Kalziumstrom durch diese Kanäle auch verantwortlich für die Plateauphase des Aktionspotentials ist. Blockierung des L-Typ-Kalziumkanals müsste also auch eine Verkürzung der APD bewirken, wie es für Kalziumantagonisten belegt ist, deren Hauptwirkung die Blockade der L-Typ-Kalziumkanäle ist (Forth et al. 2001). Für Flecainid konnte beim Menschen in vivo aber lediglich eine dezente Verlängerung der APD nachgewiesen werden (Olsson und Edvardsson 1981).

Eine Aktivierung des Natrium-Kalzium-Austauschers scheint also eine größere Rolle bei der Vermittlung des negativ inotropen Effektes zu spielen, wobei - zumindest bei höheren Konzentrationen - ein Teileffekt über Blockade der L-Typ-Kalziumkanäle mit berücksichtigt werden muss.

\subsubsection{Einfluss von Flecainid auf die Kraft-Frequenz-Beziehung}

In der vorliegenden Arbeit wurde eine für terminal insuffizientes, menschliches Myokard typische flache KFB gefunden. Es zeigte sich mit Zunahme der Stimulationsfrequenz ein maximaler Kraftanstieg auf $140 \%$ der Ausgangskraft, wobei schon ab 2,0 Hz keine weitere Zunahme der Kontraktionskraft $\mathrm{zu}$ beobachten war. Die KFB der Präparate aus den identischen Herzen zeigten unter Flecainid einen negativen Verlauf mit Abnahme der Kontraktionskraft auf etwa $90 \%$ bei maximaler Frequenz von 3,0 Hz. Diese Abnahme der entwickelten Kraft kam überwiegend durch Abnahme der systolischen Kraftentwicklung zustande, wobei die Zunahme der diastolischen Spannung auch einen Anteil daran hatte. Flecainid verschlechtert also die KFB des insuffizienten Herzens mit Einfluss sowohl auf die systolische als auch diastolische Funktion. Im Gegensatz zum insuffizienten Herzen können nicht-insuffiziente Kontrollherzen die Kontraktionskraft auf etwa 200\% der Ausgangskraft bei 3,0 Hz steigern (Pieske 1998). Derartige menschliche Herzen standen jedoch für die Untersuchungen dieser Arbeit nicht zur Verfügung. Aus diesem Grunde wurde zur Gewinnung von nicht-insuffizientem Myokard Kaninchenherzen verwendet. Diese zeigten bei den Kontrolltrabekeln eine stark positive KFB mit maximalen Anstiegen bis 313\% bei $4 \mathrm{~Hz}$. Flecainid führte auch hier zu einer deutlichen Verschlechterung der KFB (Maximalkraft bei $235 \%$ bei $3 \mathrm{~Hz}$ ). Es war dabei eindrücklich, dass Flecainid sowol die systolische als auch die diastolische Funktion beeinträchtigt.

Ito et al. (1996) erhielten insgesamt ähnliche Ergebnisse, als sie den Einfluss von Flecainid auf die KFB des Kaninchens und der Ratte miteinander verglichen (Ito et al. 1996). Es zeigte 
sich eine fast ganz aufgehobene KFB des Kaninchens. Die Ratte zeigte eine negative KFB, welche unter Flecainid vor allem bei höheren Frequenzen noch stärker herabgesetzt wurde. Bei beiden Spezies wurden die Amplituden der schnellen Kühlungskontrakturen unter Flecainid kleiner, diese gelten als Indikator für den Kalziumgehalt des SR (Bers 1989). Man folgerte daraus, dass Flecainid durch seine Natrium-Kanal blockierende Wirkung die intrazelluläre Natriumkonzentration herabsetzt, dadurch den sarkolemmalen NatriumKalzium-Austauscher in seinem „forward-mode“ aktiviert und somit vermehrt Kalzium nach extrazellulär transportiert wird. Sekundär ginge so dem SR Kalzium verloren. Bedenkt man die gesteigerte Expression und Aktivität des Natrium-Kalzium-Austauschers bei Herzinsuffizienz und dessen sekundäre Aktivierung durch Flecainid so wird klar, dass es dadurch gerade bei steigender Herzfrequenz zu einer weiteren Kalzium-Verarmung des SR kommen kann und die negativ inotrope Wirkung der Substanz bei steigenden Frequenzen verstärkt wird (negative KFB).

Unter Berücksichtigung von Befunden am Tiermodell, wonach Flecainid sarkolemmale LTyp-Kalziumkanäle hemmt und damit den langsamen Kalziumeinstrom in die Zelle (Scamps et al. 1989, Kihara et al. 1996), stellt das einen weiteren möglichen Mechanismus dar, durch den Flecainid die KFB am insuffizienten Myokard zusätzlich beeinträchtigt.

Die Verschlechterung der KFB durch Flecainid könnte zum Teil auch auf die Bindungskinetik am Natriumkanal zurückzuführen sein. Die Antiarrhythmika der Klasse I erreichen ihre Bindungsstelle in der Kanalwand direkt durch die Lipidmembran, können aber auch - nach Eindringen in die Zelle - von der zytosolischen Seite aus dorthin gelangen; letzteres ist aber nur im offenen Kanalzustand möglich. Dies ist umso wahrscheinlicher, je öfter der Kanal geöffnet, also je höher die Frequenz ist. Auch die Bindung des Antiarrhythmikums an das Kanalprotein hängt vom Aktivitätszustand des Kanals ab. Die Bindung ist nämlich nur hochaffin, solange der Kanal geöffnet oder inaktiviert ist, sie löst sich aber wieder, wenn der Kanal in seinen Ruhezustand übergeht (Forth et al. 2001). Die Wirkung eines Klasse-IAntiarrhythmikums ist also um so stärker, je öfter der Kanal pro Zeiteinheit aktiv ist, das heisst je höher die Herzfrequenz ist (,use-dependent-block“). Dies könnte die Potenzierung der negativ inotropen Effekte bei der KFB zusätzlich erklären.

\subsubsection{Diastolische Funktion unter Flecainid}

Mehrere in dieser Arbeit erhobene Befunde deuten darauf hin, dass Flecainid die diastolische Funtion des Herzens verschlechtert. Bei konstanter Frequenz von $1 \mathrm{~Hz}$ führte Flecainid in hohen Konzentrationen zu einem Anstieg der diastolischen Spannung und Verlängerung der 
Relaxationszeit (RT90). Unter Eröung der Stimulationsfrequenz (KFB-Versuche) kam es ebenso zu einem Anstieg der diastolischen Spannung. Dies war sowohl im insuffizienten Myokard zu beobachten, welches per se eine disastolische Dysfunktion aufweist, als auch im nicht-insuffizienten Kaninchenmyokard, welches die diastolische Spannung auch bei hohen Frequenzen konstant hält. Die Verschlechterung der diastolischen Funktion durch Flecainid ist also unabhängig von dem Vorbestehen einer diastolischen Dyfunktion und auch im gesunden Myokard nachzuweisen. Die maximale Relaxationsgeschwindigkeit (-dF/dt) war unter Flecainid niedriger als in der Kontrollgruppe und deviierte von der Kraftanstiegsgeschwindigkeit $(+\mathrm{dF} / \mathrm{dt})$, wobei diese beiden Parameter in der Kontrollgruppe exakt parallel verliefen. Eine Reduktion der Relaxationsgeschwindigkeit der Kontraktion bei steigenden Stimulationsfrequenzen könnte auf einer verlangsamten zytosolischen Kalziumelimination beruhen. Da die Aktivität des NCX durch Flecainid im Vorwärts-Mode gesteigert wird, scheint die nachgewiesene verlangsamte Kalziumelimination bei höheren Frequenzen unter Flecainid unabhängig vom NCX zu sein und könnte von daher am ehesten Ausdruck einer Hemmung der SERCA-Aktivität sein. Ähnlich der Wirkung auf den sarkolemmalen Natriumkanal könnte hier eine Frequenzabhängigkeit (so genannte use dependence, siehe unten) eine Rolle spielen. Hemmung der SERCA-Aktivität würde auch die Verschlechterung der systolischen KFB unter Flecainid bei Herzinsuffizienz erklären. Zur Klärung dieses Mechanismus wären direkte Messungen der SERCA-Aktivität an isolierten SR-Vesikeln nötig.

\subsubsection{Inotrope Effekte von Amiodaron am humanen Myokard}

In der vorliegenden Arbeit wurde die Wirkung von Amiodaron auf isoliertes, menschliches, insuffizientes Myokard untersucht. Um dessen Wirkung von denen des Lösungsvermittlers abgrenzen zu können, wurden parallel an Muskelstreifenpräparaten aus denselben Herzen Lösungsmittelkontrollen (Gemisch aus Benzylalkohol und Polysorbat 80) durchgeführt. Bei konstanter Stimulationsfrequenz von $1 \mathrm{~Hz}$ hatte das Lösungsmittel allein einen signifikanten, konzentrationsabhängigen, negativ inotropen Effekt. Unter Amiodaron zeigte sich eine nahezu identische Kraftabnahme wie unter Lösungsmittel, so dass Amiodaron selbst keinen eigenen negativ inotropen Effekt aufzuweisen scheint. $\mathrm{Zu}$ den Ergebnissen dieser Arbeit passen die Befunde, die beim Menschen in vivo gefunden wurden: Die intravenöse Bolusapplikation von Amiodaron bei Patienten mit linksventrikulärer Dysfunktion führt initial zu einer Abnahme der maximalen Druckanstiegsgeschwindigkeit, einer Zunahme der Herzfrequenz sowie einer Abnahme der Ejektionsfraktion und des arteriellen Blutdruckes. 
Diese Veränderungen treten während der ersten vier bis fünf Minuten nach Applikation auf, um nach etwa zehn Minuten wieder zum Ausgangswert zurückzukehren. Diese initialen Effekte könnten auf den Lösungsvermittler zurückgeführt werden (Pfisterer et al. 1985, Remme et al. 1990), da dessen Halbwertszeit im Bereich von wenigen Minuten liegt (Späth 1992). Bei chronischer Applikation oder oraler Einnahme hat Amiodaron keinen signifikanten Effekt auf die Hämodynamik (Remme und van Hoogenhuyze 1990). Die Daten der vorliegenden Arbeit sprechen ebenso dafür, dass der Blutdruckabfall und der Herzfrequenzanstieg nach Bolusgabe von Amiodaron auf das Lösungsmittel zurückzuführen sind, nicht auf den eigentlichen Wirkstoff.

\subsubsection{Wirkmechanismus von Amiodaron und dem Lösungsvermittler Polysorbat 80}

Amiodaron ist ein Antiarrhythmikum der Klasse III nach Vaughan Williams. Die Klasse-IIIAntiarrhythmika entfalten ihre Wirkung durch Blockade des repolarisierenden KaliumAuswärtsstroms während des Aktionspotentials der Herzmuskelzelle. Der für die Repolarisation der Herzmuskelzelle hauptverantwortliche Kaliumstrom ist der so genannte „,verzögerte Gleichrichterstrom“ (delayed rectifier-current, $\mathrm{I}_{\mathrm{K}}$ ). Dadurch kommt es zu einer Verlängerung der APD und der absoluten Refraktärzeit (Singh und Vaughan Williams 1970, Vaughan Williams 1984). Diese Veränderungen können im EKG als Verlängerung der QTZeit manifest werden. Amiodaron wirkt allerdings nicht selektiv auf die Repolarisation sondern zeigt sogar antiarrhythmische Eigenschaften aller vier Klassen nach VaughanWilliams. Es hat einen „use-dependent“ hemmenden Effekt auf den schnellen Natriumkanal im klinisch relevanten Frequenzbereich, der auch von der Amiodaronkonzentration abhängig ist (Mason et al. 1984). Amiodaron zeigt auch eine deutliche kalziumantagonistische Wirkung (Nishimura et al. 1986, Nattel et al. 1987, Lubic et al. 1994). Der Effekt ist frequenzabhängig mit einer Erholungskinetik von über einer Sekunde (Nattel et al. 1988). Außerdem hemmt Amiodaron kardiale adrenerge Alpha- und Beta-Rezeptoren in nicht-kompetitiver Form (Kobayashi et al. 1983, Aomine 1989).

Amiodaron als Injektionslösung enthält als Lösungsmittel Polysorbat 80 und Benzyl-Alkohol. Polysorbat 80 (Polyoxyethylen-sorbitan-monolaurat) gehört zur Stoffklasse der Emulgatoren und Schaummittel. Polysorbate sind chemisch modifizierte Verbindungen aus Fettsäuren, Alkohol und Sorbit. Polysorbat 80 ist als Hilfsstoff in der Arzneimittelzubereitung und als Nahrungsergänzungsmittel zugelassen. Polysorbate werden im Organismus wie Fettsäuren 
abgebaut, es sind für den menschlichen Organismus keine schädlichen Nebenwirkungen bekannt. Polysorbat 80 ist also Bestandteil der intravenösen Applikationsform von Amiodaron und könnte seine Wirkung nach Bolusinjektion modifizieren (Munoz et al. 1988). Für Benzylalkohol sind lokalanästhetische Wirkungen und eine Reduktion der Kontraktionskraft am Kaninchenherzen beschrieben (Eichbaum und Tasaka 1976, Yasaka et al. 1979). Über den Mechanismus der Natriumkanal-Blockade und dadurch sekundären Kalziumverlust über den Natrium-Kalzium-Austauscher, wie oben auch für Flecainid beschrieben, könnte die Reduktion der Kontraktionskraft bei intravenöser Bolusgabe zustande kommen. Der negativ inotrope Effekt des Lösungsmittels in dieser Arbeit könnte ebenfalls auf diesem Mechanismus beruhen.

Amiodaron selber bewirkt keine Reduktion der Kontraktionskraft, durch seine Kalium-Kanal blockierende Wirkung verlängert es die APD (Mason et al. 1984, Yabek et al. 1986) und damit die Repolarisation. Somit wird die Zeit verlängert, in der Kalzium durch die L-TypKalziumkanäle in das Zytosol gelangen kann, womit eher ein positiv inotroper Effekt verbunden wäre, sofern dies den direkten hemmenden Effekt von Amiodaron auf den L-TypKalziumkanal überwiegt. Tande und Refsum (1990) fanden im Rattenmyokard unter Amiodaron in der Konzentration $10^{-4} \mathrm{~mol} / \mathrm{L}$ neben Effekten auf die Erregungsbildung einen dezenten positiv inotropen Effekt um etwa $10 \%$ der Ausgangskraft (Tande und Refsum 1990). Das Lösungsmittel bewirkte hingegen einen dezenten negativ inotropen Effekt. Man erklärte die positiv inotrope Wirkung mit der Verlängerung der Repolarisation und der so verlängerten Zeit für den Kalziumeinstrom. Die Befunde von Tande und Refsum unterstützen die Hypothese, dass der Lösungsvermittler für die negativen Effekte auf die Hämodynamik bei Bolusapplikation von Amiodaron verantwortlich sein könnte.

Die maximale Kraftanstiegs- und Relaxationsgeschwindigkeit der Kontraktion verringerte sich unter Amiodaron und Lösungsmittel in gleichem Ausmaß, entsprechend der Abnahme der Kraftamplitude. Auch die Relaxationszeiten der Kontraktion unterschieden sich nicht zwischen Amiodaron und Lösungsmittel. Daraus kann geschlossen werden, dass die Sensibilität der Myofilamente für Kalzium durch Amiodaron nicht verändert zu werden scheint und kein wesentlicher Einfluss auf die Transportproteine des SR ausgeübt wird.

Einige Autoren beschreiben für Amiodaron einen negativ inotropen Effekt und diskutieren in diesem Zusammenhang eine Beteiligung des Natrium-Kalzium-Austauschers (Aomine und Fukui 1993). Sie führten ihre Untersuchungen aber ohne Lösungsmittelkontrollen durch, wodurch Effekte des Lösungsvermittlers nicht ausgeschlossen werden konnten und die 
Hemmung des Natrium-Kalzium-Austauschers auch auf dem oben beschriebenen Effekt der Natriumkanal-Blockade des Benzyl-Alkohols beruhen könnte.

\subsubsection{Einfluss von Amiodaron auf die Kraft-Frequenz-Beziehung}

Zur Bestimmung des Einflusses von Amiodaron auf die KFB wurde diese mit der Amiodaron-Konzentration von $10^{-4} \mathrm{M}$ und Steigerung der Stimulationsfrequenz von 0,5 bis 3,0 Hz durchgeführt. Die Konzentration wurde bewusst gewählt, da einige Studien zeigen konnten, dass die therapeutischen Plasmaspiegel von Amiodaron zwischen 1-2,5 $\mu \mathrm{g} / \mathrm{ml}$ liegen, was etwa $10^{-6} \mathrm{M}$ entspricht (Haffajee et al. 1983, Patterson et al. 1983). Unabhängig von der Applikationsart akkumuliert Amiodaron in etwa hundertfacher Konzentration des Plasmaspiegels im Myokard, so dass hier Konzentrationen von $10^{-4} \mathrm{M}$ erreicht werden (Latini et al. 1983). Diese Konzentration wird bei Bolusinjektion nach zehn bis zwanzig Minuten erreicht (Latini et al. 1983). Deshalb wurde auch in dieser Arbeit die Konzentration $10^{-4} \mathrm{M}$ verwendet und nach 30 Minuten Wartezeit das Frequenzprotokoll der KFB begonnen. Im Gegensatz zu den oben genannten klinischen in-vivo-Studien zur Hämodynamik muss davon ausgegangen werden, dass in der vorliegenden Versuchsanordnung nur akute Effekte von Amiodaron bestimmt werden konnten. Umgekehrt war die Wirkdauer des Lösungsmittels sicher nicht auf wenige Minuten beschränkt, weil im Organbad und Schlauchsystem der Versuchsanlage kein enzymatischer Abbau der Polysorbate stattfinden konnte.

Die KFB der unbehandelten Muskelstreifen zeigte den typischen Verlauf von terminal insuffizientem Herzmuskelgewebe. Die maximale Steigerung der Kontraktionskraft zeigte sich bei 2,0 Hz auf etwa $110 \%$ der Ausgangskraft und fiel damit etwas schlechter aus als bei den Kontroll-Trabekeln der Flecainid-Experimente. Ein möglicher Grund dafür könnte die durchschnittlich noch etwas höhere Ejektionsfraktion (EF) bei den Patienten sein, deren Herzen für die Flecainid Experimente verwendet wurden $(\mathrm{EF}=18 \%$ bei den Herzen der Amiodaron-Gruppe und $\mathrm{EF}=25 \%$ bei den Herzen der Flecainid-Gruppe).

Unter Amiodaron änderte sich der Verlauf der KFB nicht signifikant. Bis $1,5 \mathrm{~Hz}$ verlief sie ansteigend mit einer Zunahme der Kontraktionskraft auf etwa 110\% des Ausgangswertes. Die KFB unter Amiodaron unterschied sich qualitativ und quantitativ nicht von den Kontrollmuskeln. Die KFB der Lösungsmittelkontrollen dagegen verlief von Beginn an flach negativ. Die Kontraktionskraft sank auf minimal $90 \%$ des Ausgangswertes, unterschied sich statistisch aber auch nicht signifikant von der Kontroll- oder Amiodaron-Gruppe ( $p=0,103$ vs. Kontrolle; $\mathrm{p}=0,115$ vs. Amiodaron). Damit konnte in dieser Arbeit erstmals gezeigt 
werden, dass Amiodaron am terminal insuffizienten Myokard des Menschen keinen negativen Einfluss auf den Verlauf der KFB hat. Die Ergebnisse im Kaninchenmyokard sind weitgehend vergleichbar mit denen im Humanmyokard und unterstreichen, dass das Lösungsmittel, nicht jedoch Amiodaron selbst eine negative Wirkung auf die Myokardfunktion ausübt. Damit unterscheidet sich Amiodaron grundlegend von der Wirkung des Klassse-IC-Antiarrhythmikums Flecainid auf diesen wichtigen Kompensationsmechanismus des Myokards (KFB). Im Gegensatz dazu bewirkt das Lösungsmittelgemisch von Amiodaron die Umkehrung einer schwach positiven KFB in eine negative, ähnlich der oben diskutierten Wirkung von Flecainid. Als Ursache dafür kommt die Natriumkanal blockierende Wirkung des Benzyl-Alkohols (Eichbaum und Tasaka 1976, Yasaka et al. 1979) als Bestandteil des Lösungsmittelgemisches in Frage. Entsprechend der Wirkung von Flecainid könnte es dadurch zu einer sekundären Aktivierung des NatriumKalzium-Austauschers kommen und dies zu einem transsarkolemmalen Kalziumverlust der Zelle führen.

Die diastolische Funtkion wurde durch Amiodaron im Gegensatz zu Fecainid nicht negativ beeinflusst, weder im insuffizienten menschlichen Myokard noch im gesunden Kaninchenmyokard. Jedoch hatte das Lösungsmittel alleine einen verschlechternden Effekt auf die diastolische Funktion mit deutlichem Anstieg der diastolischen Spannung bei hohen Frequenzen. Auch hier kommt als Ursache am ehesten der Benzyl-Alkohol als Bestandteil des Lösungsmittels in Frage, da sein Mechanismus dem des Flecainid verwandt ist. Beide Substanzen bewirken wie oben gezeigt eine deutliche diastolische Dysfunktion.

\subsection{Klinische Relevanz der Ergebnisse}

\subsubsection{Flecainid in der antiarrhythmischen Therapie bei Herzinsuffizienz}

Die vorliegende Arbeit zeigt bezügich der Wirkungen von Flecainid drei Befunde von klinischer Relevanz: Einen kalziumabhängigen negativ inotropen Effekt, eine Verschlechterung der Kraft-Frequenz-Beziehung und die Induktion einer diastolischen Dysfunktion durch Flecainid.

Eine negativ inotrope Wirkung eines Pharmakons, wie zum Beispiel Kalziumantagonisten, kann dessen Anwendbarkeit bei Herzinsuffizienz einschränken (Elkayam et al. 1990, DAVITII 1990, Goldstein et al. 1991, Gheorghiade et al. 1991, Cohn et al. 1997). Dies stellt jedoch grundsätzlich noch keine Kontraindikation dar, wie es die Verwendung von Betablockern bei 
Herzinsuffizienz unterstreicht (Lechat et al. 1998, MERIT-HF Study Group 1999, CIBIS-II Investigators and Committees 1999, Hjalmarson et al. 2000). Die zusätzliche Verschlechterung der Kraft-Frequenz-Beziehung legt jedoch nahe, dass es unter Flecainid bei Herzinsuffizienz leicht zu einer symptomatischen Verschlechterung und Einschränkung der Belastbarkeit kommen könnte (CAST-I 1989, Greene et al. 1992, Hoppe und Erdmann 2001). Die in dieser Arbeit charakterisierten Effekte von Flecainid könnten zudem eine Erklärung dafür sein, warum es bei der Kombinationstherapie von Flecainid mit Kalziumantagonisten zu einigen Todesfällen durch kardiogenen Schock gekommen ist (Forbes et al. 1988, Buss et al. 1992). Flecainid ist für die Anwendung bei Herzinsuffizienz aufgrund der CAST Studienergebnisse nicht mehr zugelassen (CAST-I 1989). Die erhöhte Mortalität von herzinsuffizienten Patienten, die mit Antiarrhythmika der Klasse I behandelt wurden, wurde dabei maßgebich auf die pro-arrhythmische Wirkung der Substanz zurückgeführt. Diese proarrhythmische Wirkung basiert auf einer durch Flecainid induzierten Verzögerung der Leitungsgeschwindigkeit in geschädigten Myokardarealen, wodurch Refraktärzeiten verkürzt werden, die Reentry-Mechanismen begünstigen und so zu Kammertachykardien bis zum Kammerflimmern führen können (Gülker 1989).

Seinen Stellenwert hat Flecainid als Anitarrhythmikum heutzutage noch bei Ausschluss einer strukturellen Herzerkrankung, etwa bei Patienten mit Hypertonie und Vorhofflimmern. Trotz des Fehlens struktureller Veränderungen weisen diese Patienten jedoch häufig eine diastolische Dysfunktion auf (Boriani et al. 1997, Capucci et al. 1999, Martinez-Marcos et al. 2000, Hennersdorf et al. 2001). Aufgrund des in dieser Arbeit nachgewiesenen Einflusses von Flecainid auf die diastolische Funktion erscheint es möglich, dass Flecanid bei vorbestehender diastolischer Dysfunktion zu einer Verschlechterung führt, die in eine symptomatische diastolische Herzinsuffizienz münden kann. Zum anderen könnte Flecainid auch bei asymptomatischem Verlauf, durch die diastolische Kalziumüberladung kalziumabhängige Signalwege (zum Beispiel Calcineurin) aktivieren, die zu trophischen Veränderungen führen (remodeling), welche langfristig die Struktur und Funktion des Myokards schädigen (Hasenfuss et al. 1992, Hasenfuss 1998). Die Indikationsgruppe für Flecainid in der Langzeittherapie könnte sich daher aufgrund der vorliegenden Ergebnisse noch weiter einengen.

\subsubsection{Amiodaron in der antiarrhythmischen Therapie bei Herzinsuffizienz}

Die Ergebnisse der vorliegenden Arbeit können die Verwendbarkeit von Amiodaron als Antiarrhythmikum der ersten Wahl bei Herzinsuffizienz bestätigen (Gosselink et al. 1992, 
Massie et al. 1996, Amiodarone trials-metaanalyses investigators 1997, Sim et al. 1997): Amiodaron wies keinen eigenen negativ inotropen Effekt auf und war neutral hinsichtlich der Kraft-Frequenz-Beziehung und der diastolischen Funktion.

Bei chronischer Applikation wird es dementsprechend hinsichtlich Blutdruck und Hämodynamik gut toleriert (Fricke et al. 1983). Nur nach Bolusinjektion sind massive Blutdruckabfälle beschrieben (Marcus et al. 1981). Solche finden sich bereits bei Verabreichung als Kurzinfusion nur mäßig und bei Dauerinfusion über 24 Stunden gar nicht mehr (Holt und Storey 1983, Installe et al. 1981). Wie in dieser Arbeit gezeigt, sind die negativ inotropen Effekte alleinig auf das Lösungsmittel zurückzuführen. Blutdruckabfälle nach Injektion können jedoch auch über eine Abnahme des peripheren Widerstandes zu Stande kommen, wozu unterschiedliche Befunde vorliegen: Während einige Arbeitsgruppen eine Zunahme des peripheren Gefäßwiderstandes unter Amiodaron zeigten (Pfisterer et al. 1985, Remme und van Hoogenhuyze 1990), fanden andere Gruppen eine Abnahme für einige Minuten und führten dies auf eine Histaminfreisetzung durch den Lösungsvermittler zurück (Platou und Refsum 1986, Munoz et al. 1988). Nach einiger Versuchszeit beschreiben alle Gruppen eine Zunahme des peripheren Gefäßwiderstandes für etwa eine Stunde. Diese Befunde unterstützen zusammen mit den Ergebnissen dieser Arbeit die Vorstellung, dass vor allem der Lösungsvermittler als Bestandteil der Injektionslösung verantwortlich für den initialen Blutdruckabfall nach Bolusinjektion ist. Insbesondere für die notfallmäßige Anwendung bei akuter Herzinsuffizienz, könnte man durch Verwendung eines Lösungsmittels, das bei Bolusgabe hämodynamisch besser toleriert wird, die Verträglichkeit verbessern. Lösungen auf der Basis des Sulfoalkyl-Ethers Cyclodextrin könnten hierfür geeignet sein und wurden kürzlich für den Gebrauch in Amiodaron-Injektionslösungen patentiert (Firma CyDex, Us Pat. 6869939).

Im Gegensatz zu Flecainid verschlechtert Amiodaron weder die Kraft-Frequenz-Beziehung noch die diastolische Funktion. Die Einsetzbarkeit von Amiodaron ist deshalb sowohl bei systolischer als auch diastolischer Herzinsuffizienz nicht eingeschränkt. Der Enthusiasmus über seine breite Einsetzbarkeit muß allerdings aufgrund des ebenso breiten Nebenwirkungsspektrums gedämpft werden. Dieses zeichnet sich durch vielseitige, häufige und teilweise schwerwiegende und irreversible (Lungenfibrose) Komplikationen aus (Prayer et al. 1989, Dean et al. 1986). Seine spezielle Pharmakokinetik macht Amiodaron in der Dauertherapie relativ schlecht steuerbar (Holt und Storey 1983). 


\section{Zusammenfassung}

Vorhofflimmern stellt die häufigste Form kardialer Arrhythmien dar und kommt insbesondere bei arterieller Hypertonie und bei kongestiver Herzinsuffizienz vor. Flecainid wird häufig bei Vorhofflimmern eingesetzt, gilt bei Patienten mit eingeschränkter linksventrikulärer Funktion jedoch als kontraindiziert. Im Gegensatz dazu hat Amiodaron bei diesen Patienten einen wichtigen Stellenwert. Die direkten Effekte von Flecainid und Amiodaron auf die systolische und diastolische Funktion am menschlichen Herzen und die Gründe für ihre differentielle Einsetzbarkeit bei der Herzinsuffizienz sind noch unzureichend bekannt. Diese Arbeit hat daher deren Effekte am isolierten menschlichen insuffizienten Myokard im Vergleich zu gesundem Kaninchenmyokard untersucht.

Flecainid vermittelt, wie die Ergebnisse dieser Arbeit zeigen, einen direkt kalziumabhängigen, negativ inotropen Effekt. Die Kraft-Frequenz-Beziehung (KFB), ein wichtiger physiologischer Anpassungsmechanismus, wird deutlich verschlechtert. Zusätzlich zeigt die vorliegende Arbeit erstmalig eine verschlechternde Wirkung von Flecainid auf die diastolische Funktion und eine durch Flecainid verursachte Relaxationsstörung sowohl am vorgeschädigten insuffizienten humanen Myokard, als auch am gesunden Kaninchenmyokard, die möglicherweise auf eine Hemmung der Kalziumpumpe SERCA zurückzuführen ist. Amiodaron vermittelt im Gegensatz zu Flecainid keinen eigenen negativ inotropen Effekt und verändert nicht die KFB. Negativ inotrope Wirkungen kommen nur durch das notwendige Lösungsmittel zustande. Die diastolische Funktion wird durch Amiodaron auch am insuffizienten Myokard nicht negativ beeinflusst.

Die Ergebnisse dieser Arbeit ergeben somit mechanistische Einblicke, die gut mit der erhöhten Mortalität unter Flecainid und der guten Verträglichkeit von Amiodaron bei Herzinsuffizienz vereinbar sind. Zudem zeigen sie die Notwendigkeit auf, die diastolische Funktion unter Flecainidtherapie regelmäßig zu überwachen und seine frequenzabhängigen negativen Effekte durch eine optimale Herzfrequenzkontrolle zu kompensieren. Für Amiodaron hingegen könnte die Verwendung eines Lösungsmittels mit geringeren hämodynamischen Nebenwirkungen seine intravenöse Anwendbarkeit bei dekompensierter Herzinsuffizienz erleichtern. 


\section{Tabellen}

\subsection{Flecainid und Amiodaron, KWK und Kalziumtransienten}

\subsubsection{Konzentrations-Wirkungs-Kurve für Flecainid}

$\mathrm{n}=10, *=\mathrm{p}<0,05$ vs. AGW (Ausgangswert)

Tabelle 1:

\begin{tabular}{|c|c|c|c|c|c|c|c|}
\hline Mittelwerte & AGW & $10^{-8} \mathrm{M}$ & $10^{-7} \mathrm{M}$ & $10^{-6} \mathrm{M}$ & $3 * 10^{-6} \mathrm{M}$ & $10^{-5} \mathrm{M}$ & $10^{-4} \mathrm{M}$ \\
\hline Kraft $\left[\mathrm{mN} / \mathrm{mm}^{2}\right]$ & 12,97 & 12,84 & 12,71 & 10,44 & 8,82 & $5,89 *$ & $2,69 *$ \\
\hline SEM & 1,88 & 1,84 & 1,77 & 1,63 & 1,27 & 1,15 & 0,78 \\
\hline Kraft in \% & 100,00 & 99,07 & 98,63 & $81,65 *$ & $70,48 *$ & $47,83 *$ & $22,72 *$ \\
\hline SEM & 0,00 & 0,92 & 1,10 & 4,33 & 4,41 & 6,71 & 6,74 \\
\hline Diast. $\left[\mathrm{mN} / \mathrm{mm}^{2}\right]$ & 4,42 & 4,45 & 4,55 & 4,55 & 4,70 & 4,87 & 5,89 \\
\hline SEM & 1,22 & 1,23 & 1,27 & 1,30 & 1,50 & 1,54 & 1,82 \\
\hline Diast. In \% & 100,00 & 100,15 & 101,81 & 101.81 & 106,40 & 110,99 & $133,40 *$ \\
\hline SEM & 0,00 & 6,68 & 9,10 & 7,64 & 6,81 & 9,20 & 16,41 \\
\hline RT $50 \%[\mathrm{~ms}]$ & 142,90 & 145,50 & 146,80 & 144,30 & 145,00 & 139,00 & 148,90 \\
\hline SEM & 5,15 & 5,08 & 6,32 & 6,75 & 6,88 & 6,44 & 9,31 \\
\hline RT $90 \%[\mathrm{~ms}]$ & 308,60 & 294,00 & 300,80 & 315,50 & 336,40 & $377,00 *$ & $447,40 *$ \\
\hline SEM & 20,59 & 11,05 & 12,07 & 16,87 & 18,09 & 23,81 & 28,52 \\
\hline TPT [ms] & 207,40 & 211,00 & 216,20 & 211,40 & 208,30 & 201,20 & 212,30 \\
\hline SEM & 7,67 & 6,95 & 7,14 & 7,72 & 7,62 & 8,60 & 9,71 \\
\hline pos. $\mathbf{d F} / \mathbf{d t}_{\max }$ & 97,26 & 97,95 & 96,29 & 78,43 & $66,72 *$ & $43,50 *$ & $29,10 *$ \\
\hline SEM & 12,90 & 12,31 & 12,10 & 9,65 & 7,17 & 5,58 & 3,65 \\
\hline neg.dF/dt max $_{\text {max }}$ & $-57,41$ & $-57,58$ & $-56,24$ & $-45,32$ & $-36,90 *$ & $-25,43 *$ & $-16,74 *$ \\
\hline SEM & 7,60 & 7,06 & 6,89 & 5,74 & 3,89 & 3,28 & 2,15 \\
\hline pos. $\mathbf{d F} / \mathbf{d t}_{\max }[\%]$ & 100,00 & 101,87 & 100,21 & $83,26 *$ & $72,31 *$ & $49,55 *$ & $34,83 *$ \\
\hline SEM & 0,00 & 1,64 & 2,03 & 3,82 & 4,06 & 6,12 & 5,48 \\
\hline neg.dF/dt $\max _{\text {ax }}[\%]$ & 100,00 & 102,97 & 100,76 & $81,50 *$ & $69,10 *$ & $48,89 *$ & $34,95 *$ \\
\hline SEM & 0,00 & 3,30 & 3,85 & 3,66 & 5,09 & 6,28 & 6,70 \\
\hline
\end{tabular}




\subsubsection{Intrazelluläre Kalziumtransienten für Flecainid}

$\mathrm{n}=10, *=\mathrm{p}<0,05$ vs. AGW

Tabelle 2:

\begin{tabular}{|c|c|c|}
\hline Mittelwerte & AGW & Flec. \\
\hline Kraft [mN/mm²] & 23,09 & $16,29 *$ \\
\hline SEM & 3,12 & 3,68 \\
\hline Kraft in \% & 100,00 & $65,74 *$ \\
\hline SEM & 0,00 & 7,63 \\
\hline Diast. [mN/mm²] & 10,84 & 11,19 \\
\hline SEM & 3,06 & 2,63 \\
\hline Diast. In \% & 100,00 & 105,92 \\
\hline SEM & 0,00 & 3,56 \\
\hline RT 50 \% [ms] & 131,25 & 131,50 \\
\hline SEM & 7,92 & 5,39 \\
\hline RT 90 \% [ms] & 271,25 & 290,50 \\
\hline SEM & 9,48 & 9,83 \\
\hline TPT [ms] & 276,50 & 267,50 \\
\hline SEM & 11,70 & 12,81 \\
\hline pos. dF/dt & 224,64 & 205,03 \\
\hline SEM & 7,35 & 7,41 \\
\hline neg.dF/dt & $-98,11$ & $-74,21$ \\
\hline SEM & 15,19 & 16,39 \\
\hline
\end{tabular}

\begin{tabular}{|c|c|c|}
\hline Mittelwerte & AGW & Flec. \\
\hline Aequorin [mV] & 0,329 & $0,204 *$ \\
\hline SEM & 0,08 & 0,05 \\
\hline Aequorin [\%] & 100,00 & $67,55 *$ \\
\hline SEM & 0,00 & 7,17 \\
\hline TPT [ms] & 48,80 & 46,40 \\
\hline SEM & 2,81 & 2,85 \\
\hline RL 50 \% [ms] & 106,80 & 75,80 \\
\hline SEM & 12,30 & 9,11 \\
\hline RL 90 \% [ms] & 171,60 & 128,60 \\
\hline SEM & 24,01 & 13,20 \\
\hline
\end{tabular}




\subsubsection{Konzentrations-Wirkungs-Kurve für Amiodaron}

$\mathrm{n}=5, *=\mathrm{p}<0,05$ vs. AGW

Tabelle 3:

\begin{tabular}{|c|c|c|c|c|c|c|c|}
\hline Mittelwerte & AGW & $10^{-8} \mathrm{M}$ & $10^{-7} \mathrm{M}$ & $10^{-6} \mathrm{M}$ & $10^{-5} \mathrm{M}$ & $10^{-4} \mathrm{M}$ & $10^{-3} \mathrm{M}$ \\
\hline Kraft $\left[\mathrm{mN} / \mathrm{mm}^{2}\right]$ & 17,98 & 17,65 & 17,27 & 16,78 & 15,18 & $13,01 *$ & $7,45 *$ \\
\hline SEM & 3,52 & 3,40 & 3,27 & 3,27 & 2,92 & 2,59 & 2,15 \\
\hline Kraft in \% & 100,00 & 98,35 & 96,27 & 93,09 & 83,92 & $71,81 *$ & $43,95 *$ \\
\hline SEM & 0,00 & 1,46 & 1,87 & 2,64 & 5,42 & 5,16 & 10,23 \\
\hline Diast. $\left[\mathrm{mN} / \mathrm{mm}^{2}\right]$ & 5,36 & 5,31 & 5,22 & 5,09 & 4,73 & 4,27 & 1,77 \\
\hline SEM & 2,58 & 2,57 & 2,58 & 2,51 & 2,35 & 2,08 & 0,88 \\
\hline Diast. In \% & 100,00 & 98,38 & $95,15 *$ & $92,52 *$ & $84,04 *$ & $76,23 *$ & $52,63 *$ \\
\hline SEM & 0,00 & 0,66 & 1,95 & 2,01 & 5,18 & 5,58 & 8,44 \\
\hline RT $50 \%[\mathrm{~ms}]$ & 163,80 & 165,40 & 163,80 & 162,80 & 153,00 & 156,60 & 142,85 \\
\hline SEM & 29,13 & 28,69 & 28,60 & 28,87 & 22,64 & 27,00 & 23,64 \\
\hline RT $90 \%[\mathrm{~ms}]$ & 376,60 & 375,80 & 373,00 & 368,60 & 352,40 & 351,60 & 348,44 \\
\hline SEM & 81,55 & 81,76 & 82,35 & 83,37 & 82,33 & 80,75 & 78,41 \\
\hline TPT [ms] & 202,40 & 210,00 & 212,20 & 214,40 & 209,30 & 202,20 & 209,30 \\
\hline SEM & 7,35 & 6,85 & 6,88 & 7,67 & 7,71 & 8,20 & 8,91 \\
\hline pos. $\mathbf{d F} / \mathbf{d t}_{\max }$ & 131,77 & 130,69 & 128,68 & 125,74 & 118,37 & 104,53 & 59,96 \\
\hline SEM & 32,18 & 32,96 & 31,52 & 32,79 & 31,06 & 26,71 & 15,74 \\
\hline neg.dF/dt $\max$ & 131,77 & 130,69 & 128,68 & 125,74 & 118,37 & 104,53 & 59,96 \\
\hline SEM & 32,18 & 32,96 & 31,52 & 32,79 & 31,06 & 26,71 & 15,74 \\
\hline pos. $\mathbf{d F} \mathbf{d t}_{\max }[\%]$ & 100 & 98,21 & 98,37 & 94,31 & 90,67 & $80,04 *$ & $57,93 *$ \\
\hline SEM & 0,00 & 2,23 & 3,03 & 3,27 & 6,18 & 4,93 & 11,01 \\
\hline neg.dF/dt $\max [\%]$ & 100 & 100,03 & 98,85 & 96,32 & 91,98 & $77,54 *$ & $50,79 *$ \\
\hline SEM & 0 & 1,12 & 2,84 & 3,29 & 8,56 & 7,87 & 16,03 \\
\hline
\end{tabular}




\subsubsection{Konzentrations-Wirkungs-Kurve für das Lösungsmittel (Amiodaron)}

$\mathrm{n}=5, *=\mathrm{p}<0,05$ vs. AGW

Tabelle 4:

\begin{tabular}{|c|c|c|c|c|c|c|c|}
\hline Mittelwerte & AGW & $10^{-8} \mathrm{M}$ & $10^{-7} \mathrm{M}$ & $10^{-6} \mathrm{M}$ & $10^{-5} \mathrm{M}$ & $10^{-4} M$ & $10^{-3} \mathrm{M}$ \\
\hline Kraft $\left[\mathrm{mN} / \mathrm{mm}^{2}\right]$ & 16,75 & 16,32 & 16,07 & 16,09 & 13,93 & 12,28 & 6,35 \\
\hline SEM & 3,85 & 3,72 & 3,81 & 3,85 & 3,41 & 3,17 & 1,80 \\
\hline Kraft in \% & 100,00 & 97,08 & 94,36 & 94,46 & 81,24 & $70,62 *$ & $42,84 *$ \\
\hline SEM & 0,00 & 1,17 & 3,04 & 4,12 & 4,08 & 5,05 & 5,98 \\
\hline Diast. $\left[\mathrm{mN} / \mathrm{mm}^{2}\right]$ & 4,75 & 4,53 & 4,21 & 4,11 & 3,60 & 3,26 & 2,96 \\
\hline SEM & 1,47 & 1,40 & 1,23 & 1,15 & 1,06 & 1,09 & 1,04 \\
\hline Diast. In \% & 100,00 & $95,24 *$ & $91,08 *$ & $90,80 *$ & $78,05 *$ & $67,56 *$ & $49,62 *$ \\
\hline SEM & 0,00 & 0,72 & 2,09 & 3,63 & 3,47 & 6,52 & 9,00 \\
\hline RT $50 \%$ [ms] & 207,00 & 208,80 & 207,80 & 207,00 & 198,00 & 188,60 & 197,60 \\
\hline SEM & 46,17 & 46,53 & 46,88 & 46,62 & 44,53 & 43,24 & 46,08 \\
\hline RT $90 \%$ [ms] & 464,40 & 464,20 & 462,40 & 456,00 & 445,80 & 439,80 & 516,15 \\
\hline SEM & 90,68 & 90,14 & 90,63 & 92,83 & 96,23 & 99,40 & 91,44 \\
\hline TPT [ms] & 232,40 & 240,00 & 232,20 & 234,40 & 229,30 & 232,20 & 229,30 \\
\hline SEM & 7,65 & 7,25 & 6,728 & 6,97 & 8,01 & 8,43 & 7,98 \\
\hline pos. $\mathbf{d F} / \mathbf{d t}_{\max }$ & 32,27 & 32,01 & 33,20 & 33,90 & 32,19 & 15,86 & 12,94 \\
\hline SEM & 103,69 & 104,28 & 101,38 & 103,48 & 94,89 & 67,83 & 42,91 \\
\hline neg.dF/dt ${ }_{\max }$ & $-84,11$ & $-84,27$ & $-83,34$ & $-86,44$ & $-73,73$ & $-49,12$ & $-28,66$ \\
\hline SEM & 32,81 & 32,87 & 34,40 & 37,19 & 30,84 & 14,29 & 8,90 \\
\hline 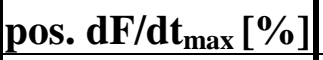 & 100,00 & 101,01 & 96,23 & 98,37 & 89,92 & $71,12 *$ & $56,76 *$ \\
\hline SEM & 0,00 & 1,11 & 3,89 & 4,24 & 5,07 & 7,69 & 8,74 \\
\hline neg.dF/dt $\max [\%]$ & 100,00 & 100,02 & 96,83 & 98,22 & 84,56 & $67,19 *$ & $53,09 *$ \\
\hline SEM & 0,00 & 1,15 & 4,08 & 5,77 & 5,35 & 8,63 & 4,47 \\
\hline
\end{tabular}




\subsection{Kraft-Frequenz-Beziehung, Antiarrhythmika (humanes Myokard)}

\subsubsection{Flecainid}

\section{Kontroll - Gruppe}

$\mathrm{n}=16$, Querschnittsfläche $=0,17 \pm 0,03 \mathrm{~mm}^{2}, *=\mathrm{p}<0,05$ vs. $0,5 \mathrm{~Hz}$

Tabelle 5:

$\#=\mathrm{p}<0,05$ vs. Flecainid

\begin{tabular}{|c|c|c|c|c|c|c|}
\hline Mittelwerte & $0.5 \mathrm{~Hz}$ & $1.0 \mathrm{~Hz}$ & $1.5 \mathrm{~Hz}$ & $2.0 \mathrm{~Hz}$ & $2.5 \mathrm{~Hz}$ & $3.0 \mathrm{~Hz}$ \\
\hline Kraft $\left[\mathrm{mN} / \mathrm{mm}^{2}\right]$ & 7,10 & 8,60 & 9,50 & 9,98 & 10,03 & $9,96 \#$ \\
\hline SEM & 0,94 & 1,32 & 1,42 & 1,52 & 1,56 & 1,63 \\
\hline Kraft in \% & 100,00 & $120,13 * \#$ & $133,53 * \#$ & $140,74 * \#$ & $141,80 * \#$ & $140,52 * \#$ \\
\hline SEM & 0,00 & 6,96 & 9,12 & 11,82 & 13,43 & 14,91 \\
\hline Diast. $\left[\mathrm{mN} / \mathbf{m m}^{2}\right]$ & 1,05 & 1,08 & 1,10 & $1,14 \#$ & $1,20 \#$ & $1,31 \#$ \\
\hline SEM & 0,12 & 0,12 & 0,14 & 0,13 & 0,14 & 0,13 \\
\hline Diast. In \% & 100,00 & 106,41 & 106,07 & 112,33 & $117,16 \#$ & $135,64 * \#$ \\
\hline SEM & 0,00 & 3,54 & 5,42 & 6,86 & 8,82 & 10,35 \\
\hline RT $50 \%[\mathrm{~ms}]$ & 136,81 & 131,25 & $122,81 *$ & $117,56 *$ & $112,38 *$ & $107,94 *$ \\
\hline SEM & 4,58 & 3,96 & 3,25 & 2,90 & 3,08 & 2,77 \\
\hline RT $90 \%[\mathrm{~ms}]$ & 286,31 & 280,19 & 263,06 & $230,50 *$ & $217,63 *$ & $209,31 *$ \\
\hline SEM & 10,07 & 12,31 & 11,71 & 9,57 & 6,05 & 6,16 \\
\hline TPT [ms] & 204,00 & 189,31 & 177,69 & 181,31 & 189,94 & 197,13 \\
\hline SEM & 9,22 & 8,00 & 7,18 & 10,26 & 12,95 & 12,09 \\
\hline pos. $\mathbf{d F} / \mathbf{d t}_{\max }$ & 57,14 & 74,70 & $89,70 *$ & $100,91 *$ & $106,43 *$ & $112,03 *$ \\
\hline SEM & 7,01 & 10,79 & 13,04 & 15,29 & 16,50 & 17,93 \\
\hline neg.dF/dt ${ }_{\max }$ & $-36,33$ & $-48,07$ & $-55,23$ & $-61,80 *$ & $-65,29 *$ & $-69,10 *$ \\
\hline SEM & 4,54 & 6,82 & 7,96 & 8,85 & 9,30 & 10,28 \\
\hline pos. $\mathbf{d F} / \mathbf{d t}_{\max }[\%]$ & 100,00 & $128,80 * \#$ & $154,54 * \#$ & $174,13 * \#$ & $182,99 * \#$ & $191,95 * \#$ \\
\hline SEM & 0,00 & 6,37 & 8,86 & 11,90 & 13,37 & 15,32 \\
\hline neg.dF/dt ${ }_{\max }[\%]$ & 100,00 & $132,00 * \#$ & $152,67 * \#$ & $173,18 * \#$ & $183,85 * \#$ & $193,81 * \#$ \\
\hline SEM & 0,00 & 7,70 & 10,09 & 12,53 & 13,57 & 15,99 \\
\hline
\end{tabular}




\section{Flecainid - Gruppe}

$\mathrm{n}=19$, Querschnittsfläche $=0,19 \pm 0,03 \mathrm{~mm}^{2},{ }^{*}=\mathrm{p}<0,05$ vs. $0,5 \mathrm{~Hz}$

Tabelle 6:

\begin{tabular}{|c|c|c|c|c|c|c|}
\hline Mittelwerte & $0.5 \mathrm{~Hz}$ & $1.0 \mathrm{~Hz}$ & $1.5 \mathrm{~Hz}$ & $2.0 \mathrm{~Hz}$ & $2.5 \mathrm{~Hz}$ & $3.0 \mathrm{~Hz}$ \\
\hline Kraft $\left[\mathrm{mN} / \mathrm{mm}^{2}\right]$ & 9,08 & 8,28 & 7,65 & 7,21 & 6,74 & 6,07 \\
\hline SEM & 1,56 & 1,29 & 1,12 & 1,06 & 1,05 & 1,06 \\
\hline Kraft in \% & 100,00 & 95,03 & 94,18 & 94,31 & 93,64 & 88,40 \\
\hline SEM & 0,00 & 3,44 & 5,42 & 7,04 & 8,72 & 10,24 \\
\hline Diast. $\left[\mathrm{mN} / \mathrm{mm}^{2}\right]$ & 1,48 & 1,54 & 1,74 & 1,95 & 2,21 & $2,48 *$ \\
\hline SEM & 0,20 & 0,20 & 0,28 & 0,32 & 0,34 & 0,38 \\
\hline Diast. In \% & 100,00 & $107,62 *$ & $120,84 *$ & $137,77 *$ & $161,53 *$ & $186,90 *$ \\
\hline SEM & 0,00 & 3,20 & 6,38 & 9,66 & 17,46 & 25,77 \\
\hline RT $50 \%$ [ms] & 142,32 & 130,11 & $122,16 *$ & $115,95 *$ & $109,53 *$ & $105,89 *$ \\
\hline SEM & 6,92 & 5,91 & 6,05 & 5,03 & 4,60 & 4,12 \\
\hline RT $90 \%[\mathrm{~ms}]$ & 308,37 & 284,37 & $260,79 *$ & $240,53 *$ & $223,37 *$ & $213,26 *$ \\
\hline SEM & 10,98 & 8,29 & 6,30 & 4,83 & 4,48 & 3,96 \\
\hline TPT [ms] & 217,00 & 196,16 & 183,68 & $169,63 *$ & $168,84 *$ & $179,37 *$ \\
\hline SEM & 15,11 & 11,59 & 9,69 & 9,00 & 8,83 & 9,94 \\
\hline pos. $\mathrm{dF} / \mathrm{dt}_{\max }$ & 61,94 & 67,54 & 73,15 & 78,63 & 82,71 & 84,32 \\
\hline SEM & 9,55 & 10,08 & 10,77 & 11,35 & 12,11 & 12,43 \\
\hline neg.dF/dt max $_{\text {max }}$ & $-45,24$ & $-43,63$ & $-42,70$ & $-42,47$ & $-41,59$ & $-39,15$ \\
\hline SEM & 7,79 & 6,35 & 5,52 & 5,59 & 5,98 & 6,40 \\
\hline 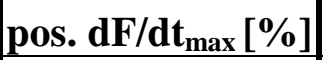 & 100,00 & 109,31 & $119,65 *$ & $130,39 *$ & $138,05 *$ & $142,69 *$ \\
\hline SEM & 0,00 & 3,51 & 4,54 & 5,63 & 7,14 & 8,39 \\
\hline neg.dF/dt $\max _{\max }[\%]$ & 100,00 & 102,30 & 110,57 & 115,64 & 118,28 & 117,03 \\
\hline SEM & 0,00 & 4,56 & 8,08 & 9,86 & 12,01 & 14,82 \\
\hline
\end{tabular}




\subsubsection{Amiodaron}

\section{Kontroll - Gruppe}

$\mathrm{n}=7$, Querschnittsfläche $=0,112 \pm 0,02 \mathrm{~mm}^{2}, *=\mathrm{p}<0,05$ vs. $0,5 \mathrm{~Hz}$,

Unterschiede zwischen den Gruppen n.s.

Tabelle 7:

\begin{tabular}{|c|c|c|c|c|c|c|}
\hline Mittelwerte & $0,5 \mathrm{~Hz}$ & $1,0 \mathrm{~Hz}$ & $1,5 \mathrm{~Hz}$ & $2,0 \mathrm{~Hz}$ & $2,5 \mathrm{~Hz}$ & $3,0 \mathrm{~Hz}$ \\
\hline Kraft $\left[\mathrm{mN} / \mathrm{mm}^{2}\right]$ & 12,93 & 13,77 & 13,94 & 14,25 & 13,75 & 13,24 \\
\hline SEM & 4,40 & 4,17 & 3,69 & 3,27 & 3,03 & 2,72 \\
\hline Kraft in \% & 100,00 & 106,13 & 107,73 & 110,28 & 106,11 & 102,10 \\
\hline SEM & 0,00 & 9,14 & 9,86 & 11,70 & 13,80 & 15,15 \\
\hline Diast. $\left[\mathrm{mN} / \mathrm{mm}^{2}\right]$ & 4,70 & 4,91 & 5,53 & 6,36 & 7,13 & 7,55 \\
\hline SEM & 2,04 & 2,12 & 2,35 & 2,65 & 2,86 & 2,92 \\
\hline Diast. In \% & 100,00 & 103,10 & 110,47 & 120,61 & $144,76 *$ & $167,25 *$ \\
\hline SEM & 0,00 & 3,47 & 7,32 & 7,40 & 14,72 & 24,75 \\
\hline RT $50 \%$ [ms] & 145,43 & 137,57 & 125,57 & 122,43 & $112,57 *$ & $107,43 *$ \\
\hline SEM & 9,26 & 8,78 & 6,61 & 6,81 & 5,41 & 5,29 \\
\hline RT $90 \%[\mathrm{~ms}]$ & 243,00 & 246,57 & 243,14 & 243,86 & 228,29 & 222,71 \\
\hline SEM & 20,45 & 19,82 & 15,30 & 18,60 & 13,31 & 18,04 \\
\hline TPT [ms] & 205,29 & 188,43 & 175,43 & $163,43 *$ & $159,71 *$ & $158,71 *$ \\
\hline SEM & 11,33 & 9,16 & 6,49 & 6,69 & 6,21 & 5,36 \\
\hline pos. $\mathrm{dF} / \mathrm{dt}_{\max }$ & 122,18 & 140,86 & 150,48 & 155,63 & 156,53 & 160,46 \\
\hline SEM & 27,26 & 28,38 & 27,59 & 24,86 & 24,88 & 21,93 \\
\hline neg.dF/dt max $_{\text {ax }}$ & $-89,41$ & $-88,71$ & $-87,09$ & $-86,75$ & $-88,40$ & $-91,83$ \\
\hline SEM & 23,10 & 18,70 & 15,84 & 13,78 & 12,03 & 10,32 \\
\hline 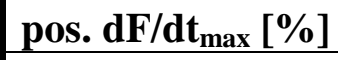 & 100,00 & $123,82 *$ & $142,65 *$ & 159,56 & 172,51 & 180,96 \\
\hline SEM & 0,00 & 8,39 & 18,04 & 27,98 & 40,39 & 41,67 \\
\hline neg.dF/dt $\max _{\max }[\%]$ & 100,00 & 119,74 & 134,28 & 154,94 & 177,81 & 194,95 \\
\hline SEM & 0,00 & 14,71 & 25,92 & 42,25 & 56,74 & 63,64 \\
\hline
\end{tabular}




\section{Amiodaron - Gruppe}

$\mathrm{n}=7$, Querschnittsfläche $=0,118 \pm 0,01 \mathrm{~mm}^{2},{ }^{*}=\mathrm{p}<0,05$ vs. $0,5 \mathrm{~Hz}$.

Tabelle 8:

\begin{tabular}{|c|c|c|c|c|c|c|}
\hline Mittelwerte & $0,5 \mathrm{~Hz}$ & $1,0 \mathrm{~Hz}$ & $1,5 \mathrm{~Hz}$ & $2,0 \mathrm{~Hz}$ & $2,5 \mathrm{~Hz}$ & $3,0 \mathrm{~Hz}$ \\
\hline Kraft [mN/mm²] & 8,54 & 9,99 & 10,09 & 9,97 & 9,91 & 9,65 \\
\hline SEM & 1,38 & 2,13 & 2,17 & 2,18 & 2,25 & 2,29 \\
\hline Kraft in \% & 100,00 & 110,13 & 110,28 & 107,73 & 106,11 & 102,10 \\
\hline SEM & 0,00 & 9,14 & 9,86 & 11,70 & 13,80 & 15,15 \\
\hline Diast. $\left[\mathbf{m N} / \mathbf{m m}^{2}\right]$ & 5,58 & 5,80 & 5,92 & 6,08 & 6,18 & 6,19 \\
\hline SEM & 1,17 & 1,13 & 1,11 & 1,14 & 1,14 & 1,09 \\
\hline Diast. In \% & 100,00 & 101,07 & 100,78 & 101,45 & 103,07 & 105,07 \\
\hline SEM & 0,00 & 0,33 & 1,21 & 2,16 & 1,74 & 1,83 \\
\hline RT $50 \%$ [ms] & 137,86 & 132,57 & 125,86 & $114,14 *$ & $110,14 *$ & $108,43 *$ \\
\hline SEM & 5,71 & 6,84 & 6,54 & 5,57 & 2,67 & 4,06 \\
\hline RT $90 \%[\mathrm{~ms}]$ & 233,14 & 231,43 & 230,00 & 216,86 & 211,57 & 214,43 \\
\hline SEM & 15,48 & 12,08 & 12,55 & 9,22 & 10,51 & 13,77 \\
\hline TPT [ms] & 206,14 & 189,71 & 177,71 & 172,14 & $162,71 *$ & $162,57 *$ \\
\hline SEM & 12,40 & 11,07 & 11,14 & 9,56 & 10,15 & 11,94 \\
\hline pos. $\mathbf{d F} / \mathbf{d t}_{\max }$ & 103,33 & 116,50 & 121,16 & 123,52 & 126,90 & 126,24 \\
\hline SEM & 21,81 & 15,72 & 15,23 & 15,90 & 16,95 & 19,76 \\
\hline neg.dF/dt $\max$ & $-71,75$ & $-75,16$ & $-79,01$ & $-82,81$ & $-85,01$ & $-85,42$ \\
\hline SEM & 17,38 & 10,32 & 10,70 & 10,93 & 11,09 & 12,04 \\
\hline 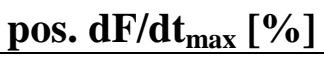 & 100,00 & $121,91 *$ & $129,40 *$ & 133,34 & 137,24 & 136,66 \\
\hline SEM & 0,00 & 9,11 & 12,14 & 14,82 & 16,88 & 20,61 \\
\hline neg.dF/dt $\max [\%]$ & 100,00 & 120,52 & 127,89 & 135,96 & 140,79 & 142,39 \\
\hline SEM & 0,00 & 11,88 & 13,38 & 16,34 & 18,86 & 22,32 \\
\hline
\end{tabular}




\section{Lösungsmittel - Gruppe}

$\mathrm{n}=7$, Querschnittsfläche $=0,114 \pm 0,02 \mathrm{~mm}^{2},{ }^{*}=\mathrm{p}<0,05$ vs. $0,5 \mathrm{~Hz}$.

Tabelle 9:

\begin{tabular}{|c|c|c|c|c|c|c|}
\hline Mittelwerte & $0,5 \mathrm{~Hz}$ & $1,0 \mathrm{~Hz}$ & $1,5 \mathrm{~Hz}$ & $2,0 \mathrm{~Hz}$ & $2,5 \mathrm{~Hz}$ & $3,0 \mathrm{~Hz}$ \\
\hline Kraft $\left[\mathbf{m N} / \mathbf{m m}^{2}\right]$ & 9,36 & 7,51 & 6,49 & 6,43 & 6,62 & 6,73 \\
\hline SEM & 2,45 & 1,49 & 1,32 & 1,48 & 1,48 & 1,53 \\
\hline Kraft in \% & 100,00 & 95,12 & 90,81 & 90,53 & 90,09 & 89,83 \\
\hline SEM & 0,00 & 15,08 & 19,30 & 20,52 & 20,18 & 20,34 \\
\hline Diast. $\left[\mathrm{mN} / \mathbf{m m}^{2}\right]$ & 3,78 & 4,33 & 5,04 & 5,38 & 5,58 & 5,59 \\
\hline SEM & 0,91 & 0,92 & 1,13 & 1,31 & 1,50 & 1,63 \\
\hline Diast. In \% & 100,00 & 124,00 & 138,60 & $154,70 *$ & $161,30 *$ & $183,70 *$ \\
\hline SEM & 0,00 & 2,43 & 4,50 & 5,41 & 9,83 & 12,15 \\
\hline RT $50 \%[\mathrm{~ms}]$ & 129,86 & 129,14 & $111,43 *$ & $113,43 *$ & $108,00 *$ & $110,14 *$ \\
\hline SEM & 3,60 & 6,63 & 2,81 & 5,96 & 4,61 & 6,77 \\
\hline RT $90 \%[\mathrm{~ms}]$ & 258,71 & 267,00 & 265,14 & 260,29 & 249,14 & 246,43 \\
\hline SEM & 12,67 & 12,62 & 15,63 & 19,21 & 19,57 & 22,28 \\
\hline TPT [ms] & 184,00 & 160,29 & 152,71 & $145,43 *$ & $145,00 *$ & $138,14 *$ \\
\hline SEM & 13,86 & 10,04 & 8,35 & 8,49 & 8,26 & 7,46 \\
\hline pos. $\mathbf{d F} / \mathbf{d t}_{\max }$ & 128,16 & 109,18 & 102,20 & 98,87 & 104,50 & 103,57 \\
\hline SEM & 36,50 & 25,44 & 22,25 & 20,47 & 18,23 & 16,87 \\
\hline neg.dF/dt ${ }_{\max }$ & $-78,60$ & $-58,93$ & $-52,25$ & $-49,06$ & $-51,30$ & $-51,66$ \\
\hline SEM & 20,76 & 10,19 & 8,83 & 8,84 & 8,87 & 10,12 \\
\hline pos. $\mathbf{d F} / \mathbf{d t}_{\max }[\%]$ & 100,00 & 101,61 & 104,18 & 106,02 & 112,12 & 113,93 \\
\hline SEM & 0,00 & 15,33 & 19,64 & 22,46 & 22,13 & 23,30 \\
\hline neg.dF/dt $\max _{\text {max }}[\%]$ & 100,00 & 85,62 & 85,23 & 85,63 & 92,44 & 95,66 \\
\hline SEM & 0,00 & 9,85 & 16,24 & 18,38 & 19,33 & 21,34 \\
\hline
\end{tabular}


6.3. Kraft-Frequenz-Beziehung, Antiarrhythmika (KaninchenMyokard)

\subsubsection{Flecainid}

Kontroll-Gruppe, $\mathrm{n}=6$, Querschnittsfläche $=0,12 \pm 0,03 \mathrm{~mm}^{2}, *=\mathrm{p}<0,05$ vs. $1,0 \mathrm{~Hz}$

Tabelle 13:

\begin{tabular}{|c|c|c|c|c|c|}
\hline Mittelwerte & $1 \mathrm{~Hz}$ & $2 \mathrm{~Hz}$ & $3 \mathbf{H z}$ & $4 \mathrm{~Hz}$ & $5 \mathrm{~Hz}$ \\
\hline Kraft $\left[\mathrm{mN} / \mathbf{m m}^{2}\right]$ & 3,7 & 7,8 & $10,4 *$ & $11,0 *$ & $10,1 *$ \\
\hline SEM & 1,2 & 2,6 & 4,3 & 3,8 & 3,4 \\
\hline Kraft in \% & 100 & $214,2 *$ & $306,7 *$ & $312,8 *$ & $289,5 *$ \\
\hline SEM & 0 & 14,0 & 17,1 & 19,2 & 25,0 \\
\hline Diast. $\left[\mathrm{mN} / \mathbf{m m}^{2}\right]$ & 2,6 & 2,6 & 2,4 & 2,3 & 2,2 \\
\hline SEM & 0,4 & 0,5 & 0,5 & 0,5 & 0,5 \\
\hline Diast. In \% & 100 & 98,1 & 94,4 & 89,3 & 83,8 \\
\hline SEM & 0 & 3,2 & 6,3 & 8,2 & 11,0 \\
\hline RT $50 \%[\mathrm{~ms}]$ & 54,2 & 47,7 & 49,2 & 47,7 & 52,0 \\
\hline SEM & 3,9 & 8,2 & 9,1 & 8,2 & 5,0 \\
\hline RT $90 \%[\mathrm{~ms}]$ & 123,6 & 124,2 & 114,9 & 106,8 & 95,7 \\
\hline SEM & 10,9 & 10,5 & 7,9 & 6,3 & 6,0 \\
\hline TPT $[\mathrm{ms}]$ & 101,1 & 102,2 & 103,6 & 95,5 & 92,8 \\
\hline SEM & 3,1 & 2,8 & 3,4 & 3,1 & 3,1 \\
\hline pos. $\mathbf{d F} / \mathbf{d t}_{\max }$ & 57,1 & 82,6 & 112,8 & 119,1 & 117,3 \\
\hline SEM & 22,6 & 33,0 & 45,6 & 49,2 & 49,2 \\
\hline neg.dF/dt ${ }_{\max }$ & $-83,8$ & $-131,1$ & $-157,1$ & $-177,0$ & $-183,1$ \\
\hline SEM & 21,9 & 23,3 & 24,3 & 25,7 & 27,3 \\
\hline pos. $\mathbf{d F} / \mathbf{d t}_{\max }[\%]$ & 100 & 153,2 & $205,1 *$ & $223,6 *$ & $201,2 *$ \\
\hline SEM & 0 & 14,6 & 22,9 & 21,5 & 28,1 \\
\hline neg.dF/dt $\max [\%]$ & 100 & 182,1 & $240,6 *$ & $248,6 *$ & $253,3 *$ \\
\hline SEM & 0 & 21,1 & 34,4 & 41,8 & 20,2 \\
\hline
\end{tabular}


Flecainid-Gruppe, $\mathrm{n}=6$, Querschnittsfläche $=0,13 \pm 0,03 \mathrm{~mm}^{2}, *=\mathrm{p}<0,05 \mathrm{vs.} 1,0 \mathrm{~Hz}$

Tabelle 14:

\begin{tabular}{|c|c|c|c|c|c|}
\hline Mittelwerte & $1 \mathrm{~Hz}$ & $2 \mathrm{~Hz}$ & $3 \mathbf{H z}$ & $4 \mathrm{~Hz}$ & $5 \mathrm{~Hz}$ \\
\hline Kraft $\left[\mathrm{mN} / \mathrm{mm}^{2}\right]$ & 10,5 & 18,5 & $22,9 *$ & 20,6 & 16,8 \\
\hline SEM & 4,8 & 6,5 & 6,6 & 6,4 & 5,8 \\
\hline Kraft in \% & 100 & $196,6 *$ & $235,6 *$ & $207,6 *$ & $179,2 *$ \\
\hline SEM & 0 & 23,7 & 20,8 & 22,0 & 18,6 \\
\hline Diast. $\left[\mathrm{mN} / \mathrm{mm}^{2}\right]$ & 3,8 & 4,1 & 4,9 & 5,3 & $5,8 *$ \\
\hline SEM & 0,9 & 0,8 & 0,8 & 0,6 & 0,7 \\
\hline Diast. In \% & 100 & 109,9 & 117,8 & 127,2 & 152,7 * \\
\hline SEM & 0 & 14,7 & 12,4 & 16,8 & 12,4 \\
\hline RT $50 \%[\mathrm{~ms}]$ & 55,2 & 57,5 & 58,2 & 57,7 & 52,4 \\
\hline SEM & 3,9 & 7,2 & 6,1 & 7,2 & 5,4 \\
\hline RT $90 \%[\mathrm{~ms}]$ & 113,6 & 114,4 & 117,2 & 103,2 & 96,2 \\
\hline SEM & 9,9 & 9,5 & 7,8 & 6,3 & 6,2 \\
\hline TPT [ms] & 102,1 & 103,3 & 103,5 & 92,7 & 93,4 \\
\hline SEM & 3,2 & 2,9 & 3,7 & 3,4 & 3,1 \\
\hline pos. $\mathbf{d F} / \mathbf{d t}_{\max }$ & 145,5 & 241,1 & 284,1 & 288,3 & 278,8 \\
\hline SEM & 30,2 & 30,0 & 27,3 & 36,2 & 31,7 \\
\hline neg.dF/dt ${ }_{\max }$ & $-121,3$ & $-207,3$ & $-227,8$ & $-216,2$ & $-195,3$ \\
\hline SEM & 30,3 & 34,1 & 34,4 & 34,0 & 30,6 \\
\hline pos. $\mathbf{d F} / \mathbf{d t}_{\max }[\%]$ & 100 & $190,0 *$ & $224,4 *$ & $216,1 *$ & $201,7 *$ \\
\hline SEM & 0 & 23,6 & 20,4 & 16,1 & 10,1 \\
\hline neg.dF/dt $t_{\max }[\%]$ & 100 & $193,0 *$ & $232,4 *$ & $247,2 *$ & 251,3 * \\
\hline SEM & 0 & 19,3 & 24,0 & 22,2 & 24,1 \\
\hline
\end{tabular}




\subsubsection{Amiodaron}

Kontroll-Gruppe, $\mathrm{n}=8$, Querschnittsfläche $=0,14 \pm 0,03 \mathrm{~mm}^{2}, *=\mathrm{p}<0,05 \mathrm{vs} .1,0 \mathrm{~Hz}$

Tabelle 10: $\quad$ Unterschiede zwischen den Gruppen n.s.

\begin{tabular}{|c|c|c|c|c|c|}
\hline Mittelwerte & $1 \mathrm{~Hz}$ & $2 \mathrm{~Hz}$ & $3 \mathbf{H z}$ & $4 \mathrm{~Hz}$ & $5 \mathrm{~Hz}$ \\
\hline Kraft $\left[\mathrm{mN} / \mathbf{m m}^{2}\right]$ & 5,3 & $9,8^{*}$ & $14,2^{*}$ & $16,1 *$ & $17,4^{*}$ \\
\hline SEM & 1,9 & 3,5 & 5,0 & 5,7 & 6,2 \\
\hline Kraft in \% & 100 & $202,6^{*}$ & $292,7^{*}$ & $320,9 *$ & $341,3^{*}$ \\
\hline SEM & 0,0 & 19,4 & 33,3 & 33,2 & 42,6 \\
\hline RT $50 \%[\mathrm{~ms}]$ & 60,8 & 60,8 & 60,4 & 55,8 & 52,8 \\
\hline SEM & 3,5 & 3,6 & 2,7 & 2,8 & 2,9 \\
\hline RT $90 \%[\mathrm{~ms}]$ & 129,6 & 121,6 & 111,9 & 102,9 & $97,9 *$ \\
\hline SEM & 11,9 & 10,9 & 6,9 & 6,3 & 5,9 \\
\hline TPT [ms] & 111,3 & 110,3 & 106,5 & 102,3 & 97,9 \\
\hline SEM & 4,3 & 4,5 & 4,8 & 5,6 & 5,6 \\
\hline pos. $\mathbf{d F} / \mathbf{d t}_{\max }$ & 110 & 168,7 & $214,8^{*}$ & $214,9 *$ & $213,0^{*}$ \\
\hline SEM & 32,3 & 38,1 & 29 & 22,8 & 26,1 \\
\hline neg.dF/dt ${ }_{\max }$ & $-83,8$ & $-141,1$ & $-171,0^{*}$ & $-181,0^{*}$ & $-183,4^{*}$ \\
\hline SEM & 22,9 & 27,3 & 29,3 & 28,7 & 30,3 \\
\hline pos. $\mathbf{d F} / \mathrm{dt}_{\max }[\%]$ & 100 & $183,2^{*}$ & $262,0^{*}$ & $279,4^{*}$ & $293,7 *$ \\
\hline SEM & 0,0 & 23 & 38,4 & 44,8 & 57,5 \\
\hline neg.dF/dt $t_{\max }[\%]$ & 100 & $195,1^{*}$ & $255,6^{*}$ & $280,6^{*}$ & $298,3^{*}$ \\
\hline SEM & 0,0 & 21,1 & 34,4 & 41,8 & 55,2 \\
\hline
\end{tabular}


Amiodaron-Gruppe, $\mathrm{n}=8$, Querschnittsfläche $=0,10 \pm 0,03 \mathrm{~mm}^{2}, *=\mathrm{p}<0,05 \mathrm{vs} .1,0 \mathrm{~Hz}$

Tabelle 11:

\begin{tabular}{|c|c|c|c|c|c|}
\hline Mittelwerte & $1 \mathrm{~Hz}$ & $2 \mathrm{~Hz}$ & $3 \mathbf{H z}$ & $4 \mathrm{~Hz}$ & $5 \mathrm{~Hz}$ \\
\hline Kraft $\left[\mathrm{mN} / \mathrm{mm}^{2}\right]$ & 5,6 & 11,7 & $16,4^{*}$ & $17,7 *$ & $19,0^{*}$ \\
\hline SEM & 1,5 & 3,1 & 4,0 & 3,3 & 3,6 \\
\hline Kraft in \% & 100 & $209,3^{*}$ & $298,0^{*}$ & $345,2 *$ & $368,3^{*}$ \\
\hline SEM & 0 & 17,6 & 19,1 & 25,9 & 36,0 \\
\hline RT $50 \%[\mathrm{~ms}]$ & 53,9 & 54,3 & 53,8 & 52,8 & 50,0 \\
\hline SEM & 2,4 & 2,0 & 2,4 & 2,8 & 2,4 \\
\hline RT $90 \%[\mathrm{~ms}]$ & 121,3 & 104 & 101,5 & 98,9 & $92,4^{*}$ \\
\hline SEM & 10,2 & 3,6 & 4,7 & 5,0 & 4,4 \\
\hline TPT [ms] & 101,1 & 102,5 & 101,6 & 96,5 & 93,5 \\
\hline SEM & 3,1 & 2,8 & 3,4 & 3,0 & 3,1 \\
\hline pos. $d F / d_{\max }$ & 69,2 & $167,7 *$ & $228,1^{*}$ & $251,4 *$ & $284,2^{*}$ \\
\hline SEM & 8,6 & 24,5 & 30,9 & 29,3 & 40,8 \\
\hline neg.dF/dt max $_{\text {max }}$ & $-48,4$ & $-123,1 *$ & $-169,3^{*}$ & $-191,3^{*}$ & $-220,3^{*}$ \\
\hline SEM & 7,2 & 26,3 & 34,4 & 31,5 & 40,6 \\
\hline pos. $\mathbf{d F} / \mathbf{d t}_{\max }[\%]$ & 100 & $259,4^{*}$ & $356,4^{*}$ & $390,3 *$ & $435,0^{*}$ \\
\hline SEM & 0 & 38,9 & 49,7 & 44,7 & 59,9 \\
\hline neg.dF/dt $\max _{\max }[\%]$ & 100 & $240,0^{*}$ & $335,4^{*}$ & $396,5^{*}$ & $447,1 *$ \\
\hline SEM & 0 & 22,1 & 32,5 & 34,6 & 46,0 \\
\hline
\end{tabular}


Lösungsmittel-Gruppe, $\mathrm{n}=8$, Querschnittsfläche $=0,11 \pm 0,03 \mathrm{~mm}^{2},{ }^{*}=\mathrm{p}<0,05$ vs. $1,0 \mathrm{~Hz}$

Tabelle 12:

\begin{tabular}{|c|c|c|c|c|c|}
\hline Mittelwerte & $1 \mathrm{~Hz}$ & $2 \mathrm{~Hz}$ & $3 \mathbf{H z}$ & $4 \mathrm{~Hz}$ & $5 \mathrm{~Hz}$ \\
\hline Kraft $\left[\mathrm{mN} / \mathrm{mm}^{2}\right]$ & 6,3 & 13,4 & $16,8^{*}$ & $18,9^{*}$ & $19,0^{*}$ \\
\hline SEM & 1,1 & 3,1 & 2,9 & 3,3 & 3,4 \\
\hline Kraft in \% & 100 & $203,4 *$ & $270,7 *$ & $309,2 *$ & $309,3^{*}$ \\
\hline SEM & 0,0 & 13,2 & 20,6 & 33,9 & 38,5 \\
\hline RT $50 \%[\mathrm{~ms}]$ & 57 & 55,6 & 56,9 & 57 & 56,6 \\
\hline SEM & 2,6 & 3,4 & 3,7 & 3,2 & 3,6 \\
\hline RT $90 \%[\mathrm{~ms}]$ & 138,5 & 109,9 & $107,8^{*}$ & $106,5 *$ & $107,1 *$ \\
\hline SEM & 11,5 & 6,6 & 6,8 & 5,6 & 5,3 \\
\hline TPT [ms] & 115,3 & 117,3 & 113,9 & 110,1 & 106,4 \\
\hline SEM & 7,4 & 6,9 & 7,5 & 8,1 & 8,0 \\
\hline pos. $d F / d_{\max }$ & 98 & 177,9 & $228,0^{*}$ & $276,9 *$ & $294,9 *$ \\
\hline SEM & 18,5 & 33,7 & 27,6 & 26,1 & 28,9 \\
\hline neg.dF/dt max $_{\text {max }}$ & $-70,1$ & $-144,2 *$ & $-194,0^{*}$ & $-220,7^{*}$ & $-218,0^{*}$ \\
\hline SEM & 14,9 & 28,6 & 34 & 36,3 & 37,6 \\
\hline pos. $\mathbf{d F} / \mathbf{d t}_{\max }[\%]$ & 100 & $190,4^{*}$ & $268,1^{*}$ & $341,4^{*}$ & $365,8^{*}$ \\
\hline SEM & 0,0 & 13 & 29,6 & 46,3 & 53,5 \\
\hline neg.dF/dt $\max _{\max }[\%]$ & 100 & $212,6^{*}$ & $299,2 *$ & $357,2 *$ & $353,4 *$ \\
\hline SEM & 0 & 10,3 & 29,7 & 52,3 & 60 \\
\hline
\end{tabular}




\section{Literaturverzeichnis}

Allen DG: The interval-strength relationship of cardiac muscle: past, present and future. In: The interval-force relationship of the heart; Cambridge University Press, Cambridge 1992, 43-65.

Allen DG, Blinks JR (1978): Calcium transients in aequorin-injected frog cardiac muscle. Nature $\underline{273}, 509-513$.

Amiodarone trials-metaanalyses investigators (1997): Effect of prophylactic amiodarone on mortality after acute myocardial infarction and in congestive heart failure: meta-analyses of individual data from 6500 patients in randomized trials. Lancet $\underline{350}, 1417-1424$.

Andreasen F, Agerbaek H, Bjerregaard P, Gotzsche H (1981): Pharmacokinetics of amiodarone after intravenous and oral administraion. Eur J Clin Pharmacol 19: 293-299.

Anger M, Samuel JL, Marotte F, Wuytack F, Rappaport L, Lompre AM (1994): In situ mRNA distribution of sarco(endo)plasmic reticulum Ca2+ ATPase isoforms during ontogeny in the rat. J Mol Cell Cardiol 26: 539-550.

Aomine M (1989): Effects of amiodarone on barium-induced automatic activity in guinea pig ventricular muscle. Gen Pharmacol 20: 35-37.

Aomine M, Fukui H (1993): The negative inotropic effects of amiodarone on isolated guinea pig heart: A possible role of $\mathrm{Na}^{+}-\mathrm{Ca}^{2+}$ exchange. Gen Pharmacol 24 (2): 305-310.

Arai M, Matsui H, Periasamy M (1994): Sarcoplasmic reticulum gene expression in cardiac hypertrophy and heart failure. Circ Res $\underline{74}$ : 555-564.

Bassani JWM, Bassani RA, Bers DM (1994): Relaxation in rabbit and rat cardiac cells: species-dependent differences in cellular mechanisms. J Physiol 476: 279-293. 
Bassani RA, Bers DM (1994): Na-Ca exchange is required for rest-decay but not for restpotentiation of twitches in rabbit and rat ventricular myocytes. J Mol Cell Cardiol 26: 13351347.

Bassani RA, Mattiazzi A, Bers DM (1995): CaMK-II is responsible for activity-dependent acceleration of relaxation in rat ventricular myocytes. Am J Physiol 268: H 703-712.

Bers DM (1989): SR Ca loading in cardiac muscle preparations based on rapid-cooling contractures. Am J Physiol 256: C109-120.

Bers DM: Excitation-contraction coupling and cardiac contractile force. In: 2nd Edition; Kluwer Academic Publishers, Dordrecht 2001.

Bers DM (2002): Cardiac excitation-contraction coupling. Nature 415: 198-205.

Bers DM, Bridge JHB (1989): Relaxation of rabbit ventricular muscle by Na-Ca exchange and sarcoplasmic reticulum calcium pump. Ryanodine and voltage sensitivity. Circ Res $\underline{65}$ : 334-342.

Beuckelmann DJ, Erdmann E (1992): $\mathrm{Ca}^{2+}$-currents and intracellular $\left(\mathrm{Ca}^{2+}\right)_{\mathrm{i}}$-transients in single ventricular myocytes isolated from terminally failing human myocardium. Basic Res Cardiol 97: 235-243.

Beuckelmann DJ, Näbauer M, Erdmann E (1993): Alterations of $\mathrm{K}^{+}$currents in isolated human ventricular myocytes from patients with terminal heart failure. Circ Res $\underline{73}$ : 379-385.

Bigger JT, jr. (1987): Why patients with congestive heart failure die: Arrhythmias and sudden cardiac death. Circulation $\underline{75}$ : 28-35.

Blanchard EM, Mulieri LA, Alpert NR (1984): The effect of 2,3-butanedione monoxime (BDM) on the relation between initial heat and mechanical output of rabbit papillary muscle. Biophys J 45: 48. 
Blanchard EM, Smith GL, Allen DG, Alpert NR (1990): The effect of 2,3-butanedione monoxime on initial heat, tension and aequorin light output of ferret papillary musckes. Pflugers Arch 416: 219-221.

Blatter LA, Wier WG (1990): Intracellular diffusion, binding, and compartmentalization of the fluorescent calcium indicators indo-1 and fura-2. Biophys J 58:1491-1499.

Blinks JR: The use of photoproteins as calcium indicators in cellular physiology. In: Techniques in Cellular Physiology; Elsevier, Amsterdam 1982, 1-38.

Blinks JR (1989): Use of calcium regulated photoproteins as intracellular $\mathrm{Ca}^{2+}$ indicators. Methods Enzymol 172: 164-203.

Blinks JR: Intracellular $\left[\mathrm{Ca}^{2+}\right]$ Measurements. In: The Heart and Cardiovascular System, Second Edition; Raven Press, New York 1992, 1171-1201.

Blinks JR, Koch-Weser J (1961): Analysis of the effects of changes in rate and rhythm upon myocardial contractility. J Pharmacol Exp Ther 134: 373-389.

Blinks JR, Wier WG, Hess P, Prendergast FG (1982): Measurement of calcium concentration in living cells. Prog Biophys Mol Biol 40:1-114.

Böhm M, Reiger B, Schwinger RHG, Erdmann E (1994): cAMP concentrations, cAMP dependent protein kinase activity and phospholamban in non-failing and failing myocardium. Cardiovasc Res 28: 1713-1719.

Bonati M, Galletti F, Volp A, Cumetti C, Tognan G (1983): Amiodarone in patients on long term dialysis. N Engl J Med 308: 906-909.

Boriani G, Biffi M, Capucci A, Botto GL, Broffoni T, Rubino I, DellaCasa S, Sanguinetti M, Magnani B (1997): Oral propafenone to convert recent-onset atrial fibrillation in patients with and without underlying heart disease. A randomized, controlled trial. Ann Intern Med 126: 621-625. 
Boyett MR, Hart G, Levi AJ (1987): Factors affecting intracellular sodium during repetetive activity in isolated sheep purkinje fibres. J Physiol 384: 405-429.

Boyett MR, Frampton JE, Harrison SM, Kirby MS, Levi AJ, McCall E, Milner DR, Orchard CH: The role of intracellular calcium, sodium and $\mathrm{pH}$ in rate-dependent changes of cardiac contractile force. In: The interval-force relationship of the heart; Cambridge University Press, Cambridge 1992, 111-172.

Brandl CJ, Greene NM, Korczak B, MacLennan DH (1986): Two $\mathrm{Ca}^{2+}$ ATPase genes: homologies and mechanistic implications of deduced amino acid sequences. Cell 44: 597-607.

Brenner B, Eisenberg E (1987): The mechanisms of muscle contraction, biochemical, mechanical, and structural approches to elucidate cross bridge action in muscle. Basic Res Cardiol 82: 3-16.

Brillantes AM, Allen P, Takahashi T (1992): Differences in cardiac calcium release channel (ryanodine receptor) expression in myocardium from patients with end-stage heart failure caused by ischemic versus dukated cardiomyopathy. Circ Res 71: 18-26.

Buss J, Lasserre JJ, Heene DL (1992): Asytole and cardiogenic shock due to combined treatment with verapamil and flecainid. Lancet $\underline{340: 546 .}$

Capucci A, Villani GQ, Aschieri D, Piepoli M (1999): Safety of oral propafenone in the conversion of recent onset atrial fibrillation to sinus rhythm: A prospective parallel placebocontrolled multicentre study. Int J Cardiol 68: 187-196.

CAST-I, The Cardiac Arrhythmia Suppression Trial Investigators. Preliminary report (1989): Effect of encainide and flecainide on mortality in a randomized trial of arrhythmia suppression after myocardial infarction. N Engl J Med 321: 406-412.

CIBIS-II Investigators and Committees (1999): The Cardiac Insufficiency Bisoprolol Study II (CIBIS-II): A randomised trial. Lancet 353: 9-13. 
Claasen M, Diehl V, Kochsiek K: Herzinsuffizienz. In: Innere Medizin; Urban und Schwarzenberg, München-Wien-Baltimore 1998, 1103-1114.

Cleland JGF, Thygesen K, Uretsky BF (2001): Cardiovascular critical event pathways for the progression of heart failure; a report from the ATLAS study. Eur Heart J 22: 1601-1612.

Cleland JGF, Chattopadhyay S, Khand A, Houghton T, Kaye GC (2002): Prevalence and incidence of arrhythmias and sudden death inheart failure. Heart Failure Rev 7: 229-242.

Cobbold PH, Rink TJ (1987): Fluorescence and bioluminescence measurement of cytoplasmic free calcium. Biochem J 248: 313-328.

Cohn JN, Ziesche S, Smith R, Anand I, Dunkman WB, Loeb H, Cintron G, Boden W, Baruch L, Rochin P, Loss L (1997): Effect of the calcium antagonist felodipine as supplementary vasodilator therapy in patients with chronic heart failure. Circulation 96: 856863.

Cowie MR, Mosterd A, Wood DA, Deckers JW, Poole-Wilson PA, Sutton GC, Grobbee DE (1997): The epidemiology of heart failure. Eur Heart J 18: 208-225.

DAVIT II (The Danish Verapamil Infarction Trial II) (1990): Danish Study Group on Verapamil in Myocardial Infarction: Effect of verapamil on mortality and major events after acute myocardial infarction. Am J Cardiol 66: 779-785.

Dean PJ, Groshart KD, Porterfield JG, Iansmith DH, Golden EB (1986): Amiodaroneassociated pulmonary toxicity. Am J Clin Pathol 87: 7-13.

Deedwania PC, Singh BN, Ellenbogen K, Fisher S, Fletcher R, Singh SN (1998): Spontaneous conversion and maintenance of sinus rhythm by amiodarone in patients with heart failure and atrial fibrillation: observations from the veterans affairs congestive heart failure survival trail of antiarrhythmic therapy (CHF-STAT). Circulation 98: 2574-2579. 
de Vries RJ, van Veldhuisen DJ, Dunselman PH (2000): Efficacy and safety of calcium channel blockers in heart failure: focus on recent trials with second generation dihydropyridines. Am Heart J 139: 185-194.

Diaz ME, Eisner DA, O`Neill SC (2002): Depressed ryanodine receptor activity increaes variability and duration of the systolic $\mathrm{Ca}^{2}{ }^{+}$Transient in rat ventricular myocytes. Circ Res 91: 585-593.

Eichbaum FW, Tasaka WJ (1976): Antiarrhythmic effects of solvents: propylene glycol, benzyl alcohol. Basic Res Cardiol 71: 355-370.

Elkayam U, Amin J, Mehra A, Vasquez J, Weber L, Rahimtoola SH (1990): A prospective, randomized, double-blind, crossover study to compare the efficacy and savety of chronic nifedipine therapy with that of isosorbide dinitrate and their combination in the treatment of chronic congestive heart failure. Circulation $\underline{82: 1954-1961 .}$

Eriksson H (1995): Heart failure: A growing public health problem. J Intern Med 237: 16941699.

Fabiato A (1981): Myoplasmic free calcium concentration reached during the twich of an intact isolated cardiac cell and during calcium-induced release of calcium from the sarcoplasmic reticulum of a skinned cardiac cell from the adult rat or rabbit ventricle. J Gen Physiol 78: 457-497.

Feldmann MD, Gwathmey JK, Phillips P, Schoen F, Morgan JP (1988): Reversal of the force-frequency relationship in working myocardium from patients with end-stage heartfailure. J Appl Cardiol 3: 273-283.

Forbes WP, Hee TT, Mohiuddin SM, Hillman DE (1988): Flecainide-induced cardiogenic shock. Chest 94: 1121.

Forth W, Henschler D, Rummel W, Förstermann U, Starke K: Pharmakologie des kardiovaskulären Systems: das Herz. In: Allgemeine und spezielle Pharmakologie und Toxikologie; Urban \& Fischer, München und Jena 2001, 439-446. 
Fricke G, Mattern H, Runkel W: Klinische Wirksamkeit von Amiodaron bei therapierefraktären supraventrikulären und ventrikulären Arrhythmien. In: Neue Aspekte in der medikamentösen Behandlung von Tachyarrhythmien. Die Bedeutung von Amiodaron; Urban und Schwarzenberg, München 1983, 239-245.

Fryer MW, Neering IR, Stephenson DG (1988 a): Effects of 2,3- butanedione monoxime on the contractile activation properties of fast- and slow twitch rat muscle fibres. J Physiol 407: 53-75.

Fryer MW, Gage PW, Neering IR (1988 b): Paralysis of skeletal muscle by butanedione monoxime, a chemical phosphatase. Pflugers Arch 411: 76-79.

Gaughan JP, Furukawa S, Jeevanandam V, Hefner CA, Kubo H, Margulies KB, McGowan BS, Mattiallo JA, Dipla K, Piacentino V (1999): Sodium/calcium exchange contributes to contraction and relaxation in failed human ventricular myocytes. Am J Physiol 277: H 714-724.

Gheorghiade M, Hall V, Goldberg D, Levine TB, Goldstein S (1991): Longterm clinical and neurohormonal effects of nicardipine in patients with severe heart failure on maintenance therapy with angiotensine converting enzyme inhibitors. J Am Coll Cardiol 17 (A): 274.

Go LO, Moschella MC, Watras J (1995): Differential regulation of two types of intracellular calcium release channels during end-stage heart failure. J Clin Invest 95: 888894.

Goldstein RE, Boccuzzi SJ, Cruess D, Nattel S (1991): Diltiazem increases late-onset congestive heart failure in postinfarction patients with early reduction in ejection fraction. Circulation 83: 52-60.

Gosselink ATM, Crijns HJGM, van Gelder IC, Hillige H, Wiesfeld ACP, Lie KI (1992): Low-dose amiodarone for maintenance of sinus ryhthm after cardioversion of atrial fibbrillation or flutter. JAMA 267: 3289-3293. 
Greene HL, Katz RJ, Woosley RL, Salerno DM, Henthorn RW (1992): The cardiac arrhythmia suppression trial: first CAST, then CAST-II. J Am Coll Cardiol 19: 894-898.

Gülker H: Herzryhthmusstörungen bei Myokardischämie und Myokardnekrose. In: Pathophysiologische Grundlagen, therapeutische Beeinflussbarkeit und Aspekte der Prävention; Springer, Berlin, Heidelberg, New York 1989, 46-54.

Guido J, Bues Genis A, Dominguez de Rozas JM, Fiol M, Vinolas X, Bayes de Luna A (1997): Sudden death in heart failure. Heart Fail Rev 1: 249-260.

Gwathmey JK, Hajjar RJ, Solaro RJ (1991): Contractile deactivation and uncoupling of crossbridges-effects of 2,3-butanedione monoxime on mammalian myocardium. Circ Res $\underline{69}$ : 1280-1292.

Haffajee CI, Lowe JC, Canada AT, Lesko LJ, Asdourian G, Albert JS (1983): Clinical pharmacokinetics and efficacy of amiodarone for refractory tachyarrhythmias. Circulation $\underline{67}$ : 1347-1353.

Harrison SM, McCall E, Boyett MR (1992): The relationship between contraction and intracellular sodium in rat and guinea-pig ventricular myocytes. J Physiol 449: 517-550.

Hasenfuss G (1998): Animal models of human cardiovascular disease, heart failure and hypertrophy. Cardiovasc Res 39: 60-76.

Hasenfuss G, Mulieri LA, Leavitt BJ, Allen PD, Haeberle JR, Alpert NR (1992): Alteration of contractile function and excitation-contraction coupling in dilated cardiomyopathy. Circ Res 무: 1225-1232.

\section{Hasenfuss G, Holubarsch C, Hermann HP, Astheimer K, Pieske B, Just H (1994 a):} Influence of the force-frequency relationship on haemodynamics and left ventricular function in patients with non-failing hearts and in patients with dilated cardiomyopathy. Eur Heart $\mathbf{J}$ 15: $164-170$. 
Hasenfuss G, Reinecke H, Studer H, Pieske B, Holubarsch C, Just H (1994 b): Relation between myocardial function and expression of sarcoplasmic reticulum $\mathrm{Ca}^{2+}$-ATP-ase in failing and nonfailing human myocardium. Circ Res 75: 434-442.

Hasenfuss G, Schillinger W, Lehnart SE, Pieske B, Just H (1999): Relationship between $\mathrm{Na}^{+} / \mathrm{Ca}^{2+}$-exchanger protein levels and diastolic function of failing human myocardium. Circulation 99: 641-648.

Hastings JW, Mitchell G, Matlingly PH, Blinks JR, van Leeuwen M (1969): Response of Aequorin bioluminiscence to rapid changes in $\left[\mathrm{Ca}^{2+}\right]$. Nature 222: 1047-1050.

Hennersdorf MG, Evers S, Perings C, Strauer BE (2001): Antiarrhythmische Therapie bei Vorhofflimmern. Herzschr Elektrophysiol 12: 86-94.

Hjalmarson A, Goldstein S, Fagerberg B, Wedel H, Waagstein F, Kjekshus J, Wikstrand J, El Allaf D, Aldershville J, Halinen M, Dietz R, Neuhaus KL, Thorgeirsson G, Dunselmann PHJM, Gullestad L, Kuch J, Herlitz J, Rickenbacher P, Ball S, Gottlieb S, Deedwania P (2000): Effects of controlled-release metoprolol on total mortality, hospitalization, and well-being in patients with heart failure. The metoprolol CR/XL randomized intervention trial in congestive heart failure (MERIT-HF). JAMA 283: 12951302.

Holt DW, Storey GCA: Die Pharmakokinetik von Amiodaron. In: Neue Aspekte in der medikamentösen Behandlung von Tachyarrhythmien. Die Bedeutung von Amiodaron; Urban und Schwarzenberg, München 1983, 75-79.

Hoppe UC, Erdmann E (2001): Leitlinien zur Therapie der chronischen Herzinsuffizienz. Z Kardiol 90: 218-237.

Inesi G, Cavagna M, O'Donnell JM, Sumbilla C, Zhong L, Ma H, Klein MG: Adenovirus-mediated gene transfer of SERCA isoforms. In: Molecular approaches to heart failure therapy; Steinkopff, Darmstadt 2000, 76-88. 
Installe E, Schoevaerdts JC, Gadisseux P, Charles S (1981): Intravenous amidarone in the treatment of various arrhythmias following cardiac operations. J Thorac Cardiovasc Surg $\underline{81}$ : 302-308.

Inui M, Saito A, Fleischer S (1987): Isolation of the ryanodine receptor from cardiac sarcoplasmic reticulum and identity with the feet structures. J Biol Chem 262: 15637-15642.

Ito K, Nagafuchi K, Taga A, Yorikane R, Koike H (1996): Possible involvement of altered $\mathrm{Na}^{+}-\mathrm{Ca}^{2+}$ Exchange in negative inotropic effects of class I antiarrhythmic drugs on rabbit and rat ventricles. J Cardiovasc Pharmacol 27: 355-361.

Izu LT, Wier WG, Balke CW (2001): Evolution of cardiac calcium waves from stochastic calcium sparks. Biophys J 80: 103-120.

Jansen TL, Joosten P, Brouwer J (2003): Cardiac failure following group A streptococcal infection with echocardiographically proven pericarditis, still insufficient arguments for acute rheumatic fever: a case report and literature update. Neth J Med 61: 57-61.

Kennedy H, Akera D, Brody T (1987): The effect of stimulation frequency and calcium concentration on maintaince of developed tension in isolated heart muscle preparations. $\mathrm{J}$ Pharmacol Methods 17: 95-110.

Kieval RS, Bloch RJ, Lindenmayer GE, Ambesi A, Lederer WJ (1992): Immunofluorescence localization of the Na-Ca exchanger in heart cells. Am J Physiol 263: C 545-550.

Kihara Y, Morgan JP (1989): A comparative study of 3 methods for intracellular loading of the calcium indicator aequorin in ferret papillary muscles. Biochem Biophys Res Commun 162: 402-407.

Kihara Y, Grossmann W, Morgan JP (1989): Direct measurements of changes in intracellular calcium transients during hypoxia, ischemia and reperfusion of the intact mammalian heart. Circ Res 65: 1029-1044. 
Kihara Y, Inoko M, Hatakeyama N, Momose Y, Sasayama S (1996): Mechanisms of negative inotropic effects of class Ic antiarrhythmic agents: Comparative study of the effects of flecainide and pilsicainide on intracellular calcium handling in dog ventricular myocardium. J Cardiovasc Pharmacol 27: 42-51.

Kimura J, Noma A, Irisawa H (1986): Na-Ca exchange current in mammalian heart cells. Nature 319: 596-597.

Kobayashi M, Godin D, Nadeau R (1983): Acute effects of amiodarone in the isolated dog heart. Can J Physiol Pharmacol 61: 308-314.

Koch-Weser J, Blinks JR (1963): The influence of the interval between beats on myocardial contractility. Pharmacol Rev 15: 601-652.

Koss KL, Kranias EG (1996): Phospholamban: a prominent regulator of myocardial contractility. Circ Res 79: 1059-1063.

Krishnan SC, Schuger CD, Goldstein S (2002): Sudden death in heart failure: Underlying electrophysiological mechanisms. Heart Fail Rev 7: 255-260.

Latini R, Connoly SJ, Kates RE (1983): Myocardial disposition of amiodarone in the dog. J Pharmacol Exp Ther 224: 603-608.

Lechat P, Packer M, Chalon S, Cucherat M, Arab T, Boissell JP (1998): Clinical effects of beta-adrenergic blockade in chronic heart failure: a metaanalysis of double-blind, placebocontrolled, randomized trials. Circulation 98: 1184-1194.

Lehnart SE, Terrenoire C, Reiken S, Wehrens XH, Song LS, Tillman EJ, Mancarella S, Coromilas J, Lederer WJ, Kass RS, Marks AR (2006): Stabilization of cardiac ryanodine receptor prevents intracellular calcium leak and arrhythmias. Proc Natl Acad Sci USA 16: 7906-10.

Lubic SP, Nguyen KPV, Dave B, Giacomini JC (1994): Antiarrhythmic agent amiodarone posesses calcium channel blocker properties. J Cardiovasc Pharmacol 24: 707-714. 
Lytton J, Zarain-Herzberg A, Periasamy M, MacLannan DH (1989): Molecular cloning of the mammalian smooth muscle serco(endo)plasmic reticulum $\mathrm{Ca}^{2+}$ ATPase. J Biol Chem 264: 7059-7065.

Magnusson Y, Wallukat G, Waagstein F, Hjalmarson A, Hoebeke J (1994): Autoimmunity in idiopathic dilated cardiomyopathy. Characterization of antibodies against the beta1-adrenoceptor with positive chronotropic effect. Circulation $\underline{89}$ : 2760-2767.

Maier LS, Bers DM, Pieske B (2000): Differences in $\mathrm{Ca}^{2+}$ handling and sarcoplasmic reticulum $\mathrm{Ca}^{2+}$ content in isolated rat and rabbit myocardium. J Mol Cell Cardiol 32: 22492258.

Marcus FI, Fontaine GH, Frank R, Grosgogeat Y (1981): Clinical pharmacology and therapeutic applications of the antiarrhythmic agent, amiodarone. Am Heart J 101: 489-493.

Martinez-Marcos FJ, Garcia-Garmendia JL, Ortega-Carpio A, Fernandez-Gomez JM, Santos JM, Camacho C (2000): Comparison of intravenous flecainide, propafenone and amiodarone for conversion of acute atrial fibrillation to sinus rhythm. Am J Cardiol 86: 950953.

Mason JW, Hondeghem LM, Katzung BG (1984): Block of inactivated sodium channels and of depolaization-induced automaticity in guinea pig papillary muscle by amiodarone. Circ Res 55: 277-285.

Massie BM, Fisher SG, Deedwania PC, Singh BN, Fletcher RD, Singh SN (1996): Effect of amiodarone on clinical status and left ventricular function in patients with congestive heart failure. Circulation 93: 2128-2134.

Mercadier JJ, Lompre AM, Duc P (1990): Altered sarcoplasmic reticulum $\mathrm{Ca}^{2+}$-ATPase gene expression in the human ventricle during end-stage heart failure. J Clin Invest $\underline{85}$ : 305309. 
MERIT-HF Study Group (1999): Effect of metoprolol CR/XL in chronic heart failure: Metoprolol CR/XL Randomised Intervention Trial in Congestive Heart Failure (MERIT-HF). Lancet 353: 2001-2007.

Mewes T, Ravens U (1994): L-Type calcium currents of human myocytes from ventricle of non-failing and failing hearts and from atrium. J Mol Cell Cardiol 26: 1307-1320.

Meyer M, Schillinger W, Pieske B, Holubarsch C, Hasenfuss G, Just H (1995): Alterations of sarcoplasmic reticulum proteins in failing human dilated cardiomyopathy. Circulation 92: 778-784.

Miller AL, Karplus E, Jaffe LF: Imaging $\left[\mathrm{Ca}^{2+}\right]$ with aequorin using a photon imaging detector. In: Methods in Cell Biology. Volume 40: A practical guide to the study of calcium in living cells; Academic Press, San Diego 1994, 305-338.

Mitchell MR, Powell T, Terrer DA, Twist VW (1987): Calcium-activated inward current and contraction in rat and guinea-pig ventricular myocytes. J Physiol 391: 545-560.

Morgan JP, De Foe TT, Morgan KG (1984): A chemical procedure for loading the calcium indicator aequorin into mammalian working myocardium. Pflugers Arch 400: 338-340.

Mulieri LA, Alpert NR (1984): Differential effects of 2,3-butanedione monoxime (BDM) on activation and contraction. Biophys $\mathrm{J} \underline{45}$ : 47.

Mulieri LA, Hasenfuss G, Ittlemann F, Blanchard EM, Alpert NR (1989): Protection of human left ventricular myocardium from cutting injury with 2,3-butanedione monoxime. Circ Res 65: 1441-1444.

Mulieri LA, Hasenfuss G, Leavitt BJ, Allen PD, Alpert NR (1992): Altered myocardial force-frequency relation in human heart failure. Circulation 85: 1743-1750.

Mullins LJ (1966): Ion and molecule fluxes in squid axons. Ann NY Acad Sci 137: 830-836. 
Munoz A, Karila P, Gallay P, Zettelmeier F, Messner P, Mery M, Grolleau R (1988): A randomized hemodynamic comparison of intravenous amiodarone with and without Tween 80. Eur Heart J 9: 142-148.

Naccarelli GV, Wolbrette DL, Bhatta L, Khan M, Hynes J, Samii S, Luck J (2003): A review of clinical trials assessing the efficacy and safety of newer antiarrhythmic drugs in atrial fibrillation. J Interv Card Electrophysiol 9: 215-222.

Nattel S, Talajic M, Quantz M, De Roode M (1987): Frequency-dependent effects of amiodarone on atrio-ventricular nodal function and slow-channel action potentials: Evidence for calcium channel blocking activity. Circulation 76: 442-449.

Nattel S, Davies M, Quantz M (1988): The antiarrhythmic efficacy of amiodarone and desethylamiodarone, alone and in combination, in dogs with acute myocardial infarction. Circulation 77: 200-208.

Neering IR, Prendergast FG: Uses and physiochemical properties of the photoprotein Aequorin. In: Bioelectrochemistry; Plenum Press, New York 1980: 117-142.

Negretti N, O'Neill SC, Eisner DA (1993): The relative contributions of different intracellular and sarcolemmal systems to relaxation in rat ventricular myocytes. Cardiovasc Res 27: 1826-1830.

Nimer LR, Needleman DH, Hamilton SL, Krall J, Movesian MA (1995): Effect of ryanodine on sarcoplasmic reticulum $\mathrm{Ca}^{2+}$ accumulation in nonfailing and failing human myocardium. Circulation 92: 2504-2510.

Nishimura M, Follmer CH, Cigan AL, Yeh JZ, Singer DH (1986): Amiodarone blocks calcium current in guinea pig ventricular myocytes. Circulation 74: 162-169.

Oda T, Yano M, Yamamoto T, Tokuhisa T, Okuda S, Doi M, Ohkusa T, Ikeda Y, Kobayashi S, Ikemoto N, Matsuzaki M (2005): Defective regulation of interdomain interactions within the ryanodine receptor plays a key role in the pathogenesis of heart failure. Circulation 111: 3400-3410. 
Olsson SB, Edvardsson N (1981): Clinical electrophysiologic study of antiarrhythmic properties of flecainide: acute intraventricular delayed conduction and prolonged repolarization in regular paced and premature beats using intracardiac monophasic action potentials with programmed stimulation. Am Heart J 102: 864-871.

Orchard CH, Lakatta EG (1985): Intracellular calcium transients and developed tension in rat heart muscle. J Gen Physiol $\underline{86}$ : 637-651.

Packer M, Carver JR, Rodeheffer RJ (1991): Effect of oral milrinone on mortality in severe chronic heart failure. The PROMISE Study research group. N Engl J Med 325: 14681475.

Packer M, Bristow MR, Cohn JN, Colucci WS, Fowler MB, Gilbert EM, Shusterman NH, US Carvedilol Heart Failure Study Group (1996 a): The effect of carvediolol on morbidity and mortality in patients with chronic heart failure. N Engl J Med 334: 1349-1355.

Packer M, O`Conner CM, Ghali JK, Pressler ML, Carson PE, Belkin RN, Miller AB, Neuberg GW, Frid D, Wertheimer JH, Cropp AB, DeMets DL (1996 b): Effect of amlodipine on morbidity and mortality in severe chronic heart failure. Prospective Randomized Amlodipine Survival Evaluation Study Group. N Engl J Med 335: 1107-1114.

Paradise NF, Schmitter JL, Surmits JM (1981): Criteria for adequate oxygenation of isometric kitten papillary muscle. Am J Physiol 241: H348-353.

Patterson E, Eller BT, Abrams GD, Vasiliades J, Lucchesi BR (1983): Ventricular fibrillation in a conscious canine preparation of sudden coronary death - prevention by shortand long-term amiodarone administration. Circulation $\underline{4}$ : 857-864.

Perreault CL, Mulieri LA, Alpert NR, Ransil E, Allen PD, Morgan JP (1992 a): Cellular basis of negative inotropic effect of 2,3-BDM in human myocardium. Am J Physiol 263: H503-H510. 
Perreault CL, Gonzalez-Serratos H, Litwin SE, Morgan JP (1992 b): A chemical Method for intracellular loading of the calcium indicator aequorin in mammalian skeletal muscle. Proc Soc Exp Biol Med 199: 178-182.

Pfisterer M, Burkart F, Müller-Brand J, Kiowski W (1985): Important differences between short- and long-term hemodynamic effects of amiodarone in patients with chronic ischemic heart disease at rest and during ischemia-induced left ventricular dysfunction. $\mathbf{J}$ Am Coll Cardiol 5: 1205-1211.

Phillips RM, Altschuld RA (1996): 2,3-butanedione 2-monoxime (BDM) induces calcium release from canine cardiac sarcoplasmatic reticulum. Biochem Biophys Res Commun 229: 154-157.

Pieske B (1998): Neue Aspekte zur Pathophysiologie der Herzinsuffizienz. Wien Med Wochenschr ㅁ: 108-120.

Pieske B, Hasenfuss G (2000): Pathophysiologische Grundlagen der Herzinsuffizienz. Ther Umsch $\underline{57}$ (5): $284-292$.

Pieske B, Hasenfuss G, Holubarsch C, Schwinger R, Böhm M, Just H (1992): Alterations of the force-frequency relationship in the failing human heart depend on the underlying cardiac desease. Basic Res Cardiol 87: 213-221.

Pieske B , Kretschmann B, Meyer M, Holubarsch C, Weirich J, Posival H, Minami K, Just H, Hasenfuss G (1995): Alterations in intracellular calcium handling associated with the invers force-frequency relation in human dilated cardiomyopathy. Circulation 92: 1169-1178.

Pieske B, Maier LS, Bers DM, Hasenfuss G (1999): $\mathrm{Ca}^{2+}$ handling and sarcoplasmic reticulum $\mathrm{Ca}^{2+}$ content in isolated failing and nonfailing human myocardium. Circ Res $\underline{85}$ : 3846.

Piot C, Lemaire S, Albat B, Sequin J, Nargeot J, Richard S (1996): High frequency upregulation of human cardiac Ca currents. Circulation 93: 120-128. 
Platou ES, Refsum H (1986): Acute electrophysiologic and blood pressure effects of amiodarone and its solvent in the dog. Acta Pharmacol Toxicol 58: 163-168.

Prasher D, McCann RO, Cormier M (1985): Cloning and expression of the cDNA coding of aequorin, a bioluminescent calcium-binding protein. Biochem Biophys Res Commun 126: 1259-1268.

Prayer L, Hübsch P, Frank H (1989): Lungenveränderungen bei Amiodarontherapie. Pneumologie 43: 673-675.

Rasmussen RP, Minobe W, Bristow MR (1990): Calcium antagonist binding sites in failing and nonfailing human ventricular myocardium. Biochem Pharmacol 39: 691-696.

Regan TJ (1990): Alcohol and the cardiovascular system. JAMA 264: 377-381.

Remme WJ, van Hoogenhuyze DCA (1990): Hemodynamic profile of amiodarone during acute and long-term admisistration in patients with ventricular dysfunction. Cardioscience $\underline{1}$ : 169-176.

Reuter H, Seitz N (1986): The dependence of calcium efflux from cardiac muscle on temperature and external ion composition. J Physiol 195: 451-470.

Roden DM, Woosley RL (1986): Drug therapy: Flecainide. N Engl J Med 315: 36-40.

Scamps F, Undrovias A, Vassort G (1989): Inhibition of $\mathrm{I}_{\mathrm{Ca}}$ in single frog cardiac cells by quinidine, flecainide, ethmozin and ethacin. Am J Physiol 256: C549-559.

Schatzmann HJ (1989): The calcium pump of the surface membrane and of the sarcoplasmic reticulum. Annu Rev Physiol 51: 473-485.

Schulze JJ, Knops J (1982): Effects of flecainide on contractile force and electrophysiological parameters in cardiac muscle. Drug Res 32: 1025-1029. 
Sham JSK, Jones LR, Morad M (1991): Phospholamban mediates the b-adrenergicenhanced $\mathrm{Ca}^{2+}$-uptake in mammalian ventricular myocytes. Am J Physiol 261: H 1344-1349.

Sim I, McDonald KM, Lavori PW, Norbutas CM, Hlatky MA (1997): Quantitative overview of randomized trials of amiodarone to prevent sudden cardiac death. Circulation $\underline{96}$ : 2823-2829.

Singh BN, Vaughan Williams EM (1979): The effect of amiodarone, a new anti-anginal drug, on cardiac muscle. Br J Pharmacol 39: 657-667.

Späth G: Aktuelle Bedeutung von Amiodaron. In: Herzrhythmusstörungen; Beltz, Weinheim und Basel 1992, 43.

Stäubli M, Bircher J, Galeazzi RL, Remund H, Studer H (1983): Serum concentrations of amiodarone during long term therapy. Relation to dose, efficacy and toxicity. Eur $\mathbf{J}$ Clin Pharmacol 24: 485-494.

Stevenson WG, Stevenson LW, Middlekauf H (1993): Sudden death prevention in patients with advanced ventricular dysfunction. Circulation $\underline{88}$ : 2953-2961.

Studer R, Reinecke H, Bilger J, Pieske B, Holubarsch C, Just H (1994): Gene expression of cardiac $\mathrm{Na}^{+} / \mathrm{Ca}^{2+}$-exchanger in end-stage human heart failure. Circ Res 75: 443- 453.

Sutko JL, Bers DM, Reeves JP (1986): Postrest inotropy in rabbit ventricle: $\mathrm{Na}^{+}-\mathrm{Ca}^{2+}$ exchange determines sarcoplasmic reticulum $\mathrm{Ca}^{2+}$ content. Am J Physiol 250: H654-661.

Takahashi T, Allen PD, Lacro RV, Marks AR, Dennis AR, Schoen FJ, Grossman W, Marsh JD, Izumo S (1992): Expression of dihydropyridine receptor $\left(\mathrm{Ca}^{2+}\right.$ channel) and calsequestrin genes in the myocardium of patients with end-stage heart failure. J Clin Invest 90: 927-935.

Tande PM, Refsum H (1990): Class III antiarrhythmic action linked with positive inotropy: acute electrophysiological and inotropic effects of amiodarone in vitro. Pharmacol Toxicol 66: $18-22$. 
Toyama J, Yamada K, Futamura Y (1989): Clinical effects of a new antiarrhythmic agent, SUN 1165 in patients with ventricular arrhythmias. Ther Res 10: 2549-2558.

Twidale N, Roberts-Thomson P, McRitchie RJ, Chalmers JP (1994): Comparative haemodynamic effects of verapamil, flecainide, amiodarone and sotalol in the conscious rabbit. Clin Exp Pharmacol Physiol 21: 179-188.

Urthaler F, Walker AA, Reeves RC, Hefner LL (1993): Beat-to-beat measurements of $\left[\mathrm{Ca}^{2+}\right]_{\mathrm{i}}$ and force in ferret cardiac muscle after chemical loading of aequorin. Am $\mathrm{J}$ Physiol 265: C1703-1710.

Vaughan Williams EM (1984): A classification of antiarrhythmic actions reassessed after a decade of new drugs. J Clin Pharmacol 24: 129-147.

Verboomen H, Wuytack F, deSmedt H, Himpens B, Casteels R (1992): Functional differences between SERCA-2a and SERCA-2b Ca ${ }^{2+}$ pumps and their modulation by phospholamban. Biochem J 286: 591-596.

Weber CR, Piacentino III V, Ginsburg KS, Houser SR, Bers DM (2002): $\mathrm{Na}^{+}-\mathrm{Ca}^{2+}$ exchange current and submembrane $\left[\mathrm{Ca}^{2+}\right]$ during the cardiac action potential. Circ Res $\underline{90}$ : 182-189.

Weisser-Thomas J, Piacentino III V, Gaughan JP, Margulies K, Houser SR (2003): Calcium entry via $\mathrm{Na} / \mathrm{Ca}$ exchange during the action potential directly contributes to contraction of failing human ventricular myocytes. Cardiovasc Res 57: 974-985.

Woosley RL, Soddoway LA, Duff HJ, Roden DM (1984): Flecainide dose-response relations in stable ventricular arrhythmias. Am J Cardiol 53: B59-65.

Yabek SM, Kato R, Singh BN (1986): Effects of amiodarone and its metabolite, desethylamiodarone, on the electrophysiologic properties of isolated cardiac muscle. $\mathrm{J}$ Cardiovasc Pharmacol ㅁ: 197-207. 
Yahalom J, Klein HO, Kaplinsky E (1977): Beta-adrenergic blockade as adjunctive oral therapy in patients with chronic atrial fibrillation. Chest $\underline{71: 592-596 .}$

Yasaka WJ, Eichbaum FW, Oga S (1979): Antiarrhythmic effects of solvents: III effects of propylene glycol and benzyl alcohol on contractile force of isolated rabbit heart. Cardiovasc Res 13: 717-722.

Zarain-Herzberg A, MacLannan DH, Periasamy M (1990): Characterization of rabbit cardiac sarco(endo)plasmic reticulum $\mathrm{Ca}^{2+}$ ATPase gene. J Biol Chem 265: 4670-4677. 


\section{Danksagung}

Herrn Prof. Dr. Burkert Pieske danke ich recht herzlich für die Überlassung des Dissertationsthemas und seine Hilfe beim Erlernen der beschriebenen Methoden. Seine positive und optimistische Art sowie die Freude an der Wissenschaft haben zunächst mein Interesse geweckt und mich später immer wieder für meine Arbeit motiviert.

Herrn Dr. Egbert Bisping möchte ich für seine freundschaftliche Betreuung und Hilfe im Labor und ganz besonders für die Geduld und Unterstützung auch über eine so große Entfernung hinweg - und vor allem bis zum Schluss - sehr danken.

Herrn Dr. Dirk von Lewinski danke ich besonders für die stets selbstlose Hilfe bei allen Fragen, zu jeder Zeit. Mit seiner motivierenden Art, größter Geduld und Kompetenz war er mir immer eine große Hilfe.

Herrn Prof. Dr. Lars S. Maier und Herrn Dr. Albrecht Schmidt danke ich für die vielen kleinen nützlichen Tipps, die mir meine Arbeit stets erleichtert haben.

Danke an Paul Barckhausen und Kerstin Voß für die vielen netten Stunden im dunklen Aequorin-Labor.

Herrn Antonios Giannakos möchte ich für ein tolles gemeinsames Studium, eine einzigartige Freundschaft und unzählige schöne gemeinsame Stunden - auch im Labor - danken. 